\title{
DEVELOPMENT OF NOVEL ACTIVE TRANSPORT MEMBRANE DEVICES
}

\author{
Interim Report \\ By \\ Daniel V. Laciak
}

November 1994

Work Performed Under Contract No. DE-FC36-89ID12779

Prepared for the

U.S. Department of Energy

Under DOE Idaho Operations Office

Sponsored by the Office of the Assistant Secretary

for Energy Efficiency and Renewable Energy

office of Industrial Technologies

Washington, D.C.

Prepared by

Air Products and Chemicals, Inc.

Allentown, PA 


\section{DISCLAIMER}

Portions of this document may be illegible in electronic image products. Images are produced from the best available original document. 


\section{Foreword}

This interim report, prepared by Air Products and Chemicals, Inc., describes work performed during the second budget period of Cooperative Agreement NO. DE-FC36-89ID12779. The program was administered by the U.S. Department of Energy's Idaho Operations Office, Idaho Falls, Idaho. The Project Manager was Mr. David M. Blanchfield. Technical guidance was provided by Dr. Thomas Lawford of EG\&G Idaho, Inc.

Air Products has undertaken a research program to fabricate and evaluate gas separation membranes based upon promising "active-transport" (AT) materials recently developed in our laboratories. Active Transport materials are ionic polymers and molten salts which undergo reversible interaction or reaction with ammonia and carbon dioxide. The materials are useful for separating these gases from mixtures with hydrogen. Moreover, AT membranes have the unique property of possessing high permeability towards ammonia and carbon dioxide but low permeability towards hydrogen and can thus be used to permeate these components from a gas stream while retaining hydrogen at high pressure.

The program was divided into three major tasks, each approximately one year in duration. The work plan/milestone chart for the 43-month contract period, which includes a 3-month no cost extension, is shown in Figure i. In the first task, various fabrication concepts were screened for feasibility. In the second task, the most promising fabrication concept, multilayer composite membranes, was evaluated under conditions typical of the target applications. In the third task, prototype, lab-scale modules will be fabricated and evaluated. Finally, data obtained during performance of Tasks 2 and 3, along with a market analysis (Task 4), will be used to perform an economic evaluation of the AT membrane-based separation process.

This report summarizes technical progress made during the second budget period. Detailed event scheduling, which incorporates the recommendations made at the end of the first budget period, is shown in Figure ii. Specific work proposed and completed under this program included: 
DEVELOPMENT OF NOVEL ATM DEVICES: PROGRAM SCHEDULE

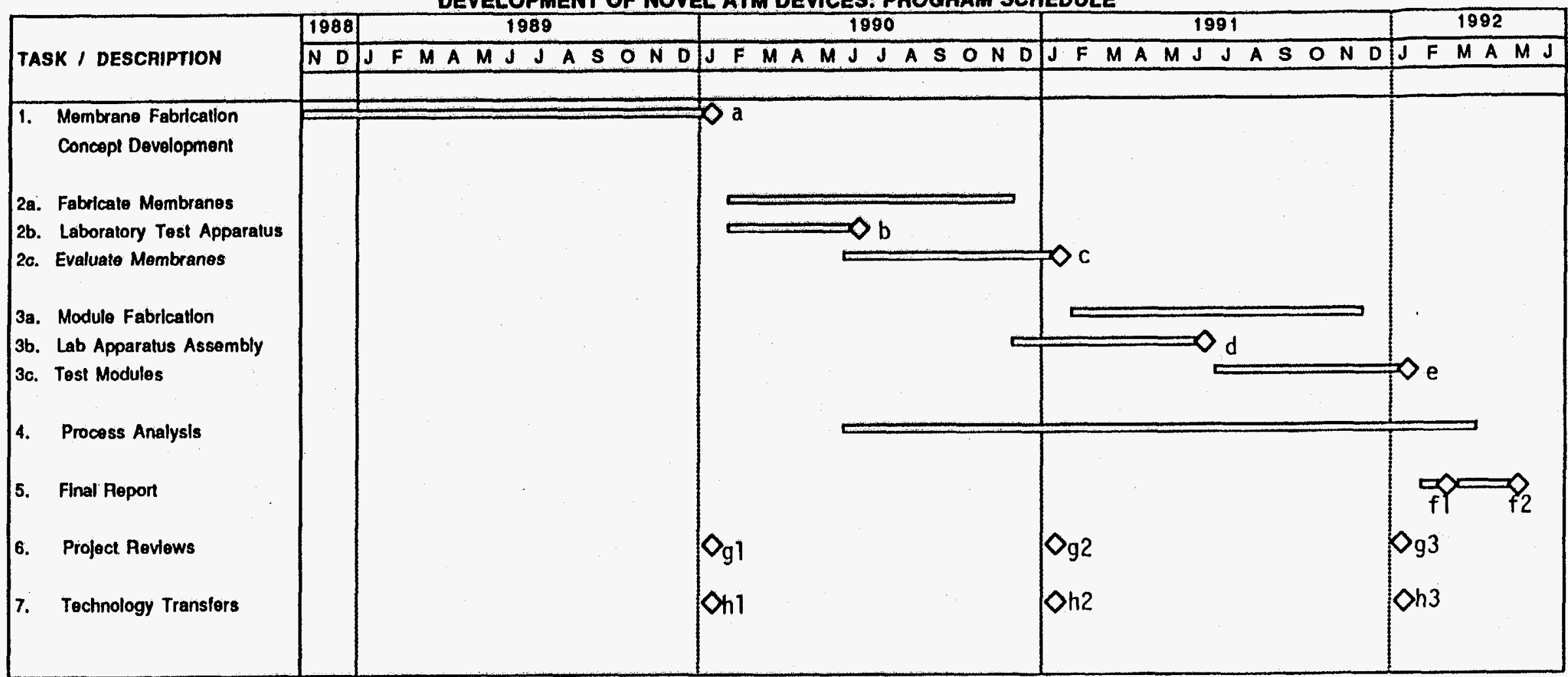
a. Interim Report
b. Complete Test Unit
c. Complete Prel iminary Tests
d. Module Test Plan
e. Complete Module Tests
fi. Draft
f2. Final
g. Review Date
h. At least one activity per year 
- Completion of microencapsulation feasibility study

- Completion of $\mathrm{CO}_{2}$-selective MLC feasibility study

- Upgrade of membrane test equipment to accommodate high pressures

- Evaluation of MLC membranes at high pressures

This report concludes with an assessment of the program status and recommendations for further work. 
Figure II: DEVELOPMENT OF NOVEL ATM DEVICES - YEAR 2

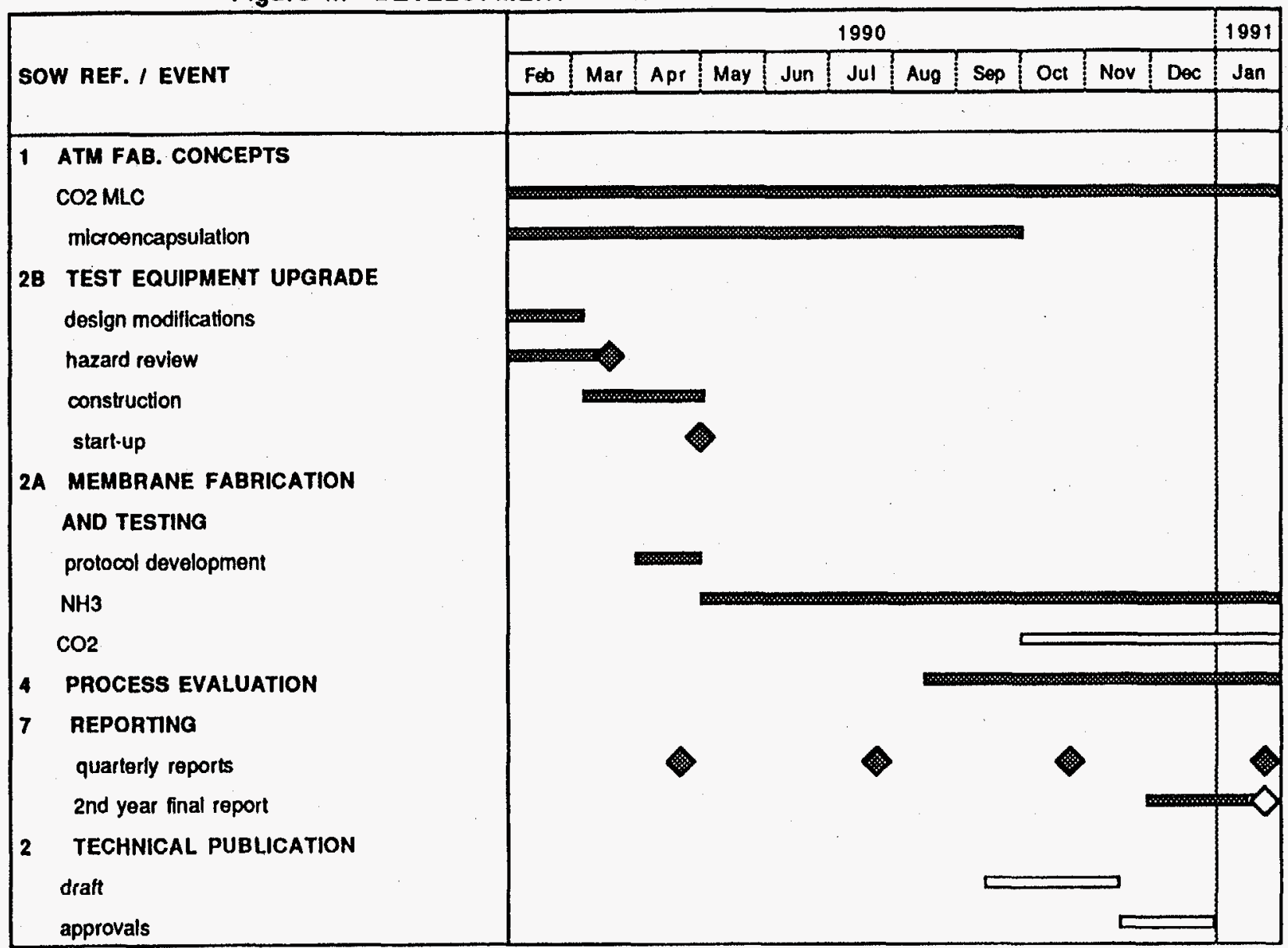


1.0 Executive Summary ...............................................................................................

2.0 Microencapsulation of Active Transport Materials ......................................................... 3

3.0 Fabrication and Evaluation of $\mathrm{CO}_{2}$-Selective MLC Membranes ................................... 26

$4.0 \quad$ Evaluation of $\mathrm{NH}_{3}$-Selective MLC Membranes ............................................................ 44

5.0 Conclusions and Recommendations ......................................................................... 75

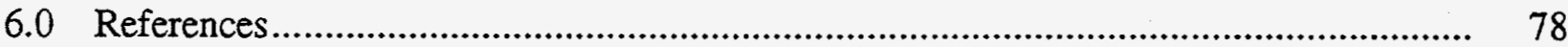

7.0 Appendix-Summary of $\mathrm{NH}_{3}$-Selective MLC Test Runs................................................ 79 


\section{List of Figures}

Figure 2.1-1 SEM of PTMSP-encapsulated $\mathrm{NH}_{4} \mathrm{SCN}$ Prepared via LCED - acetone collection (8-761)

Figure 2.1-2 SEM of PTMSP-encapsulated NH4SCN Prepared via LCED - silicone 19 oil collection (8-858)

Figure 2.1-3 SEM of PTMSP-encapsulated PVAmSCN Prepared via LRD - starch 20 collection (8-711)

Figure 2.1-4 SEM of PTMSP-encapsulated $\mathrm{NH}_{4} \mathrm{SCN}$ Prepared via LRD - acetone collection (8-711)

Figure 2.1-5 SEM of PTMSP-encapsulated TEAA $\bullet 4 \mathrm{H}_{2} \mathrm{O}$ Prepared via LRD

Techniques -silicone (8-909, 8-911)

Figure 2.1-6 SEM of PTMSP-encapsulated TEAA $\bullet 4 \mathrm{H}_{2} \mathrm{O}$ Prepared via Solvent

Extraction Techniques

Figure 2.1-7 SEM of PTMSP-encapsulated $\mathrm{NH}_{4} \mathrm{SCN}$ Prepared via Phase Separation Techniques

Figure 2.1-8 SEM of PTMSP-encapsulated TEAA $4 \mathrm{H}_{2} \mathrm{O}$ Prepared via Phase

Separation Techniques

Figure 3.1-1 SEM of PTMSP/DADMAF/PTMSP MLC (11273-75)

Figure 3.1-2

SEM of PDMS/DADMAF/PDMS MLC (11638-50)

41

Figure 3.1-3

SEM of PDMS/DADMAF/PDMS MLC after Testing (11638-50)

42

Figure 3.1-4

SEM of PDMS/DADMAF/PDMS/DADMAF/PDMS 5-layer MLC (11638-102-1)

Figure 3.2-1 $\quad \mathrm{CO}_{2}$ Permeance of PDMS/DADMAF/PDMS MLC (11638-50)

Figure 4.1-1

Debottlenecking/Hybrid Scenario Applied to Ammonia Synthesis

Figure 4.1-2

Total Ammonia Recovery from Ammonia Synthesis via Membranes

Figure 4.1-3

Relationship of Dew Point to Pressure for High Purity Ammonia

Streams

Figure 4.2-1 Process Flow Diagram-High Pressure Membrane Test System

Figure 4.2-2

CYL-2 Connection Assembly-Expanded View 


\section{List of Figures (continued)}

Figure 4.3-4 Evaluation of PTMSP/PVAmSCN/PTMSP MLC Membrane 66

Figure 4.3-5 Concentration Polarization Phenomenon 68

Figure 4.3-6 Effect of Feed Flow Rate on Membrane Performance $\quad 69$

Figure 4.3-7 Effect of Test Cell Geometry on Membrane Performance 72

$\begin{array}{lll}\text { Figure 5.3-1 Third Year Planning } & 77\end{array}$ 


\section{List of Tables}

Table 2.1-1 Centrifugal Coextrusion Microcapsules 5

Table 2.1-2 Rotating Disk Microcapsules 8

Table 2.1-3 Solvent Evaporation Encapsulation of TEAA $4 \mathrm{H}_{2} \mathrm{O}$

Table 2.1-4 Phase Separation Encapsulation 10

Table 2.2-1 Absorption Capacity of Microencapsulated AT Materials $\quad 12$

$\begin{array}{lll}\text { Table 2.2-2 Absorption Capacity of PTMSP } & 14\end{array}$

Table 2.2-3 Least Squares Fit of Microencapsulation Data 15

Table 2.2-4 Selectivity of PTMSP-Encapsulated $\mathrm{NH}_{4} \mathrm{SCN}$ and TEAA $4 \mathrm{H}_{2} \mathrm{O} \quad 15$

Table 3.2-1 Evaluation of Free-standing DADMAF Membranes 28

Table 3.2-2 Evaluation of PTMSP/DADMAF/PTMSP MLC Membranes 30

Table 3.2-3 Evaluation of PTMSP/DADMAF/PTMSP MLC with SUR-1 31

Table 3.2-4 Evaluation of MEM213/DADMAF/MEM213 MLC Membranes 32

Table 3.2-5 Evaluation of PDMS/DADMAF/PDMS MLC Membranes 33

Table 3.2-6 Effect of Dew Point and Temperature on PDMS/DADMAF/PDMS 34 MLC Membranes

Table 3.2-7 Effect of Gas Stream Hydration on Membrane Performance 35

Table 3.2-8 Evaluation of MLC Membranes with Improved Analytical System 36

Table 3.2-9 Investigation of Flaws and Defects 38

Table 3.2-10 Effect of Permeate Pressure on Membrane Performance 38

Table 4.1-1 $\quad \mathrm{NH}_{3}$ Synthesis Converter Effluent Composition 47

Table 4.1-2 Membrane Test Plan and Target Membrane Performance 52

Table 4.3-1 Diffusion Coefficients for Ammonia $\quad 70$

Table 4.3-2 Evaluation of MLC Membranes at Process Conditions 72 


\subsection{Executive Summary}

Air Products and Chemicals, Inc., has discovered "active transport" materials which may be useful for separating ammonia and carbon dioxide from mixtures with other gases, especially hydrogen. These materials are molten salts and polyelectrolytes which are, respectively, liquids and gels under conditions specific to their process application. Traditional membrane fabrication techniques limit the utility of such membranes. Air Products, under this Cooperative Agreement, has investigated new ways to fabricate liquid and liquid-like materials into practical gas separation membranes and devices. These include microencapsulation and multilayer composite, or MLC, membrane fabrication.

Microencapsulation is a process whereby the active transport material is contained within a spherical shell of poly(trimethylsilylpropyne). During the course of this program ammonium thiocyanate and tetraethylammonium acetate tetrahydrate, active transport materials for ammonia and carbon dioxide respectively, were successfully encapsulated within poly(trimethylsilylpropyne). The capsules were shown to separate ammonia and carbon dioxide from nitrogen via pressure swing absorption, however, the size $(100-500 \mu \mathrm{m})$ and payload (50\%) were not sufficient to pursue further fabrication into gas separation membranes. We believe that smaller, higher payload capsules are obtainable; however, based on promising results in other fabrication areas, no additional experimental work will be performed in this area.

MLC membranes consist of a thin film of an active transport polyelectrolyte which is contained or "sandwiched" between two films of a highly permeable but nonporous polymer such as silicone rubber or poly(trimethylsilylpropyne). The "encapsulating" polymer imparts mechanical stability to the membrane while offering minimal mass transfer resistance. MLC membranes containing carbon dioxide-selective active transport materials exhibited good permselectivity for carbon dioxide over hydrogen and showed no degradation during 3 weeks of continuous testing. MLC membranes incorporating ammonia-selective active transport polyelectrolytes were stable for up to 3 weeks of continuous testing at transmembrane pressures as high as 1900 psi. Concentration polarization effects were observed for these membranes at high feed pressures.

Based upon the promising results obtained thus far in this study, it is our recommendation to proceed with the fabrication of lab-scale membrane modules utilizing the multilayer composite 
fabrication technique. Therefore, the major planned activities for the next segment of the program include:

- synthesis of active transport polyelectrolytes and MLC component polymers

- upgrade of membrane test unit to accommodate lab-scale modules

- identification of a module fabrication subcontractor

- evaluation of lab-scale modules under end-use conditions

- continued market survey/economic analysis of membrane-based separation schemes to recover ammonia from ammonia synthesis gas and carbon dioxide from steam reformers 


\subsection{Microencapsulation of Active Transport Materials}

Microencapsulation is a process wherein one material is encased within another to form a small, usually spherical particle. An idealized microcapsule can be viewed as a core of "fill" material surrounded by a shell or "skin" as shown below.

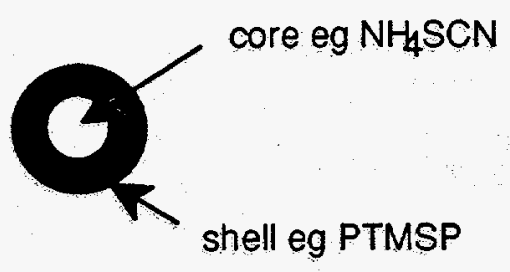

Microencapsulation has been practiced commercially for at least 30 years. Many products including medications, flavors, and pesticides incorporate microcapsules. In all these examples microencapsulation serves one of two purposes: a) to increase the shelf-life of a reactive material by storing it in an impermeable shell, or b) to control the release and delivery of the core material through the shell. Our purpose for using microencapsulation is different. We wish to permanently "store" a material within the capsule while allowing gases to permeate, in both directions, through the shell. Our concept was to microencapsulate the AT material, that is, the gas-interactive component (e.g. $\mathrm{NH}_{4} \mathrm{SCN}$ ), within a shell of a nonporous but gas-permeable polymer such as poly(trimethylsilylpropyne) or silicone rubber. These capsules could then be utilized in gas absorption processes or fabricated into a gas separation membrane via immobilization within a microporous matrix or by imbedding them within a dense polymer matrix 1 . Microencapsulation of the AT material was performed under a subcontract in the laboratories of Southwest Research Institute, San Antonio, Texas. Before fabrication into membranes was attempted, the samples were evaluated by two methods. The first was to perform scanning electron microscopy (SEM) on the "as received" samples in order to determine capsule size and general appearance. Particular attention was paid to detection of defects in the capsule wall. The second method was to measure their gas absorption capacity in order to obtain information on the activity of the AT component and the payload of the capsule. (The "payload" is defined as the weight percent AT component.) We have previously determined 2 that, to be useful in a membrane configuration, the capsule should a) be of the order of 1-50 $\mu \mathrm{m}$ in diameter, and 2 ) have a high payload (>85\%) or absorption capacity combined with good selectivity over the inert gas. 


\subsection{Capsule Fabrication}

The capsules were prepared by one or more of four microencapsulation techniques - rotating disk, centrifugal coextrusion and phase separation, and solvent evaporation. A general description of the encapsulation methods is given in a previous report 3 . The experimental parameters and other details relating to particular technologies used to microencapsulate TEAA $4 \mathrm{H}_{2} \mathrm{O}$. and $\mathrm{NH}_{4} \mathrm{SCN}$ are given below and in Tables 2.1-1 through 2.1-4. Some of the data on PTMSP-encapsulated $\mathrm{NH}_{4} \mathrm{SCN}$, was reported previously4. This data is again presented here so that the study can be viewed as a whole.

\subsubsection{Laboratory Centrifugal Extrusion Nozzle}

The laboratory centrifugal coextrusion device, LCED, was used to prepare microcapsules containing ammonium thiocyanate. This device consists of a head with two nozzles and a concentric feed tube which is sealed to the head through a seal arrangement. For these feasibility experiments, this device was used with one nozzle plugged. The head was attached to a rotating shaft such that the direction of rotation was around its long axis. The shell material was fed by a Zenith ${ }^{\oplus}$, gear pump through the feed tube into the head. The core was fed with a Zenith ${ }^{\circledR}$, pump for runs 1-1 through 1-6. For the other runs, the gear pump was replaced by a syringe pump to minimize contamination of the feed solution. As the head rotated, the shell solution flowed through the outer orifices while the core material flowed through the inner orifice of the nozzle, creating a rod of fill material surrounded by a sheath of the shell solution. The centrifugal force from the rotating head broke the extruded rod into individual droplets (capsules) which were collected in an appropriate extraction bath. The size of the capsules was controlled by head speed, feed rate, and nozzle size.

Thirteen encapsulation runs were conducted using the LCED. Table 2.1-1 describes the details of the these runs. For the first seven, an acetone bath was used to collect the microcapsules. The capsules were removed from the bath and dried in air. During the drying process the outer film was observed to shrink and crack allowing some of the core to leak out (Figure 2.1-1). The evaluation of these initial runs indicated payloads (loadings) much lower than the theoretical payload (Table 2.2-1). 
Table 2.1-1

Centrifugal Extrusion Microcapsules

\begin{tabular}{|c|c|c|c|c|c|c|}
\hline $\begin{array}{c}\text { Run \# } \\
\text { (Sample \#) }\end{array}$ & $\begin{array}{c}\text { Core } \\
\text { Formulation }\end{array}$ & $\begin{array}{c}\text { Shell } \\
\text { Formulation }\end{array}$ & $\begin{array}{l}\text { Theoretical } \\
\text { Payload (\%) }\end{array}$ & $\begin{array}{l}\text { Sample Wt } \\
\text { (grams) }\end{array}$ & $\begin{array}{l}\text { Collection } \\
\text { Bath }\end{array}$ & Comments \\
\hline $1-1$ & $\begin{array}{c}50 \% \mathrm{NH}_{4} \mathrm{SCN} \\
50 \% \mathrm{DI} \mathrm{H}_{2} \mathrm{O}\end{array}$ & $\begin{array}{l}2 \% \text { PTMSP } \\
\text { (med MW) } \\
98 \% \mathrm{CHCl}_{3}\end{array}$ & 81 & 0 & acetone & $\begin{array}{l}\text { Shell was stringing } \\
\text { at the nozzle. No } \\
\text { capsules were made. }\end{array}$ \\
\hline $\begin{array}{c}1-2 \\
(8-761)\end{array}$ & $n$ & $n$ & 81 & 0.7 & $"$ & $\begin{array}{l}\text { Sample formed OK. } \\
\text { Some stringing. } \\
5.9 \% \text { loading }\end{array}$ \\
\hline $\begin{array}{c}1-3 \\
(8-762)\end{array}$ & $"$ & $"$ & 81 & 1.7 & $"$ & $\begin{array}{l}\text { Capsules formed } \\
\text { well. } 5.7 \% \text { loading }\end{array}$ \\
\hline $\begin{array}{c}1-4 \\
(8-763)\end{array}$ & $"$ & $\begin{array}{c}\text { 0.5\% PTMSP } \\
\text { (high } \mathrm{MW} \text { ) } \\
99.5 \% \mathrm{CHCl}_{3}\end{array}$ & 92 & trace & $"$ & $\begin{array}{l}\text { Capsules not formed } \\
\text { well. Solution too } \\
\text { viscous. } \\
6.1 \% \text { loading }\end{array}$ \\
\hline $\begin{array}{c}1-5 \\
(8-764)\end{array}$ & $"$ & $\begin{array}{l}\text { 3\%PTMSP } \\
\text { (med MW) } \\
97 \% \text { hexane }\end{array}$ & 75 & 0.5 & $"$ & $\begin{array}{l}\text { Capsules flattened } \\
\text { on the surface of the } \\
\text { acetone bath. } \\
0 \% \text { loading }\end{array}$ \\
\hline $\begin{array}{c}1-6 \\
(8-765)\end{array}$ & $"$ & $\begin{array}{l}2 \% \text { PTMSP } \\
\text { (med MW) } \\
98 \% \mathrm{CHCl}_{3}\end{array}$ & 80 & 1.3 & $"$ & $\begin{array}{l}\text { Capsules formed } \\
\text { OK. Gear pump } \\
\text { replaced with a } \\
\text { syringe pump. }\end{array}$ \\
\hline $\begin{array}{c}1-7 \\
(8-857)\end{array}$ & $"$ & $"$ & 81 & 2 & $"$ & $\begin{array}{l}\text { Some stringing. } \\
\text { Capsules formed } \\
\text { fairly well. }\end{array}$ \\
\hline $1-8$ & $\begin{array}{c}66.7 \% \\
\mathrm{NH}_{4} \mathrm{SCN} \\
33.3 \% \mathrm{DI} \mathrm{H}_{2} \mathrm{O}\end{array}$ & $\begin{array}{c}5 \% \text { PTMSP } \\
\text { (low MW) } \\
95 \% \text { toluene }\end{array}$ & 84 & none & different oils & $\begin{array}{l}\text { Different collection } \\
\text { baths investigated. } \\
\text { Lightweight silicone } \\
\text { oil best. }\end{array}$ \\
\hline $1-9$ & $\begin{array}{l}31 \% \mathrm{NH}_{4} \mathrm{SCN} \\
69 \% \text { methanol }\end{array}$ & $"$ & 71 & none & different oils & $\begin{array}{l}\text { Different collection } \\
\text { baths investigated. } \\
\text { Lightweight silicone } \\
\text { oil best. }\end{array}$ \\
\hline
\end{tabular}


Table 2.1-1 (continued)

Centrifugal Extrusion Microcapsules

\begin{tabular}{|c|c|c|c|c|c|c|}
\hline $\begin{array}{c}\text { Run \# } \\
\text { (Sample \#) }\end{array}$ & $\begin{array}{c}\text { Core } \\
\text { Formulation }\end{array}$ & $\begin{array}{c}\text { Shell } \\
\text { Formulation }\end{array}$ & $\begin{array}{l}\text { Theoretical } \\
\text { Payload (\%) }\end{array}$ & $\begin{array}{c}\text { Sample Wt } \\
\text { (grams) }\end{array}$ & $\begin{array}{l}\text { Collection } \\
\text { Bath }\end{array}$ & Comments \\
\hline $\begin{array}{c}1-10 \\
(8-858)\end{array}$ & $\begin{array}{c}66.7 \% \\
\mathrm{NH}_{4} \mathrm{SCN} \\
33.3 \% \mathrm{DI} \mathrm{H} \mathrm{H}_{2} \mathrm{O}\end{array}$ & $\begin{array}{l}5 \% \text { PTMSP } \\
95 \% \text { toluene }\end{array}$ & 84 & 62 & $\begin{array}{l}\text { silicone oil } \\
\text { (10 cst })\end{array}$ & $\begin{array}{l}\text { Sample placed in } \\
\text { vacuum oven at } \\
100^{\circ} \mathrm{F} \text {. Capsules } \\
\text { sieved out, rinsed } \\
\text { with water and dried } \\
\text { in air. } \\
40 \% \text { loading }\end{array}$ \\
\hline $1-11$ & $\begin{array}{l}31 \% \mathrm{NH}_{4} \mathrm{SCN} \\
69 \% \text { methanol }\end{array}$ & $"$ & 71 & none & $"$ & Shell strings badly. \\
\hline $\begin{array}{c}1-12 \\
(8-859)\end{array}$ & $n$ & $\begin{array}{c}3.8 \% \text { PTMSP } \\
\text { (low MW) } \\
96.2 \% \text { toluene }\end{array}$ & 71 & 37 & $"$ & $\begin{array}{l}\text { Capsules flattened } \\
\text { slightly on surface } \\
\text { of silicone oil. } \\
\text { Same drying } \\
\text { procedure as above. } \\
20 \% \text { loading }\end{array}$ \\
\hline $\begin{array}{c}1-13 \\
(8-969)\end{array}$ & $\begin{array}{c}66.7 \% \\
\mathrm{NH}_{4} \mathrm{SCN} \\
33.3 \% \text { DI H} \mathrm{H}_{2} \mathrm{O}\end{array}$ & $\begin{array}{l}\text { 2\% PTMSP } \\
\text { (low MW) } \\
98 \% \text { toluene }\end{array}$ & 83 & 18 & $"$ & $\begin{array}{l}\text { Shell polymer } \\
\text { concentration } \\
\text { reduced to make } \\
\text { smaller capsules. } \\
\text { Capsules dried by } \\
\text { heating in silicone } \\
\text { oil to } 140^{\circ} \mathrm{F} \text {. }\end{array}$ \\
\hline
\end{tabular}

To prevent this problem, different collection baths were investigated including Isopar $\mathrm{E}$, different grades of silicone oil, and water. The capsules tended to flatten on the surface of the water. Addition of a surfactant allowed the microcapsules to penetrate the water bath but the capsules coalesced, forming large agglomerates. A low viscosity $(10 \mathrm{cst})$ silicone oil provided the best results. The capsules gradually harden leaving discrete particles (Figure 2.1-2). The solvent was gradually evaporated in a vacuum oven at $100^{\circ} \mathrm{F}$ or using a hot silicone bath $\left(140^{\circ} \mathrm{F}\right)$ with agitation. The capsules were then sieved, rinsed with water, and dried in air.

Other runs examined the effect of increasing the concentration of $\mathrm{NH}_{4} \mathrm{SCN}$, using a methanol solution of $\mathrm{NH}_{4} \mathrm{SCN}$ as the core, changing the solvent for the shell polymer, and varying the concentration of polymer in the shell formulation. Using methanol in the core solution should form an inner wall on the capsules to give more integrity to the coating as it dries. The use of 
different solvents for the shell polymer affects the evaporation rate which varies the solidification rate. Lowering the shell polymer concentration decreases the viscosity of the solution and, in theory, allows for the formation of smaller capsules. None of these methods was particularly effective.

\subsubsection{Laboratory Rotating Disk Device}

The laboratory rotating disk device, LRD, consists of a high-speed, rotating disk which forms small, spherical droplets from an emulsion of the aqueous or solid salt in the shell polymer solution as it is fed onto the disk. The liquid droplets, which are formed at the periphery of the disk, are solidified by solvent evaporation. The size of the microspheres is controlled by the feed rate, disk speed and emulsion viscosity. The microspheres were collected in a thin layer of Dry-Flo ${ }^{\circledR}$, starch, a solvent bath, or a silicone oil bath.

Table 2.1-2 summarizes the experimental parameters used on the samples prepared via the LRD. The first four samples were collected in Dry-Flo ${ }^{\circledR}$ starch to cushion their impact and maintain discrete, nonsticky particles; these capsules contained a gross excess of starch in the shell (Figure 2.1-3). Other samples were collected in acetone (Figure 2.1-4), methanol, or silicone oil. The samples collected in silicone oil (Figure $2.1-5$ ) were made by recrystallizing TEAA $44 \mathrm{H}_{2} \mathrm{O}$ in the shell polymer solution. For this process, the salt was dispersed in the shell solution, and the solution was then heated above the melting point of the salt $\left(46^{\circ} \mathrm{C}\right)$ with stirring to form molten spheres of TEAA $\cdot 4 \mathrm{H}_{2} \mathrm{O}$. For run 1-14 the solution, containing the molten salt, was poured onto the rotating disk. For runs 1-15 through 1-20 the solution was first cooled to room temperature to recrystallize the salt before it was poured onto the disk. Run 1-17 was rinsed in $\mathrm{CH}_{2} \mathrm{Cl}_{2}$ followed by acetone. Dichloromethane seemed to soften the wall which resulted in some agglomeration. Runs 1-18 through 1-20 were rinsed with acetone, water, and then acetone again. 
Table 2.1-2

Rotating Disk Microcapsules

\begin{tabular}{|c|c|c|c|c|c|c|}
\hline $\begin{array}{c}\text { Run \# } \\
\text { (Sample \#) }\end{array}$ & $\begin{array}{c}\text { Core } \\
\text { Formulation }\end{array}$ & $\begin{array}{c}\text { Shell } \\
\text { Formulation }\end{array}$ & $\begin{array}{l}\text { Collection } \\
\text { Medium }\end{array}$ & $\begin{array}{l}\text { Disk } \\
\text { Speed }\end{array}$ & $\begin{array}{l}\text { Sample } \\
\text { Wt (g) }\end{array}$ & $\begin{array}{l}\text { Theoretical } \\
\text { Payload }(\%)\end{array}$ \\
\hline $\begin{array}{c}1-1 \\
(8-673)\end{array}$ & $\begin{array}{l}2.5 \% \text { PVAmSCN } \\
\text { in DI } \mathrm{H}_{2} \mathrm{O}\end{array}$ & $\begin{array}{c}\text { 3\% PTMSP } \\
\text { (med MW) } \\
\text { in hexane }\end{array}$ & starch & $2030 \mathrm{rpm}$ & 1.5 & 30 \\
\hline $\begin{array}{c}1-2 \\
(8-674)\end{array}$ & $"$ & $\begin{array}{c}2 \% \text { PTMSP } \\
\text { (med MW) } \\
\text { in } \mathrm{CHCl}_{3}\end{array}$ & $"$ & $"$ & 0.4 & 39 \\
\hline $\begin{array}{c}1-3 \\
(8-675)\end{array}$ & $\begin{array}{c}50 \% \mathrm{NH}_{4} \mathrm{SCN} \\
\text { in } \mathrm{DI} \mathrm{H}_{2} \mathrm{O}\end{array}$ & $\begin{array}{l}\text { 3\% PTMSP } \\
\text { in hexane }\end{array}$ & $"$ & $"$ & 5.5 & 90 \\
\hline $\begin{array}{c}1-4 \\
(8-676)\end{array}$ & $\begin{array}{c}50 \% \mathrm{NH}_{4} \mathrm{SCN} \\
\text { in DI } \mathrm{H}_{2} \mathrm{O}\end{array}$ & $\begin{array}{c}\text { 2\% PTMSP } \\
\text { (med MW) } \\
\text { in } \mathrm{CHCl}_{3}\end{array}$ & $"$ & $"$ & 2.5 & 94 \\
\hline $\begin{array}{c}1-5 \\
(8-710)\end{array}$ & $\begin{array}{l}2.5 \% \text { PVAmSCN } \\
\text { in DI } \mathrm{H}_{2} \mathrm{O}\end{array}$ & $"$ & methanol & 900 & 0.4 & 39 \\
\hline $\begin{array}{c}1-6 \\
(8-711)\end{array}$ & $\begin{array}{l}2.5 \% \text { PVAmSCN } \\
\text { in DI } \mathrm{H}_{2} \mathrm{O}\end{array}$ & $"$ & acetone & $n$ & 0.2 & 38.5 \\
\hline $1-14$ & $\mathrm{TEAA} \cdot 4 \mathrm{H}_{2} \mathrm{O}$ & $\begin{array}{l}2 \% \text { PTMSP } \\
\text { (med MW) } \\
\text { Isopar E }\end{array}$ & $\begin{array}{l}\text { silicone oil } \\
\text { (10 cst) }\end{array}$ & 300 & $\begin{array}{c}\text { not } \\
\text { collected }\end{array}$ & 90 \\
\hline $\begin{array}{c}1-15 \\
(8-970)\end{array}$ & $"$ & $n$ & $"$ & 200 & 15.6 & $"$ \\
\hline $1-16$ & $"$ & $\begin{array}{c}2 \% \text { PTMSP } \\
\text { (high MW) } \\
\text { Isopar E }\end{array}$ & $"$ & 360 & $\begin{array}{c}\text { not } \\
\text { collected }\end{array}$ & " \\
\hline $\begin{array}{c}1-17 \\
(9-155)\end{array}$ & $"$ & $"$ & $"$ & 1032 & 0.1 & $"$ \\
\hline $\begin{array}{c}1-18 \\
(9-156)\end{array}$ & $"$ & $\begin{array}{c}2 \% \text { PTMSP } \\
\text { (low MW) } \\
\text { Isopar E }\end{array}$ & $"$ & 280 & 0.3 & $"$ \\
\hline $\begin{array}{c}1-19 \\
(9-157)\end{array}$ & $"$ & $"$ & $"$ & 1000 & 0.4 & $"$ \\
\hline $\begin{array}{c}1-20 \\
(9-158)\end{array}$ & $"$ & $"$ & $"$ & 318 & 5.4 & 95 \\
\hline
\end{tabular}




\subsubsection{Solvent Evaporation}

In the solvent evaporation method, the salt is dispersed in the carrier solvent (triacetin) or the shell polymer solution. The TEAA $4 \mathrm{H}_{2} \mathrm{O}$ was recrystallized as described in section 2.1-2. The shell polymer was then added, with agitation, to the carrier solvent. Because the carrier solvent is immiscible with the shell polymer solution, a layer of the shell solution surrounded the dispersed salt droplets. Table 2.3-1 describes the various solvent evaporation samples prepared for this project. These capsules tended to coalesce during harvesting (Figure 2.1-6).

Table 2.1-3

Solvent Evaporation Encapsulation Of TEAA $4 \mathrm{H}_{2} \mathrm{O}$

$\begin{array}{ccc}\begin{array}{c}\text { Run \# } \\ \text { (Sample \#) }\end{array} & \begin{array}{c}\text { Shell Polymer } \\ \text { Formulation }\end{array} & \begin{array}{c}\text { Theoretical } \\ \text { Payload (\%) }\end{array}\end{array}$




\subsubsection{Phase Separation}

The phase separation technique involves dispersing the salt into the shell polymer solution. Then a phase separation initiator, a material which is miscible with the shell polymer solvent but one in which the shell polymer is insoluble, is added dropwise to the dispersion to cause the polymer to precipitate from solution and onto the dispersed phase. The product was then filtered out of the solvent and dried. Table 2.1-4 contains details on the samples prepared by phase separation methods. This method worked best on $\mathrm{NH}_{4} \mathrm{SCN}$. As shown in Figure 2.1-7, capsules of 25-50 $\mu \mathrm{m}$ diameter were made, but they agglomerated into larger particles and could not be further separated.

Table 2.1-4

Phase Separation Encapsulation

\begin{tabular}{|c|c|c|c|c|}
\hline $\begin{array}{c}\text { Run\# } \\
\text { (Sample \#) }\end{array}$ & $\begin{array}{c}\text { Shell } \\
\text { Formulation }\end{array}$ & $\begin{array}{l}\text { Theoretical } \\
\text { Payload (\%) }\end{array}$ & Initiator & Comments \\
\hline $\begin{array}{c}1-1 \\
(8-909)\end{array}$ & $\begin{array}{l}\text { 3\% PTMSP } \\
\text { (low MW) } \\
97 \% \text { toluene }\end{array}$ & 77 & $\begin{array}{l}\text { silicone oil } \\
\text { (10cst) }\end{array}$ & $\begin{array}{l}\text { The product was collected on a } \\
45 \mu \mathrm{m} \text { sieve and rinsed with water. } \\
\text { Product was dried in a convection } \\
\text { oven. }\end{array}$ \\
\hline $\begin{array}{c}1-2 \\
(8-910)\end{array}$ & $\begin{array}{l}\text { 2\% PTMSP } \\
\text { (high MW) } \\
98 \% \text { hexane }\end{array}$ & 85 & ethyl acetate & $\begin{array}{l}\text { When the agitation was stopped, the } \\
\text { water layer separated out. It is } \\
\text { believed that some of the product is } \\
\text { free polymer, not encapsulated salt. } \\
\text { This may have been because the } \\
\text { ethyl acetate was added too quickly. }\end{array}$ \\
\hline $\begin{array}{c}1-3 \\
(8-911)\end{array}$ & $"$ & $"$ & $"$ & $\begin{array}{l}\text { Ethyl acetate added slower using a } \\
\text { separatory funnel. Some } \\
\text { improvement in the product. }\end{array}$ \\
\hline $\begin{array}{c}1-4 \\
(8-912)\end{array}$ & $\begin{array}{l}\text { 2\% PTMSP } \\
\text { (high MW) } \\
98 \% \text { toluene }\end{array}$ & $"$ & isopropanol & $\begin{array}{l}\text { Isopropanol seemed to work better } \\
\text { than ethyl acetate. Discrete capsules } \\
\text { were observed in the liquid. During } \\
\text { the drying process, the capsules } \\
\text { appeared to collapse and stick } \\
\text { together. }\end{array}$ \\
\hline $\begin{array}{c}1-7 \\
(8-968)\end{array}$ & $\begin{array}{l}2 \% \text { PTMSP } \\
\text { (low MW) } \\
98 \% \text { Isopar E }\end{array}$ & 90 & $\begin{array}{l}\text { silicone oil } \\
\text { (10cst) }\end{array}$ & $\begin{array}{l}\text { TEAA } 4 \mathrm{H} 2 \mathrm{O} \text { dispersed in the } \\
\text { polymer solution. Salt was } \\
\text { recrystallized by heating and then } \\
\text { cooling the solution. Polymer was } \\
\text { phased out of solution using silicone } \\
\text { oil. }\end{array}$ \\
\hline
\end{tabular}




\subsection{Capsule Evaluation}

\subsubsection{Gas Absorption Capacity}

The gas absorption capacity of the capsules was measured using standard volumetric techniques. A dosing volume of gas was expanded into a reactor containing the sample, which was previously evacuated, and then allowed to reach equilibrium. The amount of gas absorbed was calculated from the known volumes, temperatures, and pressures. Results are reported in Table 2.2-1. (The different significant figures in the absorption capacity reflect improvements made in the sensitivity of the equipment during the course of this work.) The loading, or payload, was determined by dividing the $\mathrm{NH}_{3}$ capacity of the capsule by the $\mathrm{NH}_{3}$ capacity of the salt alone (as calculated from literature values) at the same temperature and pressure. The $\mathrm{NH} 3$ capacity of most capsules was relatively poor. A few however, (e.g., 8-858, 8-911) had good $\mathrm{NH}_{3}$ capacity and were chosen for further study. For the TEAA $4 \mathrm{H}_{2} \mathrm{O} / \mathrm{PTMSP}$ capsules, interpretation of the data is more complex. Here, capacity alone is not a good indicator of payload because PTMSP itself has a relatively high capacity for $\mathrm{CO}_{2}$ (Table 2.2-2). In fact, payloads could not be calculated accurately for these systems using this method. In this case, the criterion for a well made TEAA $\cdot 4 \mathrm{H}_{2} \mathrm{O}$ capsule is the $\mathrm{CO}_{2} / \mathrm{N}_{2}$ selectivity of the capsule as compared to the $\mathrm{CO}_{2} / \mathrm{N}_{2}$ selectivity of PTMSP alone. This criteria was also applied to PTMSPencapsulated $\mathrm{NH}_{4} \mathrm{SCN}$.

\subsubsection{Selectivity}

In order to determine the selectively of the capsules, a $\mathrm{N}_{2}$ absorption isotherm was measured at the same temperature as that obtained for the reactive gas $\left(\mathrm{NH}_{3}\right.$ or $\left.\mathrm{CO}_{2}\right)$. In all cases $\mathrm{N}_{2}$ absorption was found to be linear in pressure over $50-500 \mathrm{kPa}$. A Henry's law constant was calculated from a linear least squares fit of the data (Table 2.2-3). The selectivity of the capsule was determined by calculating (from Table 2.2-3) the $\mathrm{N}_{2}$ capacity of the capsule at a pressure for which the $\mathrm{CO}_{2}$ or $\mathrm{NH}_{3}$ capacity was determined experimentally (Table 2.3-1). Ammonia, $\mathrm{CO}_{2}$, and $\mathrm{N}_{2}$ absorption isotherms were then measured for PTMSP alone at the temperature of interest, and the Henry's law constants were determined as above. The selectivity of PTMSP was calculated at the same pressure as that used in the selectivity determination for the microcapsules. Results are shown in Tables 2.2-2 through 2.2-4. It can be seen that PTMSPencapsulated TEAA $4 \mathrm{H}_{2} \mathrm{O}$ is 4-9 times more selective than PTMSP alone (8-970, 8-967). Similarly, PTMSP-encapsulated $\mathrm{NH}_{4} \mathrm{SCN}$ is roughly 17 times more selective than PTMSP. Thus, it is confirmed that the capsules do indeed contain an active component which imparts 
Table 2.2-1

Absorption Capacity of Microencapsulated AT Materials

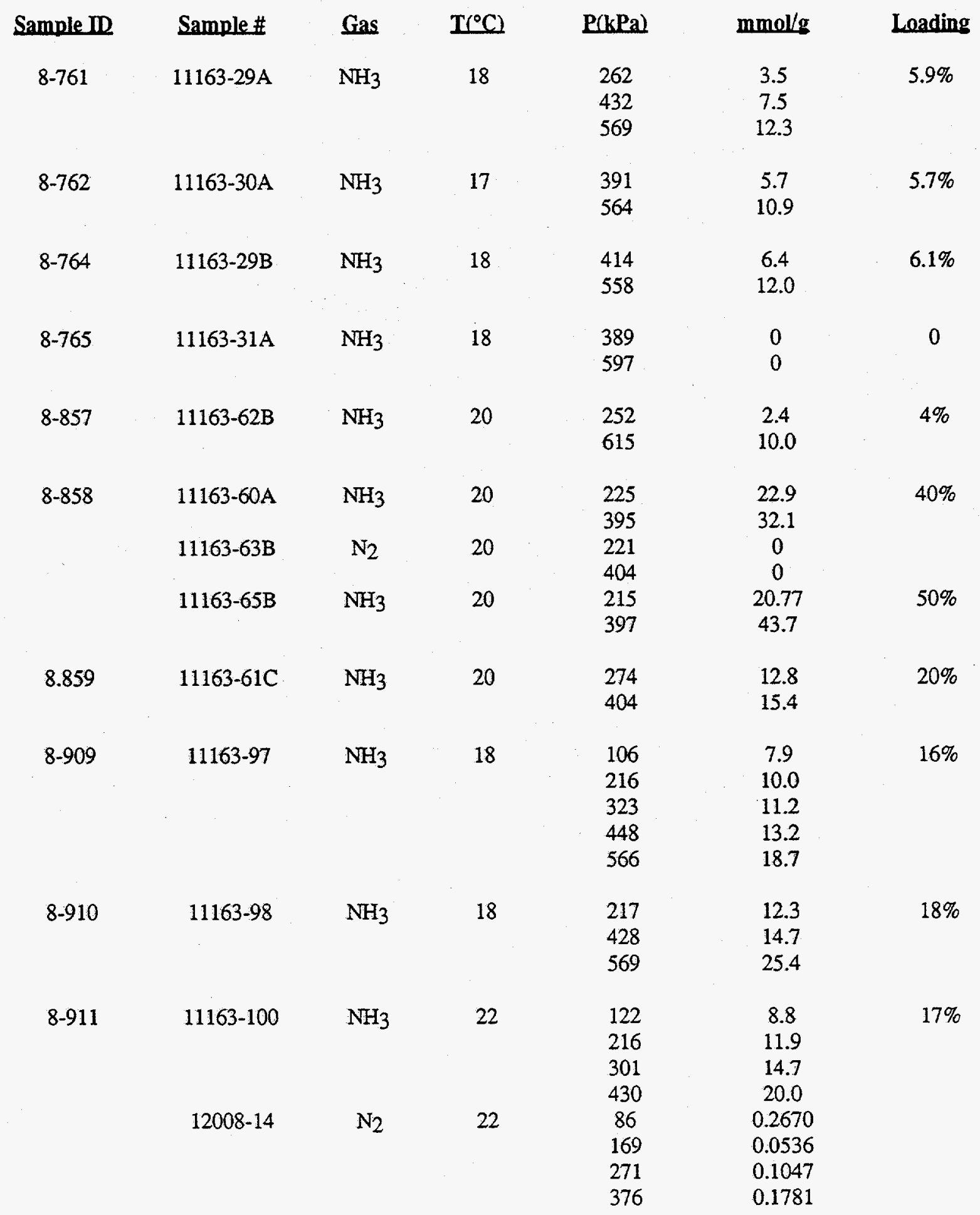


Table 2.2-1 (continued)

Absorption Capacity of Microencapsulated AT Materials

\begin{tabular}{|c|c|c|c|c|c|c|}
\hline Sample ID & Sample\# & Gas & $T\left({ }^{\circ} \mathrm{C}\right)$ & $\mathbf{P}(\mathbf{k P a})$ & $\mathrm{mmol} / \mathrm{g}$ & Loading \\
\hline $8-912$ & $11163-99$ & $\mathrm{NH}_{3}$ & 19 & $\begin{array}{l}112 \\
211 \\
330 \\
435\end{array}$ & $\begin{array}{l}0 \\
0 \\
0 \\
0\end{array}$ & 0 \\
\hline 8-969 & $11497-5$ & $\mathrm{NH}_{3}$ & 21 & $\begin{array}{l}222 \\
324 \\
445 \\
545\end{array}$ & $\begin{array}{l}0 \\
0 \\
0 \\
0\end{array}$ & 0 \\
\hline $8-913$ & $11273-90$ & $\mathrm{CO}_{2}$ & 50 & $\begin{array}{l}111 \\
267 \\
476\end{array}$ & $\begin{array}{l}0.308 \\
0.510 \\
0.772\end{array}$ & -- \\
\hline 8-967 & $11674-27$ & $\mathrm{CO}_{2}$ & 50 & $\begin{array}{c}55 \\
190 \\
341 \\
516 \\
104 \\
198 \\
291 \\
378 \\
460\end{array}$ & $\begin{array}{l}0.531 \\
1.021 \\
1.623 \\
2.016 \\
0.006 \\
0.011 \\
0.016 \\
0.021 \\
0.028\end{array}$ & $\cdots$ \\
\hline $8-968$ & $11674-29$ & $\mathrm{CO}_{2}$ & 50 & $\begin{array}{c}77 \\
156 \\
241 \\
256\end{array}$ & $\begin{array}{l}0.379 \\
0.658 \\
1.098 \\
2.588\end{array}$ & -- \\
\hline $8-970$ & $11638-93$ & $\mathrm{CO}_{2}$ & 50 & $\begin{array}{l}140 \\
222 \\
371 \\
526 \\
68 \\
121 \\
220 \\
465\end{array}$ & $\begin{array}{l}0.224 \\
0.302 \\
0.356 \\
0.453 \\
0.002 \\
0.003 \\
0.007 \\
0.017\end{array}$ & --- \\
\hline
\end{tabular}

selectivity to the system. Also, since the loadings are at best only $\sim 50 \%$, the selectivity could be enhanced even further by increasing the payload. 
Table 2.2-2

Absorption Capacity of PTMSP

\begin{tabular}{ccccc} 
Sample \# & Gas & $\underline{\mathbf{T}\left({ }^{\circ} \mathbf{C}\right)}$ & $\underline{\mathbf{P}(\mathbf{k P a})}$ & $\underline{\mathbf{m m o l} / \mathbf{g}}$ \\
$12008-16$ & $\mathrm{NH} 3$ & 24 & 70 & 0.336 \\
& & & 178 & 0.909 \\
& & & 249 & 1.400 \\
& & & 301 & 1.845 \\
& & & 373 & 3.883 \\
$12008-12$ & $\mathrm{~N}_{2}$ & 24 & 108 & 0.0528 \\
& & & 195 & 0.1002 \\
& & & 289 & 0.1524 \\
& & & 384 & 0.2038 \\
$12008-8$ & \multirow{2}{*}{$\mathrm{N}_{2}$} & & 480 & 0.2636 \\
& & & & \\
& & & 141 & 0.276 \\
& & & 186 & 0.0495 \\
& & & 373 & 0.0640 \\
& & & 432 & 0.1361 \\
$11354-71 \mathrm{~A}$ & $\mathrm{CO}_{2}$ & 50 & 120 & 0.4680 \\
& & & 289 & 1.089 \\
& & & 391 & 1.353 \\
& & & 502 & 1.728
\end{tabular}


Table 2.2-3

Least Squares Fit of Microcapsule Absorption Data

$\begin{array}{ccccc}\text { Sample } & \text { Gas } / \mathrm{T}\left({ }^{\circ} \mathrm{C}\right) & \underline{\mathrm{KH}}(\mathbf{m m o l} / \mathbf{g} \cdot \mathbf{k P a}) & \underline{\text { Intercept }} & \underline{\text { R Value }} \\ 8-911 & \mathrm{~N}_{2} / 24 & 0.005238 & -0.02735 & 0.9883 \\ 8-967 & \mathrm{~N}_{2} / 50 & 0.00005895 & -0.000394 & 0.9968 \\ 8-970 & \mathrm{~N}_{2} / 50 & 0.00003718 & -0.000699 & 0.9957 \\ 12008-16 & \mathrm{NH}_{3} / 24 & 0.006027 & -0.064019 & 0.9945 \\ \mathrm{RQ} 193 & \mathrm{CO}_{2} / 50 & 0.003417 & 0.037111 & 0.9982 \\ 12008-8 & \mathrm{~N}_{2} / 50 & 0.0003718 & -0.00416 & 0.9997 \\ 12008-12 & \mathrm{~N}_{2} / 24 & 0.0005631 & -0.009411 & 0.9997\end{array}$

Table 2.2-4

Selectivity of PTMSP-Encapsulated $\mathrm{NH}_{4} \mathrm{SCN}$ and TEAA $\cdot 4 \mathrm{H}_{2} \mathrm{O}$

\begin{tabular}{lccc} 
Gas Type & Sample id & Pressure (kPa) & Selectivity \\
\cline { 2 - 3 } $\mathrm{CO}_{2} / \mathrm{N}_{2}$ & $8-967$ & 190 & 93 \\
$\mathrm{CO}_{2} / \mathrm{N}_{2}$ & $8-970$ & 222 & 43 \\
$\mathrm{CO}_{2} / \mathrm{N}_{2}$ & PTMSP & 222 & 11 \\
& & & \\
$\mathrm{NH}_{3} / \mathrm{N}_{2}$ & $8-911$ & 122 & 185 \\
& & 216 & 131 \\
& & 301 & 114 \\
$\mathrm{NH}_{3} / \mathrm{N}_{2}$ & PTMSP & 100 & 11.4 \\
& & 200 & 11.1 \\
& & 300 & 10.9
\end{tabular}




\subsection{Summary/Status}

Some general conclusions concerning microencapsulation of $\mathrm{NH}_{4} \mathrm{SCN}$ and TEAA are summarized below.

$\mathrm{NH}_{4} \mathrm{SCN}$

Rotating Disk

Centrifugal

Coextrusion

Phase Separation

TEAA. $4 \mathrm{H}_{2} \mathrm{O}$

Rotating Disk

Solvent

Evaporation

Phase Separation
- Capsule recovery/collection in Dry-Flo® starch is not a viable process. Too much starch becomes imbedded within the capsule wall. (Figure 2.1-3)

- Collection in a nonsolvent (eg acetone, methanol) improved the overall appearance of the capsules (Figure 2.1-4) but led to the formation of small defects in the shell which allowed the core to leak out. It is believed that this accounts for the low $\mathrm{NH}_{3}$ absorption capacity of these capsules. (Table 2.2-1). Size ranged from 200-800um diameter.

- Acetone collection led to shell wall shrinkage and subsequently to cracks in the shell. As these capsules had lower than expected capacities, it seems reasonable that the core was lost through these cracks.

- Silicone or other oil baths gave best results. Capsules were defect-free and had improved $\mathrm{NH}_{3}$ absorption capacity but tended to coalesce (Figure 2.1-2). Capsule diameter was $>250 \mu \mathrm{m}$.

- Good capsule formation, but isolation of discrete particles was a problem. Capsules as small as $25-50 \mu \mathrm{m}$ were produced but agglomerated into larger $(500 \mu \mathrm{m})$ particles (Figure 2.1-7). Absorption properties were good.

- The combination of a low volatility solvent for PTMSP (Isopar E) and a silicone oil collection bath gave well-defined, discrete capsules ca 500 in diameter (Figure 2.1-5). The shell was smooth and free of defects. This technique appears viable but capsule size needs to be reduced 10-fold to be implemented in a commercially attractive membrane.

- Triacetin acceptable as a carrier solvent. Capsules were largely defectfree but tended to coalesce (Figure 2.1-6). Absorption capacity suggests capsules have lower salt content than expected.

- Good capsule formation although shell appears to contain an excess of free polymer on the surface (Figure 2.1-8). In view of the high $\mathrm{CO}_{2}$ capacity of PTMSP, this may account for the higher than expected $\mathrm{CO}_{2}$ capacity of these capsules. 
Both $\mathrm{NH}_{4} \mathrm{SCN}$ and TEAA $4 \mathrm{H}_{2} \mathrm{O}$ have been encapsulated within PTMSP. In general, TEAA seems more amenable to microencapsulation because it can be melted and is thus easily processed by phase separation or solvent evaporation microencapsulation techniques. Thus far, capsules of the necessary size and payload combination, which would be amenable to further fabrication into a membrane device, have not been produced. Thus, such fabrication has not been attempted. Based on the positive gas absorption results, a patent for the use of microencapsulated AT materials as PSA, VSA, etc. absorbents is being actively pursued. Further work addressing a decrease in capsule size with a concurrent increase in loading would be necessary before attempting to fabricate a practical membrane device. No further work is anticipated under this cooperative agreement. 
(capsule exterior)

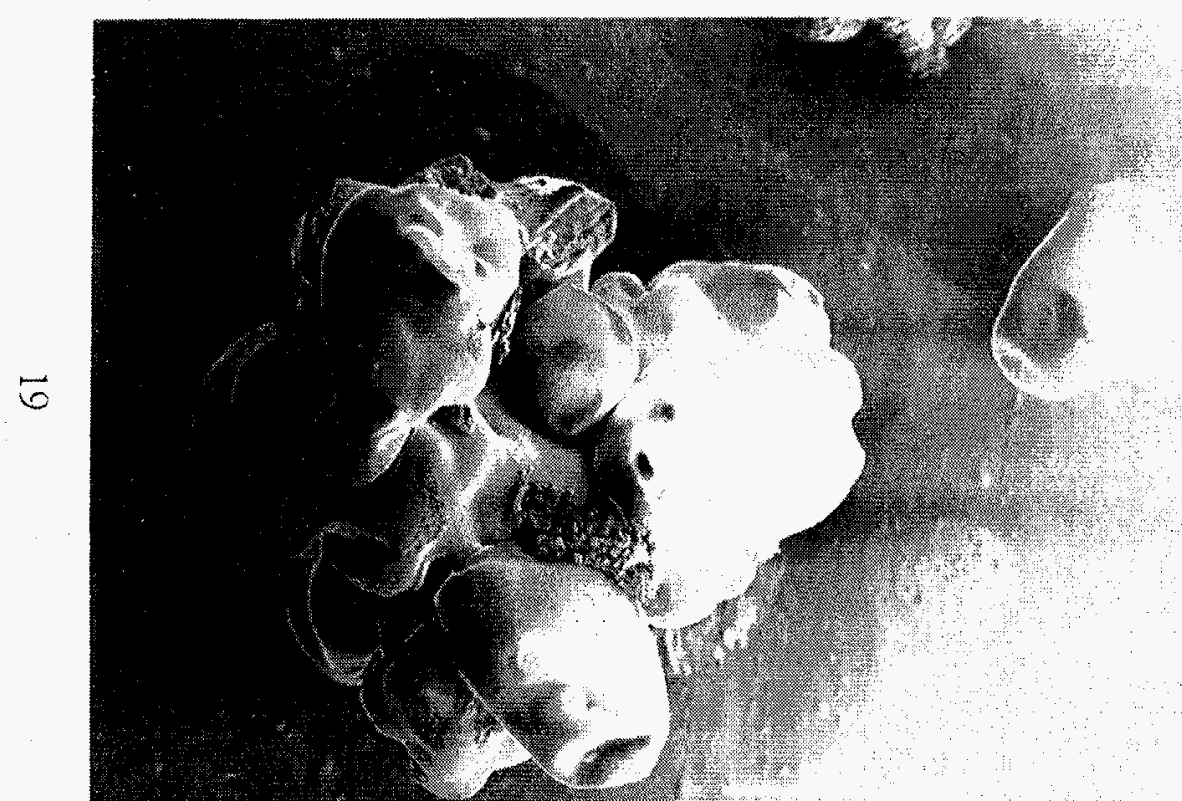

$04432.0 \mathrm{KW}$

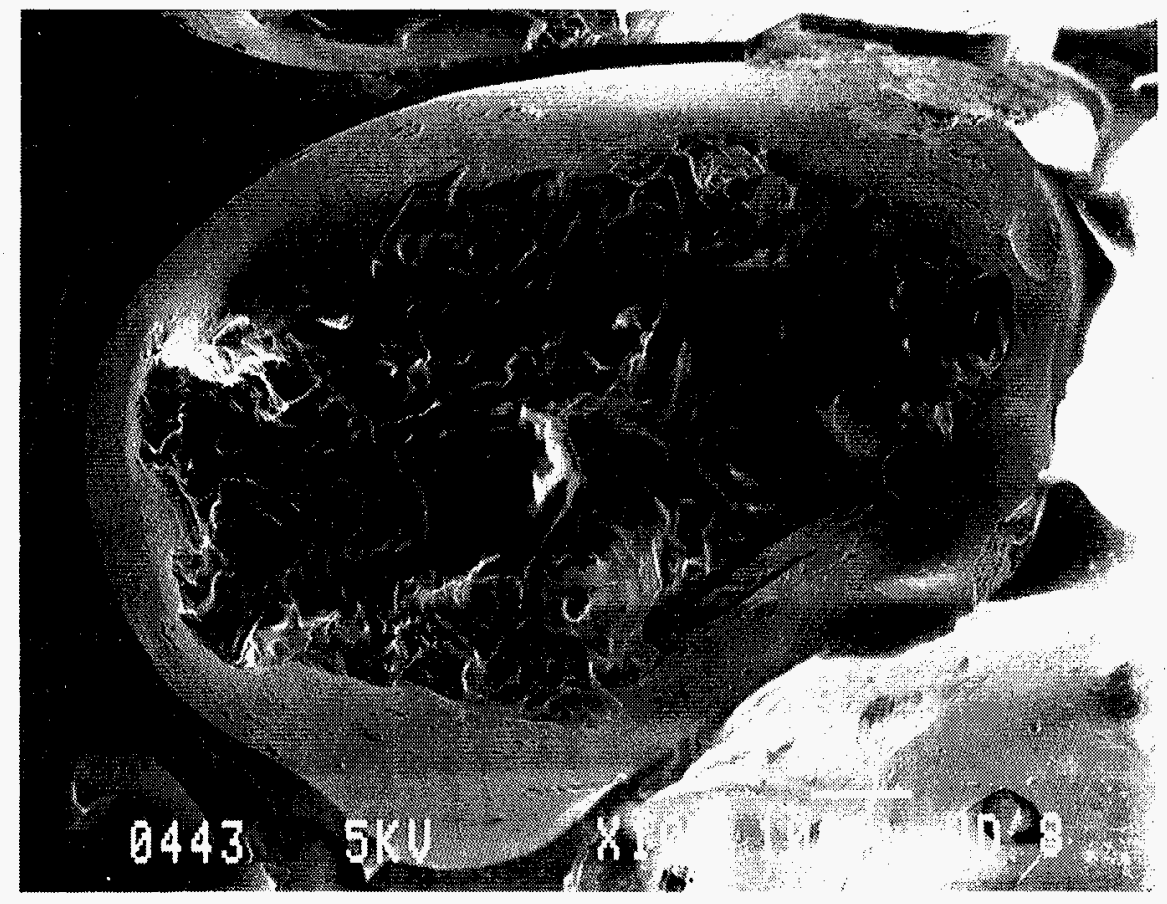

Figure 2.1-2: SEM of PTMSP-encapsulated $\mathrm{NH}_{4}$ SCN Prepared via LCED - silicone oil collection (8-858) 
(high magnification - shell)
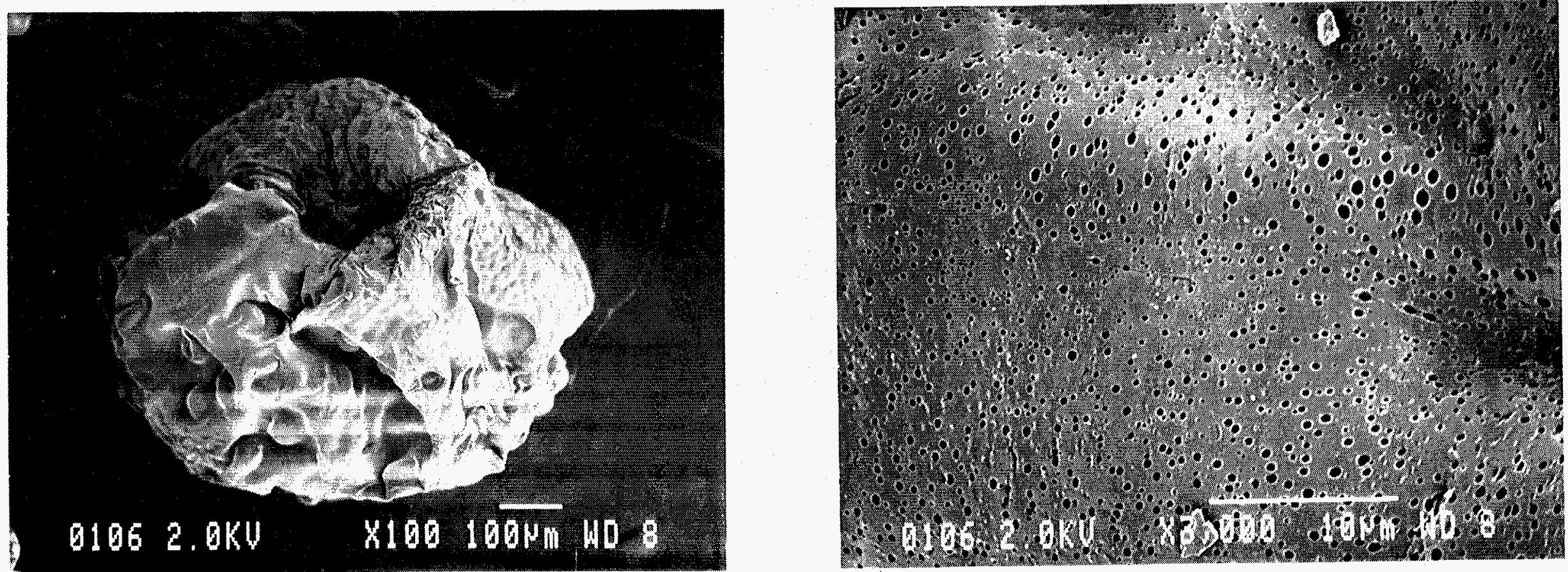

Figure 2.1-4: SEM of PTMSP-encapsulated $\mathrm{NH}_{4} \mathrm{SCN}$ Prepared via Rotating Disk - acetone collection (8-711) 


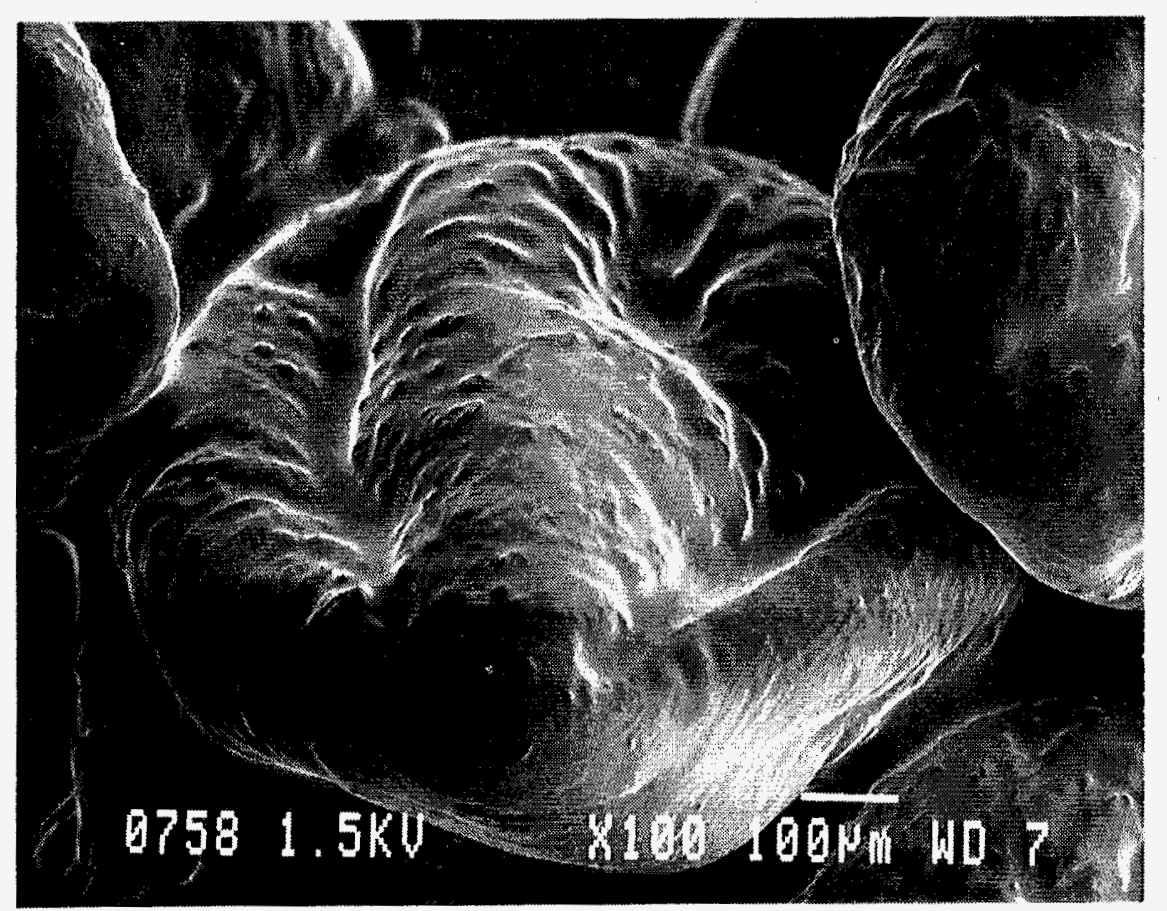

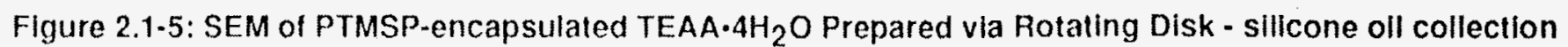
(8-970) 


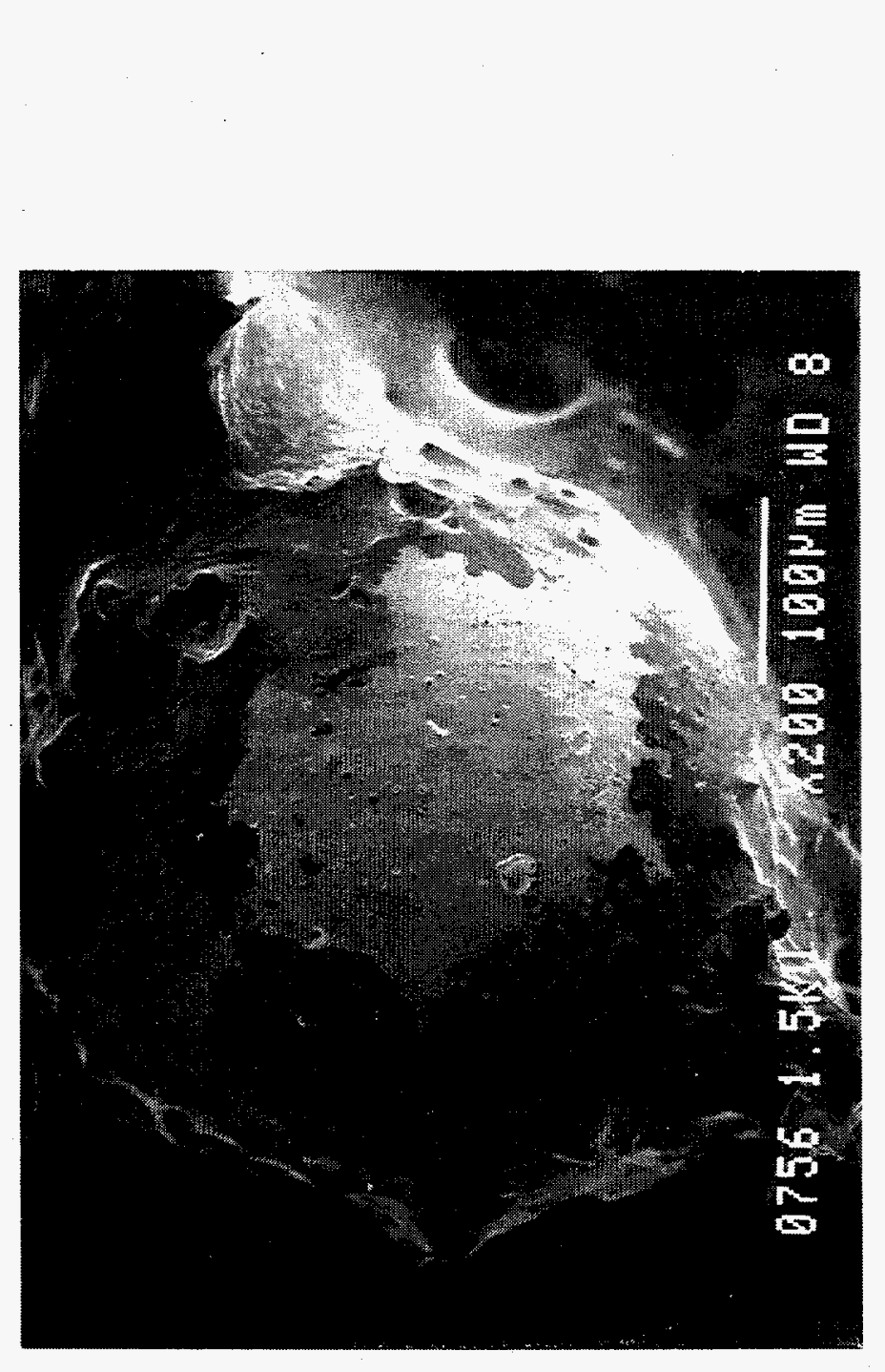

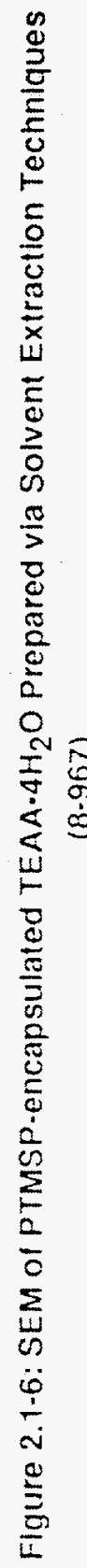




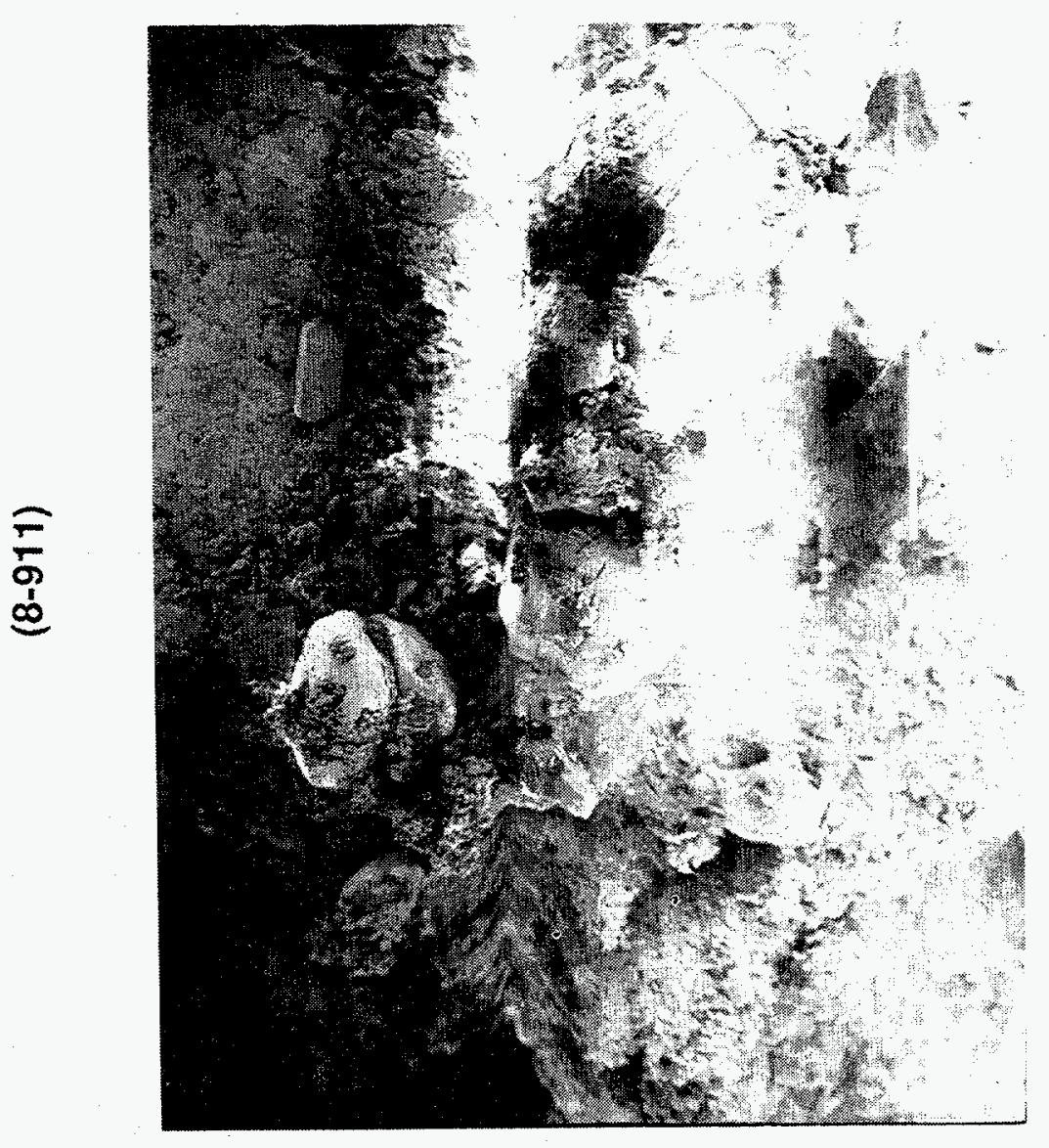

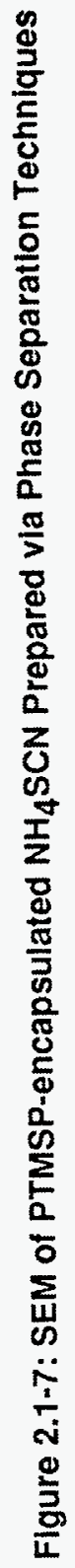




\subsection{Fabrication and Evaluation of $\mathrm{CO}_{2}$-Selective MLC Membranes}

Air Products and Chemicals, Inc., under an internally funded program, has developed new $\mathrm{CO}_{2}$ selective AT materials which are amenable to multilayer composite (MLC) fabrication. Two such compositions are poly (diallyldimethylammonium fluoride), DADMAF, and poly (vinyl benzyltrimethylammonium fluoride) PVBTAF This section covers their fabrication into multilayer composite membranes and their utility for permeating $\mathrm{CO}_{2}$ from mixtures with $\mathrm{CH}_{4}$ and especially $\mathrm{H}_{2}$.

\subsection{MLC Membrane Fabrication}

The multilayer composite concept combines the permselective properties of an AT material with the mechanical properties of a dense film of a highly permeable but relatively nonselective support polymer as shown below.

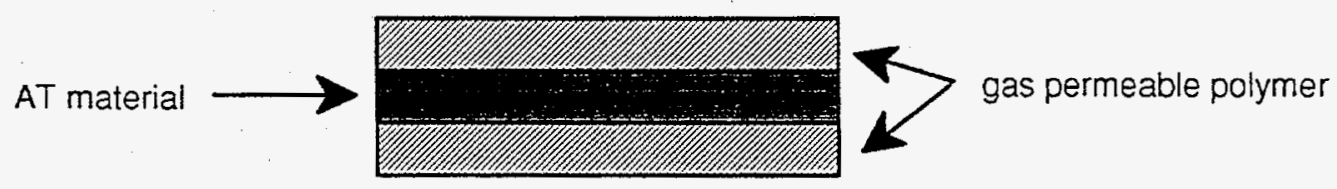

A key issue in the MLC approach is to minimize mass transfer resistance in the support polymer layer relative to the AT material layer. In this work, we have limited the support polymers to poly(trimethylsilylpropyne), PTMSP, and poly(dimethylsiloxane), PDMS. Both are nonporous in the ordinary sense of the word. The first is a glassy polymer possessing very high gas permeability (e.g. $\mathrm{P}_{0}\left(\mathrm{CO}_{2}\right)=33,100$ Barrer $)^{5}$. The latter is a rubbery polymer also exhibiting high gas permeability $\left(\mathrm{P}_{\mathrm{O}}\left(\mathrm{CO}_{2}\right)=3200 \text { Barrers }\right)^{6}$.

MLC membranes were fabricated by successive casting and drying of the respective polymer solutions using blade coating techniques. PTMSP was used as a $2 \mathrm{wt} \%$ solution in hexane or toluene; PDMS as a 4-5 wt\% solution in $\mathrm{CH}_{2} \mathrm{Cl}_{2}$. DADMAF was used as a 1-3 wt\% solution in water. In some cases a proprietary surfactant was added to the aqueous phase to improve wetting properties; it is referred to as SUR-1. The films were cast onto a level, clean glass plate which had been rinsed in methanol and dried at $80^{\circ} \mathrm{C}$. At all times, a shroud was kept over the membranes to limit accumulation of dust or other debris on the membrane surface. The shroud 
was constantly purged with $\mathrm{N}_{2}$. In some cases, MLCs were made which contained a microporous poly(acrylonitrile), PAN, layer supported on nonwoven polyester. The microporous PAN was produced by known fabrication techniques using a flat-sheet casting device 7 .

Some membranes were characterized using SEM. The membrane was sectioned by freezing it in liquid nitrogen. The cross-section was examined to estimate thicknesses of the layers, presence of defects, and overall appearance of the membrane. The thicknesses listed in the following tables were derived from SEM work unless otherwise noted. Representative photomicrographs of the different types of MLCs are shown in Figure 3.1-1 through 3.1-4. The layers are continuous and contain relatively few apparent flaws or defects. In some cases (see Figure 3.1-1) we observed a crack in the DADMAF layer; it is believed that this crack was introduced while preparing the specimen for microscopy.

\subsection{Evaluation of $\mathrm{CO}_{2}$-Selective MLC Membranes}

The membranes were evaluated in a flowing, mixed gas permeation system described previously 8 . Additionally, both the feed and helium sweep gases could be routed through a series of bubblers, filled with water, which were placed in a thermostated bath in order to hydrate these gas streams to a chosen humidity. Alternately, the test system could be operated without a helium sweep gas. In the latter case, the permeate was collected at between 1-25 psig. It was then diluted with helium for analysis at a point downstream of the membrane (see section 4.2.2). Two feed gas mixtures was used to evaluate the membranes:

Feed Mix 1: $25.6 \mathrm{~mol} \% \mathrm{CO}_{2}, 74.4 \mathrm{~mol}_{\%} \mathrm{CH}_{4}$

Feed Mix 2: $\quad 23.0 \mathrm{~mol} \% \mathrm{CO}_{2}, 23.1 \mathrm{~mol} \% \mathrm{CH}_{4}, 53.9 \mathrm{~mol} \% \mathrm{H}_{2}$

Unless otherwise specified, the membranes were evaluated at room temperature, in a heliumswept permeate mode with both the feed and sweep gases hydrated to the indicated dew points.

\subsubsection{Stand-alone DADMAF}

These DADMAF membranes did not contain any polymeric coating(s). They ranged from 30 $90 \mu \mathrm{m}$ in thickness (as measured using a micrometer). The membranes were evaluated with feed mix \#2. (except for 11273-13 which was evaluated using feed mix \#1.) The permeate was swept with helium and was maintained at -1 atm. Results are shown in Table 3.2-1. 
Table 3.2-1

Evaluation of Free-standing DADMAF Membranes

\begin{tabular}{|c|c|c|c|c|c|c|c|}
\hline $\begin{array}{c}\text { Sample } \\
\text { ID }\end{array}$ & $\begin{array}{c}\text { Thickness } \\
(\mu \mathrm{m})\end{array}$ & $\begin{array}{l}\text { Membrane } \\
\mathrm{T}\left({ }^{\circ} \mathrm{C}\right)\end{array}$ & $\begin{array}{c}\text { Bubbler } \\
\text { T }\left({ }^{\circ} \mathrm{C}\right)\end{array}$ & $\begin{array}{c}\text { P(feed) } \\
\text { psig }\end{array}$ & $\begin{array}{c}\mathrm{Po} / \mathrm{l} \\
\left(\mathrm{CO}_{2}\right)^{*}\end{array}$ & $\alpha \mathrm{CO}_{2} / \mathrm{H}_{2}$ & $\alpha \mathrm{CO}_{2} / \mathrm{CH}_{4}$ \\
\hline $11273-13$ & 90 & RT & 2.5 & $\begin{array}{c}2.3 \\
19.9 \\
55.3\end{array}$ & $\begin{array}{l}0.024 \\
0.020 \\
0.013\end{array}$ & $\begin{array}{l}--- \\
--- \\
---\end{array}$ & $\begin{array}{l}--- \\
--- \\
--\end{array}$ \\
\hline $11273-87$ & 60 & $\mathrm{RT}$ & 2.5 & 47.4 & 0.028 & --- & --- \\
\hline $11273-89$ & 30 & RT & $\begin{array}{l}2.5 \\
5.0 \\
5.0\end{array}$ & $\begin{array}{l}36.4 \\
36.4 \\
66.3\end{array}$ & $\begin{array}{l}0.042 \\
0.054 \\
0.039\end{array}$ & $\begin{array}{l}--- \\
--- \\
--\end{array}$ & $\begin{array}{l}--- \\
--- \\
--\end{array}$ \\
\hline $11273-92$ & 30 & $\begin{array}{l}22 \\
35 \\
45 \\
55 \\
55\end{array}$ & $\begin{array}{c}2.5 \\
5.0 \\
10.0 \\
15.0 \\
20.0\end{array}$ & $\begin{array}{l}44.4 \\
44.4 \\
43.9 \\
44.0 \\
44.0\end{array}$ & $\begin{array}{l}0.100 \\
0.075 \\
0.089 \\
0.103 \\
0.192\end{array}$ & $\begin{array}{l}--- \\
-- \\
--- \\
--- \\
--\end{array}$ & $\begin{array}{l}--- \\
--- \\
--- \\
-- \\
44\end{array}$ \\
\hline $11273-96$ & 40 & $\begin{array}{c}\mathrm{RT} \\
50 \\
50 \\
50\end{array}$ & $\begin{array}{c}5 \\
10 \\
15 \\
20\end{array}$ & $\begin{array}{l}39.2 \\
39.2 \\
39.2 \\
39.2\end{array}$ & $\begin{array}{l}0.074 \\
0.041 \\
0.054 \\
0.083\end{array}$ & $\begin{array}{l}5.3 \\
2.1 \\
2.6 \\
4.4\end{array}$ & $\begin{array}{l}3 .- \\
3.7 \\
6.9\end{array}$ \\
\hline *units of (cn & $\mathrm{cm}^{2} \cdot \mathrm{s}^{\circ} \mathrm{cmH}$ & $\times 10^{5}$ & & & & & \\
\hline
\end{tabular}


On average, however, only 1 in 6 of the free-standing DADMAF membranes fabricated were pinhole-free to the extent that further evaluation was even attempted. For example, membrane 11273-96 could be tested but the resulting permselective properties were poor. In the other examples, even when the selectivity was good (e.g., 11273-13), the membranes displayed poor mechanical properties and had short lifetimes.

\subsubsection{PTMSP/DADMAF MLC Membranes}

These membranes are a 3-layer composite consisting of a thin layer of DADMAF contained between layers of PTMSP, and were fabricated as described above. They were evaluated at room temperature using feed mixture \#2 with a helium sweep gas at $1 \mathrm{~atm}$. Permeation results are summarized in Table 3.2-2. The thickness, where indicated, was determined using SEM.

These MLC membranes fell into two categories. While the $\mathrm{CO}_{2}$ permeances were relatively constant, the membranes were either very selective (i.e., only $\mathrm{CO}_{2}$ was observed in the permeate as for 11273-18 or 11273-28) or exhibited relatively poor for an ATM selectivity (i.e., $\alpha\left(\mathrm{CO}_{2} / \mathrm{H}_{2}\right)<15$ ). This is surprising in light of the fact that they were all cast from the same formulation by identical techniques. To investigate whether some of the membranes may have small pinholes or fabrication defects, one membrane (11638-44) was first evaluated using dry feed and sweep gases. The fact that no gases were observed to permeate under this lowhumidity condition confirms the absence of gross defects. However, when this membrane was later tested under the conditions shown in Table 3.2-2, relatively poor selectivity was obtained. In some cases a postmortem of the sample indicated regions where there was poor adhesion between the PTMSP and DADMAF layers. This led us to investigate the use of surfactants. 
Table 3.2-2

Evaluation of PTMSP/DADMAF/PTMSP MLC Membranes

\begin{tabular}{|c|c|c|c|c|c|c|}
\hline $\begin{array}{c}\text { Sample } \\
\text { ID }\end{array}$ & $\begin{array}{c}\text { Thickness } \\
(\mu \mathrm{m})\end{array}$ & $\begin{array}{c}\text { Bubbler } \\
\mathrm{T}\left({ }^{\circ} \mathrm{C}\right)\end{array}$ & $\begin{array}{c}\text { P(feed) } \\
\text { psig }\end{array}$ & $\begin{array}{c}\mathrm{Po} / \mathrm{l} \\
\left(\mathrm{CO}_{2}\right)^{*}\end{array}$ & $\alpha \mathrm{CO}_{2} / \mathrm{H}_{2}$ & $\alpha \mathrm{CO}_{2} / \mathrm{CH}_{4}$ \\
\hline $11273-18$ & 25 & $\begin{array}{c}2.5 \\
2.5 \\
2.5 \\
2.5 \\
10.0\end{array}$ & $\begin{array}{c}3.5 \\
35.9 \\
22.1 \\
43.5 \\
43.5\end{array}$ & $\begin{array}{l}0.138 \\
0.064 \\
0.147 \\
0.102 \\
0.165\end{array}$ & $\begin{array}{l}--- \\
--- \\
--- \\
-- \\
--\end{array}$ & $\begin{array}{l}-- \\
-- \\
--- \\
---\end{array}$ \\
\hline $11273-28$ & 25 & $\begin{array}{l}5.0 \\
5.0 \\
5.0 \\
5.0 \\
5.0 \\
5.0\end{array}$ & $\begin{array}{c}8.0 \\
13.2 \\
30.8 \\
51.9 \\
82.1 \\
109.5\end{array}$ & $\begin{array}{l}0.284 \\
0.262 \\
0.208 \\
0.156 \\
0.131 \\
0.110\end{array}$ & $\begin{array}{l}--- \\
\cdots- \\
--- \\
--- \\
--- \\
---\end{array}$ & $\begin{array}{l}-- \\
-- \\
-- \\
-- \\
-- \\
--\end{array}$ \\
\hline $11273-75$ & 42 & $\begin{array}{c}2 \\
2 \\
2 \\
10 \\
10 \\
10 \\
20\end{array}$ & $\begin{array}{l}12.2 \\
25.0 \\
48.3 \\
12.1 \\
25.2 \\
47.6 \\
12.1\end{array}$ & $\begin{array}{c}0.199 \\
0.172 \\
0.125 \\
0.485 \\
0.431 \\
0.297 \\
1.94\end{array}$ & $\begin{array}{c}--- \\
--- \\
--- \\
--- \\
26 \\
--- \\
7.4\end{array}$ & $\begin{array}{l}--- \\
--- \\
--- \\
--- \\
38 \\
42 \\
16\end{array}$ \\
\hline $11273-101$ & $\mathrm{~nm}$ & $\begin{array}{l}2.5 \\
2.5 \\
2.5\end{array}$ & $\begin{array}{c}40 \\
51.1 \\
62.7\end{array}$ & $\begin{array}{l}0.225 \\
0.180 \\
0.189\end{array}$ & $\begin{array}{c}11.3 \\
10.6 \\
8.3\end{array}$ & $\begin{array}{l}71 \\
--- \\
65\end{array}$ \\
\hline $11273-103$ & $\mathrm{~nm}$ & 5.0 & 42.7 & 0.240 & 7.9 & 45 \\
\hline $11673-2$ & $\mathrm{~nm}$ & 5.0 & $\begin{array}{l}40.1 \\
40.1\end{array}$ & $\begin{array}{l}0.398 \\
0.267\end{array}$ & $\begin{array}{l}5.4 \\
4.6\end{array}$ & $\begin{array}{l}33 \\
30\end{array}$ \\
\hline $11638-44$ & $\mathrm{~nm}$ & 5.0 & 34.3 & 0.377 & 10 & 50 \\
\hline $11638-46$ & $\mathrm{~nm}$ & 5.0 & 40.6 & 0.318 & 10 & 59 \\
\hline
\end{tabular}




\subsubsection{PTMSP/DADMAF MLC with SUR-1}

A series of membranes was fabricated with SUR-1 added to the aqueous DADMAF or PVBTAF casting solution. They were then evaluated at room temperature using feed gas mix \#2 and a helium sweep gas, both humidified to the dew points shown in Table 3.2-3.

Table 3.2-3

Evaluation of PTMSP/PVBTAF/PTMSP MLC with SUR-1

$\begin{array}{clccccc}\begin{array}{c}\text { Sample } \\ \text { ID }\end{array} & \text { Material } & \begin{array}{c}\text { Bubbler } \\ \mathrm{T}\left({ }^{\circ} \mathrm{C}\right)\end{array} & \begin{array}{c}\mathrm{P}(\mathrm{feed}) \\ \mathbf{p s i g}\end{array} & \begin{array}{c}\mathrm{Po} / \mathrm{l} \\ \left(\mathrm{CO}_{2}\right)^{*}\end{array} & \alpha \mathrm{CO}_{2} / \mathrm{H}_{2} & \alpha \mathrm{CO}_{2} / \mathrm{CH}_{4} \\ 11638-6 & \text { PVBTAF } & 2.5 & 43.5 & 0.274 & 6.4 & 37 \\ & & & & & & \\ 11638-7 & \text { PVBTAF } & 2.5 & 44.1 & 0.216 & 13 & 55 \\ & & & & & & \\ 11638-8 \mathrm{~A} & \text { DADMAF } & 2.5 & 43.6 & 0.320 & 7.6 & 26 \\ 11638-8 \mathrm{~B} & \text { DADMAF } & 2.5 & 47.8 & 0.290 & 6.7 & 28 \\ & & & & & & \\ \text { *units of }\left(\mathrm{cm} 3 / \mathrm{cm}^{2} \cdot \mathrm{s} \cdot \mathrm{cmHg}\right) \times 105 & & & & \end{array}$

Still, the selectivity was less than expected. A postmortem indicated better adhesion but did not rule out the possibility of small regions where adhesion might still be poor. This seems increasingly likely in light of the above data which demonstrates that the addition of this surfactant (at this level) does not appear to improve the permselectivity.

\subsubsection{MEM213/DADMAF MLC Membranes with SUR-1}

MEM213 is a silicone rubber/polycarbonate copolymer available from General Electric Corp. in flat sheets of 1 and 2 mil thickness. MLC membranes were fabricated using MEM213 as the support or "encapsulating" polymer. Results from the evaluation of these membranes are reported in Table 3.2-4. These membranes do not exhibit attractive separation properties. 
Table 3.2-4

Evaluation of MEM213/DADMAF/MEM213 MLC Membranes

$\begin{array}{ccccccc}\begin{array}{c}\text { Sample } \\ \text { ID }\end{array} & \text { Material } & \begin{array}{c}\text { Bubbler } \\ \mathrm{T}\left({ }^{\circ} \mathrm{C}\right)\end{array} & \begin{array}{c}\mathrm{P}(\mathrm{feed}) \\ \mathrm{psig}\end{array} & \begin{array}{c}\mathrm{Po} / \mathrm{l} \\ \left(\mathrm{CO}_{2}\right) *\end{array} & \alpha \mathrm{CO}_{2} / \mathrm{H}_{2} & \alpha \mathrm{CO}_{2} / \mathrm{CH}_{4} \\ 11638-11 & \text { DADMAF } & 2.5 & 46 & 0.332 & 4.7 & 8 \\ 11638-14 & \text { DADMAF } & 2.5 & 44.6 & 0.239 & 6.1 & 28 \\ 11638-16 & \text { DADMAF } & 2.5 & 44.0 & 0.350 & 6.5 & 12 \\ \text { *units of }(\mathrm{cm} 3 / \mathrm{cm} 2 \cdot \mathrm{s} \cdot \mathrm{cmHg}) \times 105 & & & & \end{array}$

\subsubsection{PDMS/DADMAF/PDMS MLC Membranes}

These membranes consist of a layer of DADMAF contained between layers of poly(dimethylsiloxane). It was essential to use SUR-1 in order to obtain adequate wetting between the polymer and DADMAF solution. The surfactant level was held constant in all subsequent membranes except where noted. All membranes were basically identical in preparation. Permeation test results are shown in Table 3.2-5. The first membrane tested, 11638-38, had relatively poor selectivities; examination of the membrane after permeation testing revealed wrinkles or creases in the membrane which may have resulted from delamination of the layers. Membrane 11638-47-1 was initially tested using dry feed (feed mix \#2) and sweep gases; relatively small amounts of $\mathrm{CO}_{2}$ and $\mathrm{CH}_{4}$ were observed in the permeate. When the gas streams were later humidified to $5^{\circ} \mathrm{C}$, the membrane did not seal completely and exhibited poor selectivity (Table 3.2-5). Membrane 11638-47-2 (a second membrane cut from a larger section of 11638-47) exhibited no detectable $\mathrm{H}_{2}$ or $\mathrm{CH}_{4}$ permeation at the test condition. During the first 2 days of operation, membrane 11638-50 exhibited a decreasing $\mathrm{CO}_{2}$ flux; a small amount of $\mathrm{CH}_{4}$, but no $\mathrm{H}_{2}$, was observed in the permeate. Eventually, a steady state was reached at which point the $\mathrm{CO}_{2}$ flux remained constant but neither $\mathrm{H}_{2}$ or $\mathrm{CH}_{4}$ was observed in the permeate. This steady-state data is reported in Table 3.2-5. 
Table 3.2-5

Evaluation of PDMS/DADMAF/PDMS MLC Membranes

$\begin{array}{cccccc}\begin{array}{c}\text { Sample } \\ \text { ID }\end{array} & \begin{array}{c}\text { Bubbler } \\ \mathrm{T}\left({ }^{\circ} \mathrm{C}\right)\end{array} & \begin{array}{c}\mathrm{P}(\mathrm{feed}) \\ \text { psig }\end{array} & \begin{array}{c}\mathrm{Po} / \mathrm{l} \\ \left(\mathrm{CO}_{2}\right)^{*}\end{array} & \alpha \mathrm{CO}_{2} / \mathrm{H}_{2} & \alpha \mathrm{CO}_{2} / \mathrm{CH}_{4} \\ 11638-38 & 5 & 52.4 & 0.19 & 6.6 & 58 \\ & 10 & 52.4 & 0.32 & 7.2 & 34 \\ 11638-47-1 & 5 & 35.0 & 0.179 & 7.3 & 34 \\ 11638-47-2 & 5 & 34.4 & 0.196 & -- & -- \\ 11638-50 & 5 & 51.1 & 0.183 & --- & --- \\ *\left(\mathrm{~cm} 3 / \mathrm{cm}^{2} \cdot \mathrm{s} \cdot \mathrm{cmHg}\right) \times 105 & & & & \end{array}$

After the above data was collected, the test of 11638-50 was continued for an additional 23 days. No indication of instability or flux decline was observed. During this extended test feed mix \#1 was used and the feed and helium sweep gases were humidified to $5^{\circ} \mathrm{C}$; the membrane was maintained at room temperature. The total pressure in the feed stream (and hence the $\mathrm{CO}_{2}$ partial pressure) was varied during this test. No $\mathrm{CH}_{4}$ was detected in the permeate at any of the pressures studied. The steady-state data for each experimental condition is shown plotted in Figure 3.2-1. The $\mathrm{CO}_{2}$ permeance exhibits a characteristic of many facilitated transport membranes; that is, the $\mathrm{CO}_{2}$ permeance decreases with increasing $\mathrm{CO}_{2}$ partial pressure in the feed stream.

Based on the promising results of sample 11638-50, PDMS/DADMAF/PDMS MLC membranes were investigated further. Specifically, the effects of temperature and dew point were examined. In this experiment the feed gas (mixture \#1) was maintained at $38.6 \mathrm{psig}$. Results (membrane

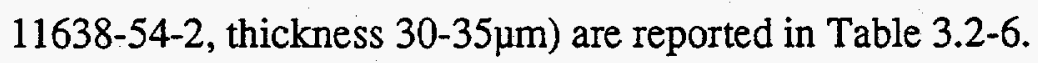

At a constant temperature of $22^{\circ} \mathrm{C}$, the $\mathrm{CO}_{2}$ permeance varies linearly with dew point in the range of $2-20^{\circ} \mathrm{C}$. For a constant dew point of $20^{\circ} \mathrm{C}, \mathrm{CO}_{2}$ permeance decreases with increasing membrane temperature. We speculate that this is a result of an equilibrium between water vapor in the feed gas stream and water absorbed in the DADMAF layer. At higher dew points, more water is absorbed by DADMAF and diffusion in this layer becomes more facile. At higher temperatures, the equilibrium is shifted in the direction of water vapor. The DADMAF layer, now depleted of water, becomes a better barrier and permeance decreases. 
Figure 3.2-1

$\mathrm{CO}_{2}$ Permeance of PDMS/EXTM-1/PDMS MLC

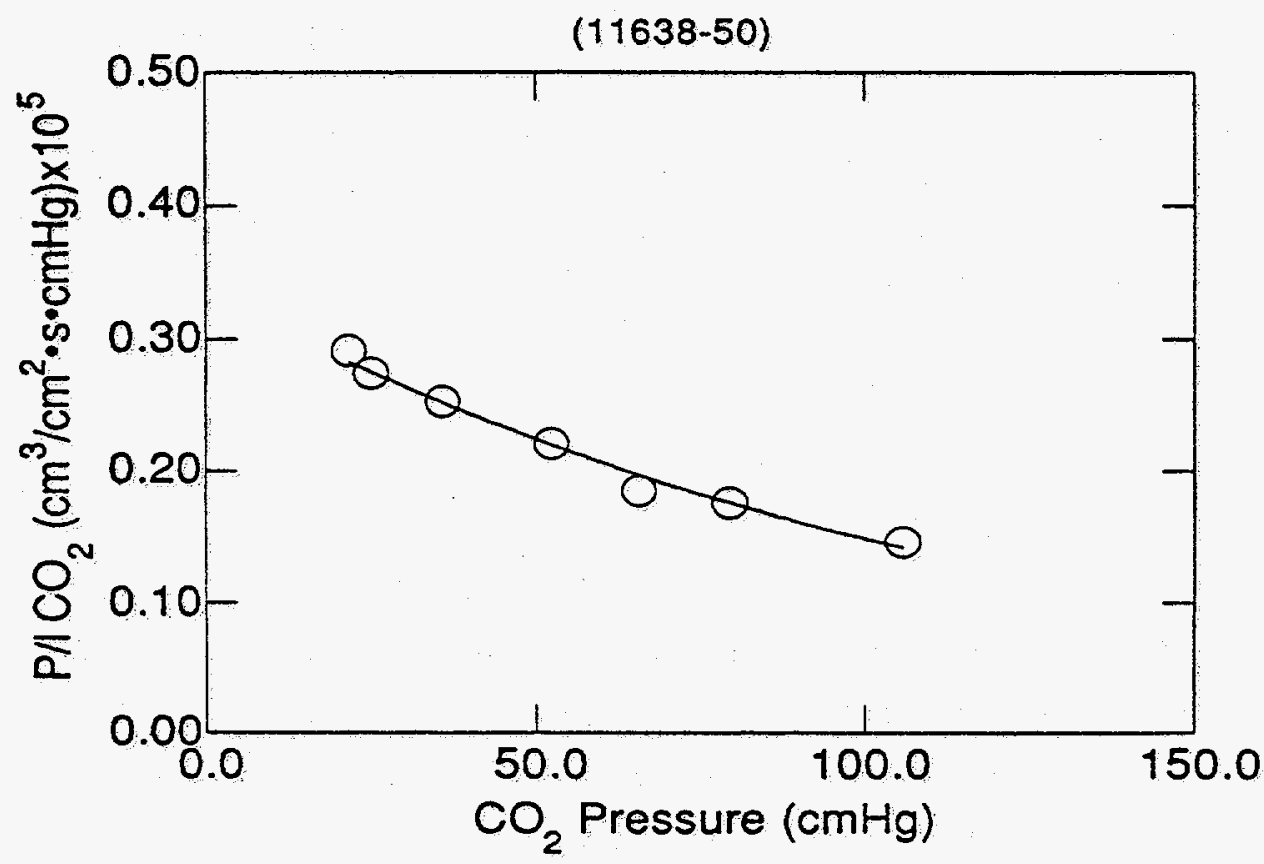

Table 3.2-6

Effect of Dew Point and Temperature on PDMS/DADMAF/PDMS MLC Membrane

\begin{tabular}{|c|c|c|}
\hline Membrane $\mathrm{T}\left({ }^{\circ} \mathrm{C}\right)$ & Dew Point $\left({ }^{\circ} \mathrm{C}\right)$ & $\mathrm{P}_{\mathrm{o}} / 1\left(\mathrm{CO}_{2}\right)^{*}$ \\
\hline 22 & 2.0 & 0.138 \\
\hline 22 & 4.0 & 0.184 \\
\hline 22 & 10.4 & 0.311 \\
\hline 22 & 14.7 & 0.377 \\
\hline 22 & 20.1 & 0.535 \\
\hline 40 & 20.1 & 0.421 \\
\hline 50 & 20.1 & 0.175 \\
\hline 60 & 20.1 & 0.108 \\
\hline 70 & 20.1 & 0.068 \\
\hline
\end{tabular}


To further investigate the role of $\mathrm{H}_{2} \mathrm{O}$ vapor in the permeation process, the PDMS/DADMAF/ PDMS MLC was evaluated at room temperature with various combinations of wet and dry feed and helium sweep gas streams. In these experiments, the "wet" condition is $5^{\circ} \mathrm{C}$. The feed gas was mix \#1 at $39.3 \mathrm{psig}$. The data was collected in the order listed in Table 3.2-7. The last line of the data shows that the dew point was raised to $20^{\circ} \mathrm{C}$. In no cases was $\mathrm{CH}_{4}$ observed in the permeate stream.

Table 3.2-7

Effect of Gas Stream Hydration of Membrane Performance

$\begin{array}{clc}\text { Feed Gas } & \text { Sweep Gas } & \mathbf{P}_{\mathbf{0}} / \mathbf{I}\left(\mathrm{CO}_{2}\right)^{*} \\ \text { wet } & \text { wet } & 0.241 \\ \text { wet } & \text { dry } & 0.022 \\ \text { wet } & \text { wet } & 0.235 \\ \text { dry } & \text { wet } & 0.140 \\ \text { wet } & \text { wet } & 0.222 \\ \text { wet }\left(20^{\circ} \mathrm{C}\right) & \text { wet }\left(20^{\circ} \mathrm{C}\right) & 0.609 \\ & & \\ \left.\text { *( } \mathrm{cm} 3 / \mathrm{cm}^{2} \cdot \mathrm{s} \cdot \mathrm{cmHg}\right) \times 105 & \end{array}$

Only the use of a dry sweep gas appears to significantly decrease the $\mathrm{CO}_{2}$ permeance; the loss of $\mathrm{CO}_{2}$ permeance can be restored by raising the dew point back to its original value. As expected, $\mathrm{CO}_{2}$ permeance is much larger at the higher $\left(20^{\circ} \mathrm{C}\right)$ dew point.

Of the membranes studied, the PDMS/DADMAF/PDMS MLC membranes have exhibited the best $\mathrm{CO}_{2}$ permselective properties. $\mathrm{A} \mathrm{CO} 2$ permeance of $\mathrm{ca} 0.2 \mathrm{Barrers} / \mathrm{cm}(\mathrm{x} 105)$ translates into a standard permeability of 70 Barrers (assuming an AT layer $35 \mu \mathrm{m}$ thick). In a "good" membrane no $\mathrm{H}_{2}$ or $\mathrm{CH}_{4}$ was detected under the test conditions and thus no selectivity can be calculated. We have recently upgraded the analytical capabilities of this test system to increase the sensitivity towards $\mathrm{H}_{2}$ by $\approx 10 \mathrm{x}$. The PDMS/DADMAF/PDMS MLC membranes listed below were evaluated using this new equipment. The feed stream was mix \#2 and the membranes were tested at room temperature. Results are shown in Table 3.2-8.

Now, for the first time, we have been able to unambiguously determine $\alpha\left(\mathrm{CO}_{2} / \mathrm{H}_{2}\right)$ and 
$\alpha\left(\mathrm{CO}_{2} / \mathrm{CH}_{4}\right)$ of these membranes. However, reproducibility was not good. Even for membranes tested under the same conditions (compare 11638-82-1 with 11638-88), the selectivity varied by a factor of 2 . We also note that a higher $\mathrm{CO}_{2}$ permeance was accompanied by a lower selectivity for membranes of approximately equal thickness (11638-88 and 11638-92-1).

Table 3.2-8

Evaluation of MLC Membranes with Improved Analytical System

$\begin{array}{cccccc}\begin{array}{c}\text { Sample } \\ \text { ID }\end{array} & \begin{array}{c}\text { Bubbler } \\ \mathbf{T}\left({ }^{\circ} \mathrm{C}\right)\end{array} & \begin{array}{c}\mathbf{P}(\mathrm{feed}) \\ \mathbf{p s i g}\end{array} & \begin{array}{c}\mathrm{Po} / \mathrm{l} \\ (\mathrm{CO} 2)^{*}\end{array} & \alpha \mathrm{CO}_{2} / \mathrm{H}_{2} & \alpha \mathrm{CO}_{2} / \mathrm{CH}_{4} \\ 11638-82-1 & 5 & 46.6 & 0.259 & 25 & 73 \\ 11638-85-1 & 10 & 37.7 & 0.336 & 29 & 90 \\ & 20 & 37.7 & 0.447 & 14 & 32 \\ 11638-87-1 & 10 & 44.7 & 0.445 & 15 & 64 \\ 11638-88 & 10 & 44.3 & 0.294 & 25 & 79 \\ & 5 & 44.3 & 0.196 & 44 & 130 \\ 11638-92-1 & 5 & 45.0 & 0.213 & 10 & 40 \\ *\left(\mathrm{~cm}^{3} / \mathrm{cm}^{2} \cdot \mathrm{s} \cdot \mathrm{cmHg}\right) \times 105 & & & & \end{array}$

The variability in flux and selectivity is still somewhat puzzling. It is not readily apparent why some membranes possess very good selectivity and why some are relatively poor. We note that the lower selectivities are not the result of a hole in the usual sense because the selectivities are much greater than 1. To investigate the possible role of very small flaws or defects in the membranes we performed several experiments. In one group we examined the effect of multiple DADMAF layers. This was done in two ways. In the first, two 3-layer MLC membranes were fitted into the test cell at the same time (11638-95-1). If there were small defects, the probability of one in each membrane lining up is very low. If the membranes were defect-free, one would expect a lower $\mathrm{CO}_{2}$ permeance (in proportion to the thickness of the DADMAF layer) but no change in selectivity. Results are shown in Table 3.2-9. The $\mathrm{CO}_{2}$ permeance fell by a factor of 2. (Compare with 11638-95-1 which contains only 1 piece of the same 3-layer composite.) This is expected since the DADMAF layer was approximately twice as thick. More importantly sample 11638-95-1 exhibited improved $\alpha\left(\mathrm{CO}_{2} / \mathrm{H}_{2}\right)$ and $\alpha\left(\mathrm{CO}_{2} / \mathrm{CH}_{4}\right)$. This result strongly 
suggests that the membranes contain microscopic flaws which detract from the intrinsic selectivity of DADMAF. In a similar experiment, a 5-layer MLC membrane was fabricated (11638-102-1). Its structure is shown below (SEM in Figure 3.1-4).

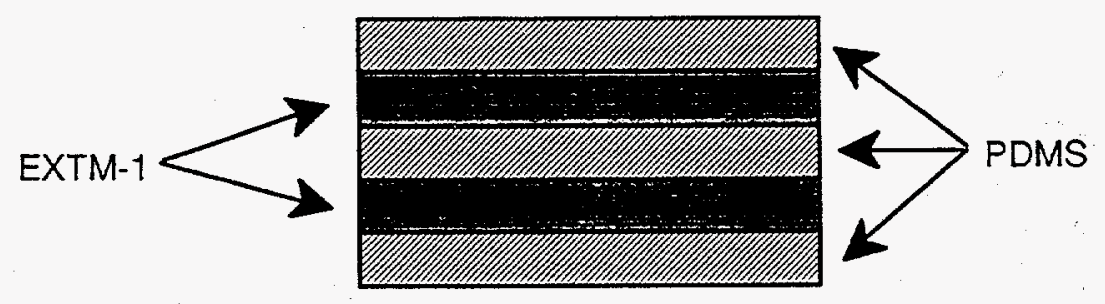

The $\mathrm{CO}_{2}$ permeance was approximately half that of its 3-layer counterpart but the selectivity was much improved. These results support the theory that adhesion between the layers is less than adequate or that microscopic cracks, dust or other particulate matter give rise to flaws and defects.

In the last set of experiments, the amount of SUR-1 was increased by a factor of 4 . The results on 3-layer composite MLCs are presented in Table 3.2-9 (12110-2-1 and 12110-3-1). The $\mathrm{CO}_{2} / \mathrm{H}_{2}$ selectivity of $50-80$ is the highest reported. (Polymer membranes typically have $\mathrm{CO}_{2} / \mathrm{H}_{2}$ selectivity $<1$ ). The results strongly suggest the need to keep good adhesion between the various layers. Future work will address the surfactant level and its effect on membrane performance as well as screen different surfactants.

\section{2-6 Evaluation of PDMS/DADMAF MLC Membranes at Elevated Permeate Pressure}

There is limited permeation data on these $\mathrm{CO}_{2}$-selective MLC membranes taken at elevated permeate pressures. However, the data that does exists suggests that the membranes will be effective at permeate pressures approaching 20 psia. Table 3.2-10 contains data for two MLC membranes: 11273-54, a PTMSP/DADMAF/PTMSP composite and 11638-66, a PDMS/DADMAF/PDMS composite. In the first case, the membrane (7um DADMAF layer) was tested with feed mix \#1 and gas streams humidified to $10^{\circ} \mathrm{C}$. In the first two entries, a helium sweep gas was used. In the third entry, the permeate gases were collected at 19.2 psig. The data show that membrane performance is comparable in the two cases. 
Table 3.2-9

Investigation of Flaws and Defects

\begin{tabular}{|c|c|c|c|c|c|}
\hline $\begin{array}{c}\text { Sample } \\
\text { ID }\end{array}$ & $\begin{array}{l}\text { Bubbler } \\
\text { T }\left({ }^{\circ} \mathrm{C}\right)\end{array}$ & $\begin{array}{c}\text { P(feed) } \\
\text { psig }\end{array}$ & $\begin{array}{c}\mathrm{Po} / \mathrm{l} \\
\left(\mathrm{CO}_{2}\right)^{*}\end{array}$ & $\alpha \mathrm{CO}_{2} / \mathrm{H}_{2}$ & $\alpha \mathrm{CO}_{2} / \mathrm{CH}_{4}$ \\
\hline $\begin{array}{c}11638-95-1 \\
2 \text { pieces }\end{array}$ & 5 & 42.9 & 0.0973 & 42 & --- \\
\hline $\begin{array}{c}11638-95-1 \\
1 \text { piece }\end{array}$ & $\begin{array}{c}5 \\
10 \\
15\end{array}$ & $\begin{array}{l}41.1 \\
41.1 \\
41.1\end{array}$ & $\begin{array}{l}0.176 \\
0.288 \\
0.378\end{array}$ & $\begin{array}{l}31 \\
22 \\
12\end{array}$ & $\begin{array}{l}49 \\
85 \\
37\end{array}$ \\
\hline $\begin{array}{l}11638-102-1 \\
5 \text { layer } \\
\text { MLC }\end{array}$ & $\begin{array}{c}5 \\
5 \\
5 \\
10\end{array}$ & $\begin{array}{l}42.8 \\
67.2 \\
40.6 \\
40.6\end{array}$ & $\begin{array}{c}0.101 \\
0.0801 \\
0.0941 \\
0.161\end{array}$ & $\begin{array}{l}65 \\
55 \\
62 \\
38\end{array}$ & $\begin{array}{l}-- \\
-- \\
-- \\
--\end{array}$ \\
\hline $12110-2-1$ & $\begin{array}{l}5 \\
5 \\
5 \\
5 \\
5\end{array}$ & $\begin{array}{c}10.5 \\
26.4 \\
41.4 \\
68.7 \\
108.8\end{array}$ & $\begin{array}{l}0.183 \\
0.155 \\
0.145 \\
0.120 \\
0.087\end{array}$ & $\begin{array}{l}81 \\
76 \\
81 \\
69 \\
53\end{array}$ & $\begin{array}{l}--- \\
-- \\
-- \\
-- \\
--\end{array}$ \\
\hline $12110-3-1$ & 5 & 16.0 & 0.203 & 67 & -- \\
\hline
\end{tabular}

Table 3.2-10

Effect of Permeate Pressure on Membrane Performance

$\begin{array}{cccc}\begin{array}{c}\text { Sample } \\ \text { ID }\end{array} & \begin{array}{c}\mathbf{P f}\left(\mathbf{C O}_{2}\right) \\ \text { psig }\end{array} & \begin{array}{c}\mathbf{P} \text { (perm) } \\ \text { psig }\end{array} & \begin{array}{c}\text { Po/1 } \\ \left(\mathbf{C O}_{2}\right)^{*}\end{array} \\ 11273-54 & 56 & 0 & 0.0481 \\ & 85.9 & 0 & 0.0453 \\ & 85.8 & 19.2 & 0.0440 \\ 11638-66 & 40.5 & 0 & 0.202 \\ & 40.5 & 0.9 & 0.176 \\ & & & \\ \text { * }\left(\mathrm{cm}^{3} / \mathrm{cm}^{2} \cdot \mathrm{s} \cdot \mathrm{cmHg}\right) \times 105 & & \end{array}$




\subsection{SUMMARY/STATUS}

We have demonstrated that it is possible to fabricate MLC membranes from DADMAF and PDMS. We have shown that these membranes can be highly selective for $\mathrm{CO}_{2}$ over $\mathrm{H}_{2}$ $\left.\left(\mathrm{CO}_{2} / \mathrm{H}_{2}\right) \approx 80\right)$ if adequate adhesion is maintained between the layers. The membranes appear to function via a facilitated transport mechanism. They are able to withstand a transmembrane pressure of at least $90 \mathrm{psi}$ and are stable for at least 3 weeks of continuous testing. Water vapor plays an important role in the functioning of the membranes; its effect is being studied further. 


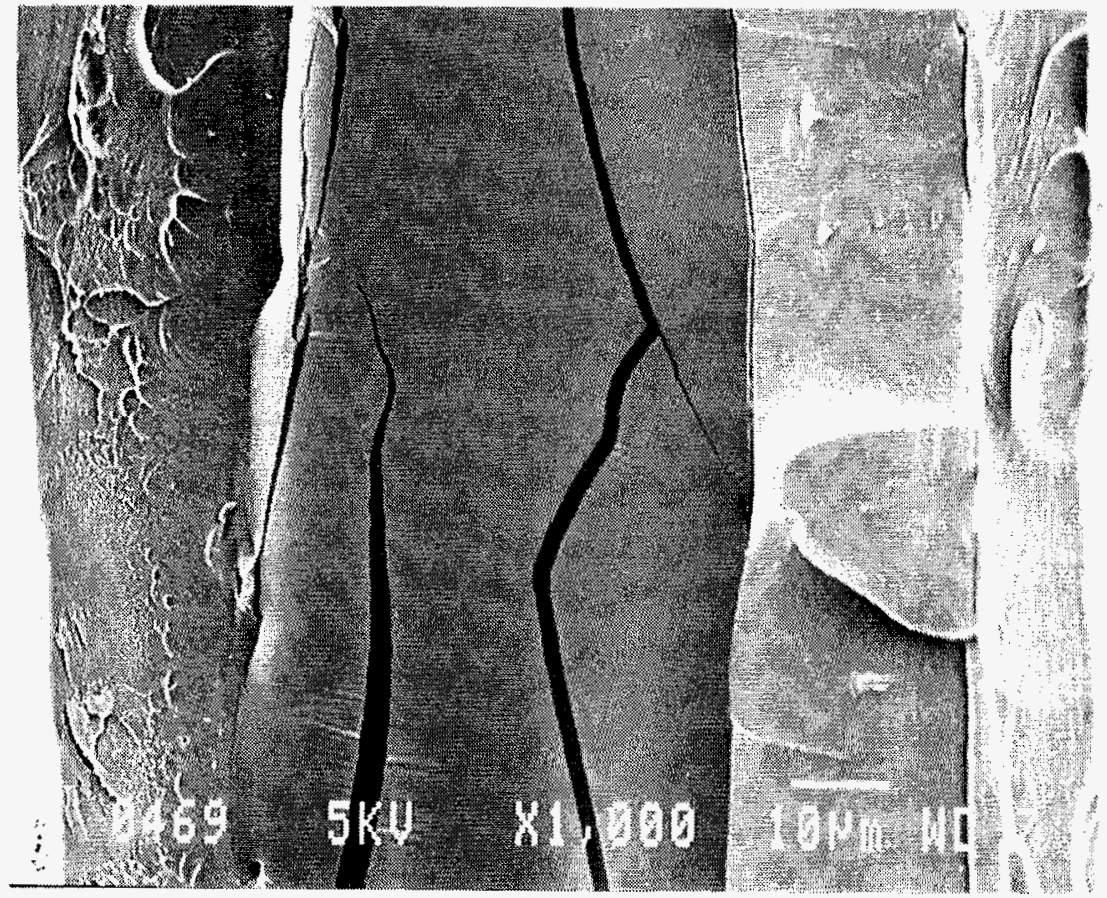

Figure 3.1-1: Scanning Electron Microscopy of PTMSP/EXTM-1/PTMSP MLC cross-section (11273-75) 


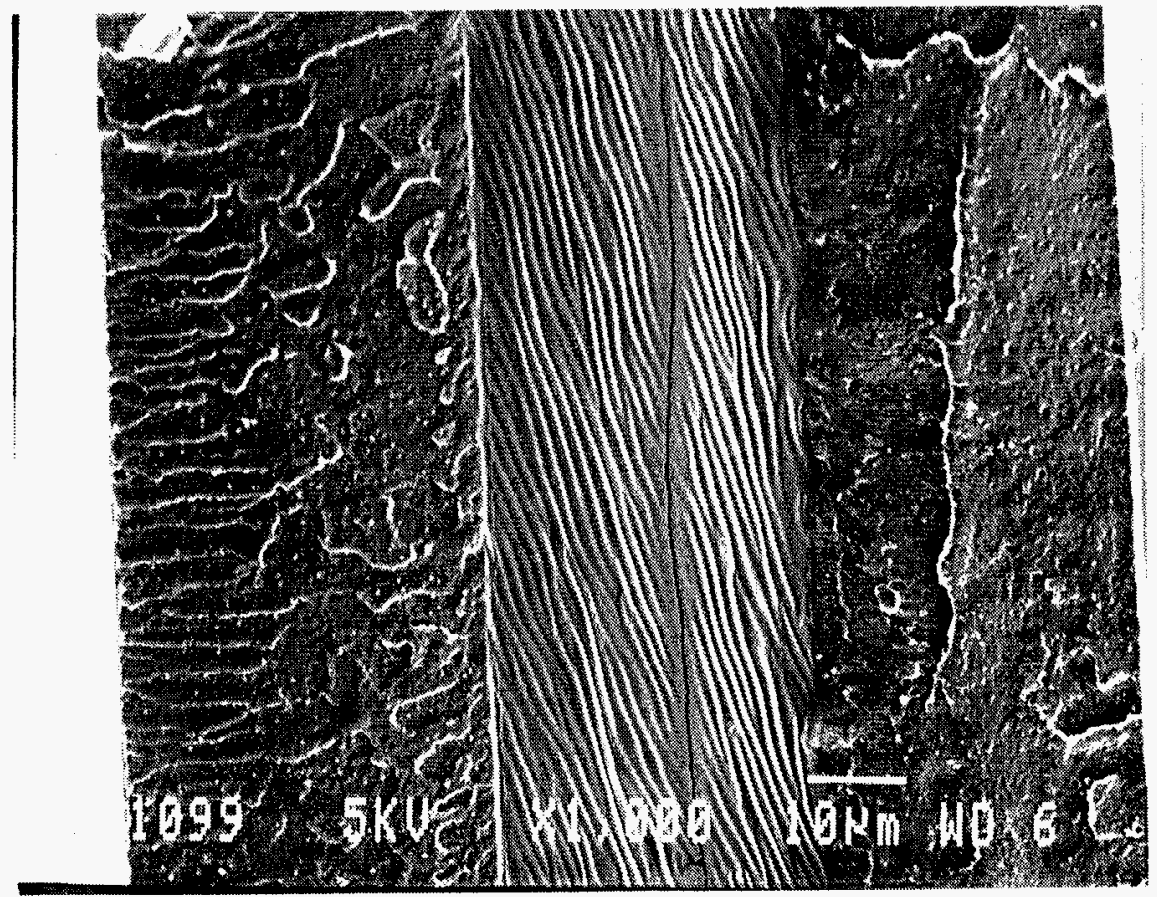

Figure 3.1-2: Scanning Electron Microscopy of PDMS/EXTM-1/PDMS MLC cross-section (11638-50) 


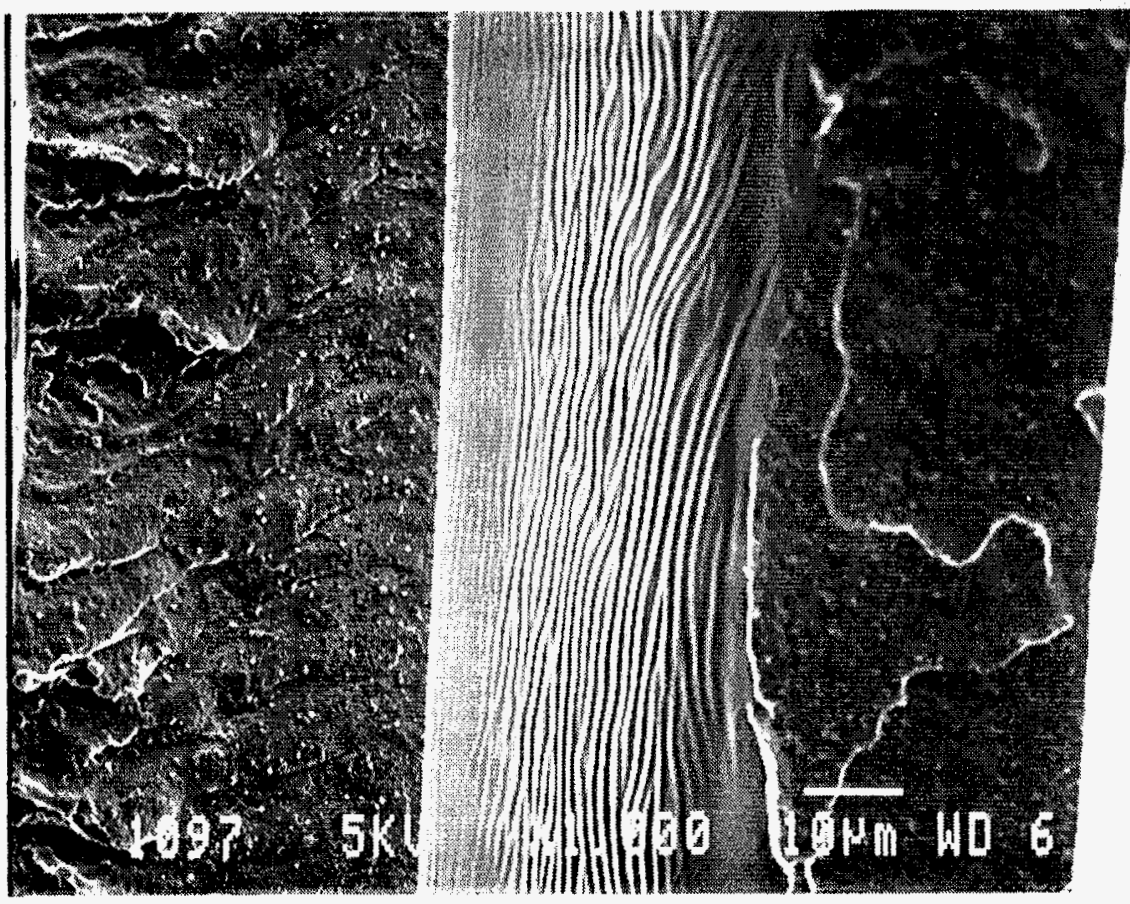

Figure 3.1-3: Scanning Electron Microscopy of PDMS/EXTM-1/PDMS MLC after Testing - cross-section (11638-50) 


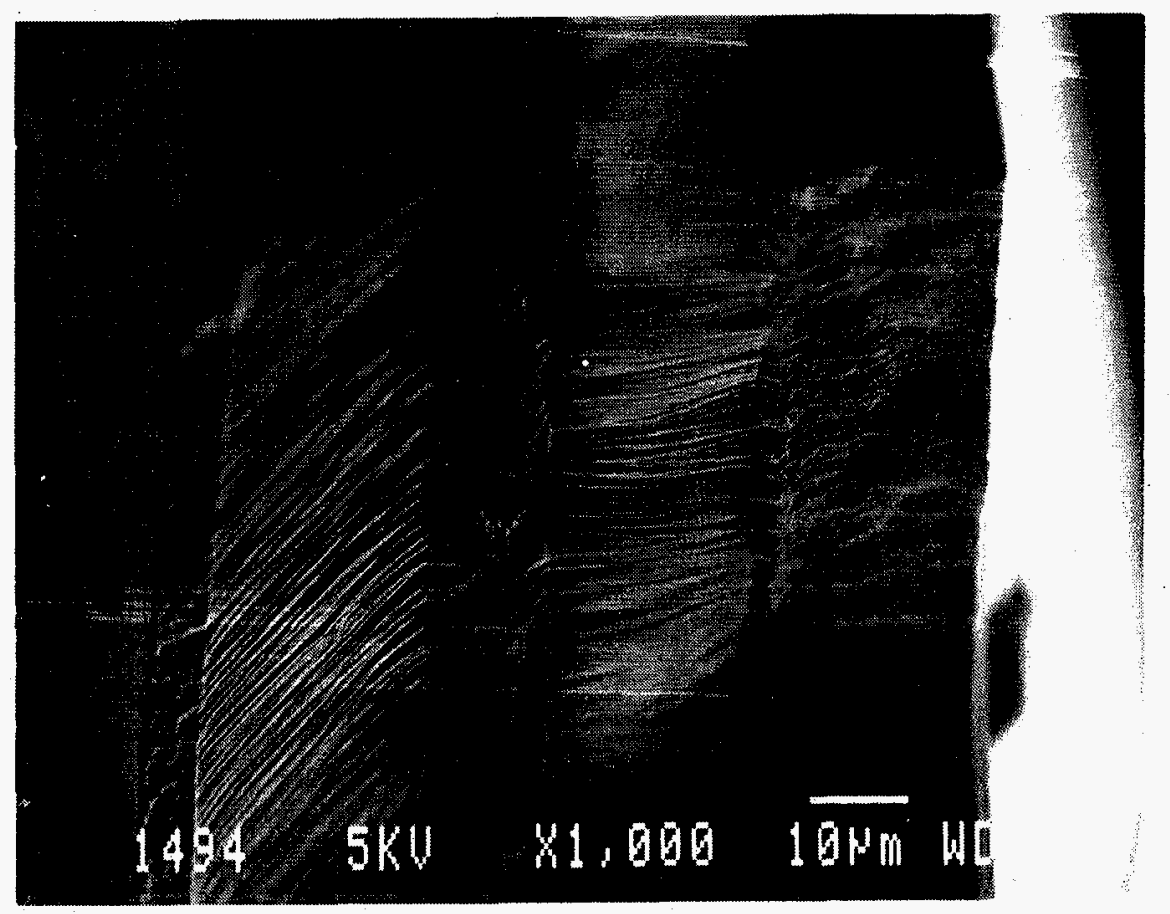

Figure 3.1-4: Scanning Electron Microscopy of PDMS/EXTM-1/PDMS/EXTM-1/PDMS 5-layer MLC - cross-section (11638-102-1) 


\subsection{Evaluation of $\mathrm{NH}_{3}$-Selective MLC Membranes}

\subsection{Process Application/Evaluation: $\mathrm{NH}_{3}$ Recovery in Ammonia Synthesis}

A major market for $\mathrm{NH}_{3}$-selective membrane technology is in ammonia synthesis applications. As described previously 9 ammonia-selective membranes could be used in at least three scenarios. Two anticipated major applications are given below. Air Products has conducted a cursory examination the two process applications (cases $A$ and $B$ ) following inquiries from two major suppliers of ammonia plants and equipment. This preliminary analysis addressed the technical feasibility of integrating membrane-based separations into ammonia synthesis plants. Membrane properties and lifetimes were projected from lab data. A more detailed analysis will be conducted using permeation data collected under task 3 of the program. In these analyses the membranes were used:

A) As part of a debottlenecking/refrigeration hybrid retrofit to existing ammonia plants and/or in construction of new plants. In this case, the membrane would be placed immediately downstream of the converter to reduce the load on the refrigeration system. (Figure 4.1-1) This scheme would most likely be used in connection with upgrading an older reactor, i.e., increase conversion from $12.8 \%$ to $15.9 \%$ (an increase in yield of $\approx 24 \%$ ). In order to recover the additional product by conventional means, the refrigeration loop must be significantly expanded. Alternatively, the hybrid scheme shown in Figure 4.1-1 could be used where only a portion of the $\mathrm{NH}_{3}$ is removed via a membrane. The reject stream from the membrane, which has a similar composition to that of the old converter, would then be sent to the existing refrigeration system which, in this hybrid scheme, requires only a minimal expansion. From an economic viewpoint, the $\mathrm{NH}_{3}$-selective membrane should be able to compete with conventional recovery methods because of the projected savings in refrigeration system upgrade and operating costs (i.e. power consumption).

B) As a means to effect total $\mathrm{NH}_{3}$ recovery; that is, a cascading series of membrane stages are placed immediately downstream of the converter to remove ammonia to the same extent as in the conventional, refrigeration-based process. This eliminates the need for a large refrigeration system. This general concept was initially proposed by Brubaker and Kammermeyer in 195410 but has not been 


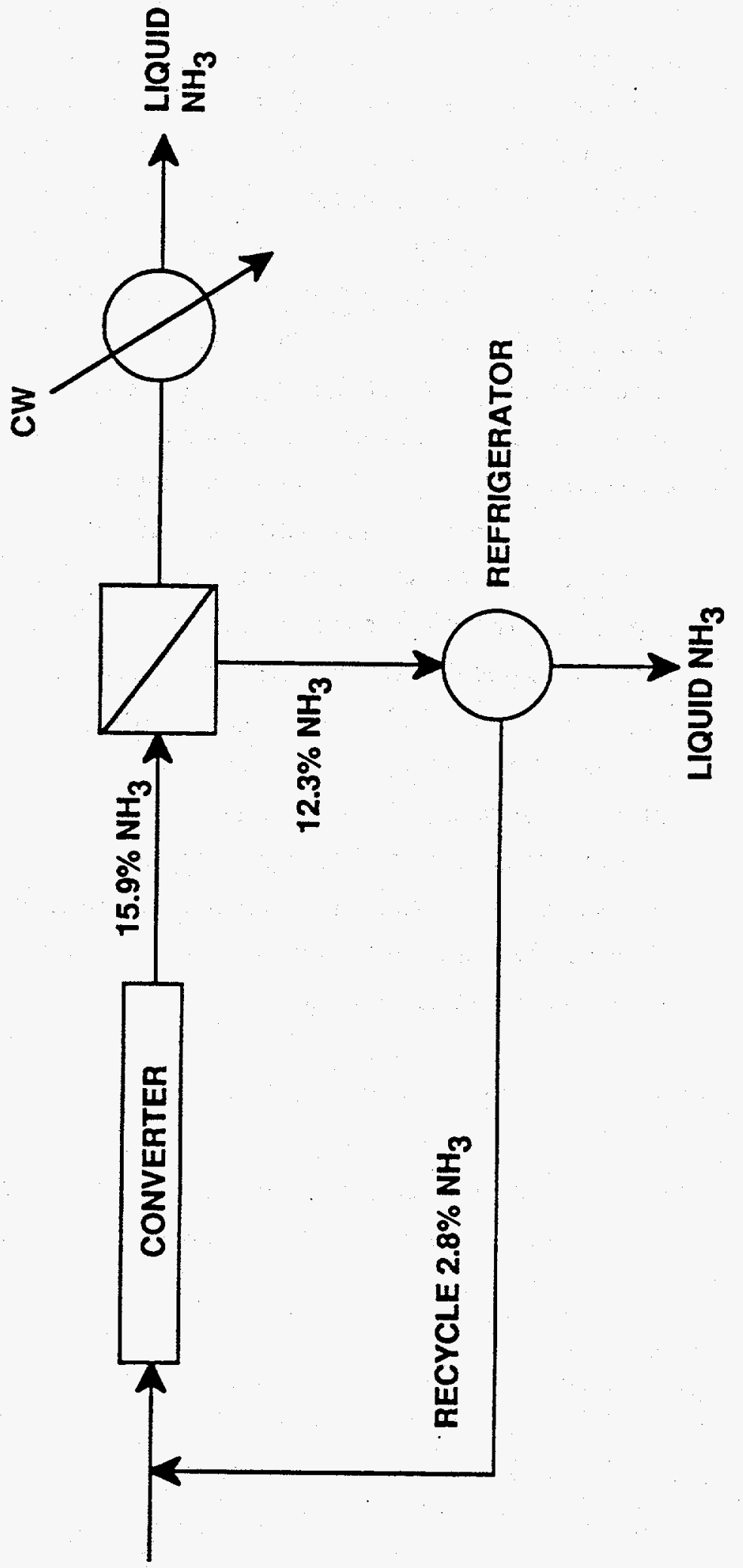

$\frac{0}{9}$
$\frac{\Phi}{5}$
$\frac{5}{\infty}$

톨

운

$\frac{8}{\frac{0}{2}}$

을

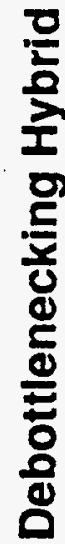

$\frac{7}{7}$
$\frac{0}{9}$
$\frac{9}{5}$ 
implemented because membranes with adequate $\mathrm{NH}_{3} / \mathrm{H}_{2}$ selectivity had not been identified. This case involves replacing the current ammonia separation scheme with a membrane system to effect the same $\mathrm{NH}_{3}$ recovery achieved in the conventional purification system. The current recovery system reduces the $\mathrm{NH}_{3}$ concentration in the syngas stream from $15.8 \%$ to $2.8 \%$. Product $\mathrm{NH}_{3}$ is recovered by cooling, first with water and ultimately with liquid $\mathrm{NH}_{3}$ cycled from the ammonia refrigeration loop. The reject stream, containing $2.8 \% \mathrm{NH}_{3}$, is recycled to the converter. In the scheme proposed by APCI (Figure 4.1-2), this same separation is effected in three membrane stages. Permeate gas from the second and third stages are compressed to 225 psia and mixed with first-stage permeate and then liquified against cooling water. This is possible only because the permeate stream is essentially pure $\mathrm{NH}_{3}$ (due to the high selectivity of the membrane) and as such can be liquified at $225 \mathrm{psia}$ and $100^{\circ} \mathrm{F}$. While approximately $50 \%$ of the product is recovered at $100^{\circ} \mathrm{F}\left(38^{\circ} \mathrm{C}\right)$ it is interesting to note that raising the permeate pressure to 227 psia increases $\mathrm{NH}_{3}$ recovery in the condenser to $66 \%$, and that cooling the stream further to $95^{\circ} \mathrm{F}\left(35^{\circ} \mathrm{C}\right)$ increases the amount of $\mathrm{NH}_{3}$ liquified to $83 \%$. At this time Case $\mathrm{B}$ appears marginally attractive. Although the use of a membrane results in a substantial power savings over refrigeration, it is offset against the additional capital cost of the two-stage compressor as well as the large membrane area required to achieve the separation. However, because there is a large net power savings, both parties continue to show interest in this scenario.

\subsubsection{Membrane Operating Parameters at Process Conditions - $\mathrm{NH}_{3}$ Synthesis}

The following sets of conditions were used in the process analysis described above. They provided the basis for evaluating lab-scale membranes under "process conditions" as described in the test plan in section 4.1.2.

Feed/Permeate Conditions: In Case A we determined the separation achievable when the permeate stream from the membrane is set to 222 psia to allow high purity $\mathrm{NH}_{3}$ to be condensed against cooling water. In case $\mathrm{B}$, the permeate pressure was set to 225 psia. The $\mathrm{NH}_{3}$ synthesis stream from the converter (feed stream to the membrane) was set at a pressure of 1980 psia with the gas composition shown in Table 4.1-1. These conditions are typical in state-of-the-art $\mathrm{NH}_{3}$ synthesis plants. 
Table 4.1-1

$\mathrm{NH}_{3}$ Synthesis Converter Effluent Composition

\section{Component}

Ammonia

Hydrogen

Nitrogen

Methane

Argon

Total
Mol\%

15.85

54.83

20.24

6.66

2.42

100

\section{Partial Pressure (psia)}

313.8

$1,085.5$

400.8

132.0

$\underline{47.9}$

1,980

Operating Temperature: In this analysis, $150^{\circ} \mathrm{F}\left(66^{\circ} \mathrm{C}\right)$ was chosen as the operating temperature for the membrane. In order to choose an appropriate working temperature, the dew points of both the feed and permeate streams had to be determined. The $\mathrm{NH}_{3}$ dew point in the feed stream is about $99^{\circ} \mathrm{F}\left(40^{\circ} \mathrm{C}\right)$. The relationship of dew point to ammonia partial pressure for high purity ammonia streams (90-99 mol\% $\left.\mathrm{NH}_{3}\right)$ is shown in Figure 4.1-3. According to the curve, at a permeate pressure of 222 psia, $\mathrm{NH} 3$ will condense between 100 and $104^{\circ} \mathrm{F}$ ( 38 and $40^{\circ} \mathrm{C}$ ) which is considered the lower limit for cooling water. The operating temperature of the membrane must be set greater than $100^{\circ} \mathrm{F}\left(37^{\circ} \mathrm{C}\right)$ to avoid condensation of $\mathrm{NH}_{3}$ in both the feed and permeate streams. In addition, gas permeating the membrane will cause some Joule-Thompson cooling, which is estimated to be $5^{\circ} \mathrm{F}\left(3^{\circ} \mathrm{C}\right)$ for this case and $15^{\circ} \mathrm{F}\left(8^{\circ} \mathrm{C}\right)$ for Case $\mathrm{B}$. Accordingly, $150^{\circ} \mathrm{F}\left(66^{\circ} \mathrm{C}\right)$ was chosen as the operating temperature. 


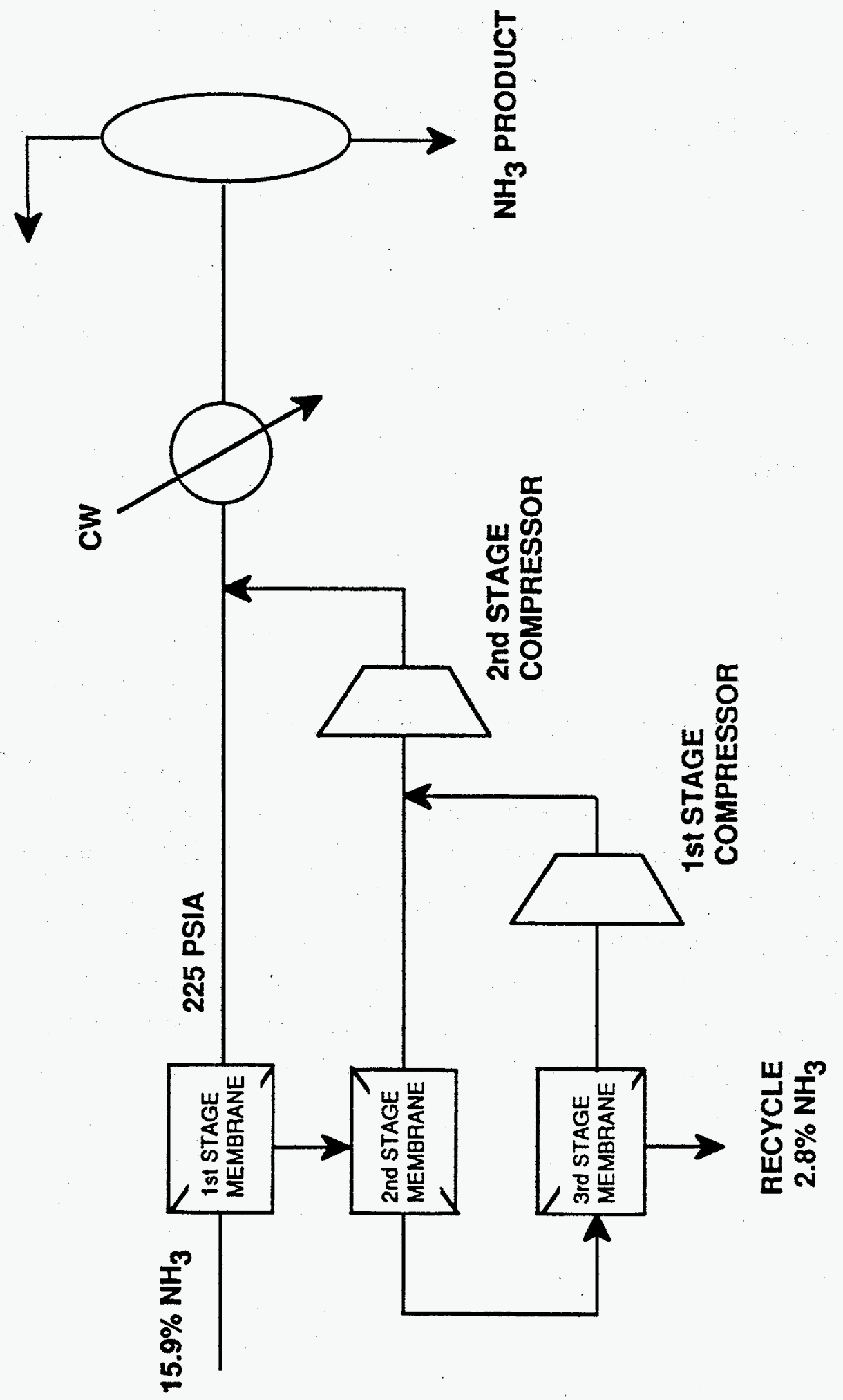




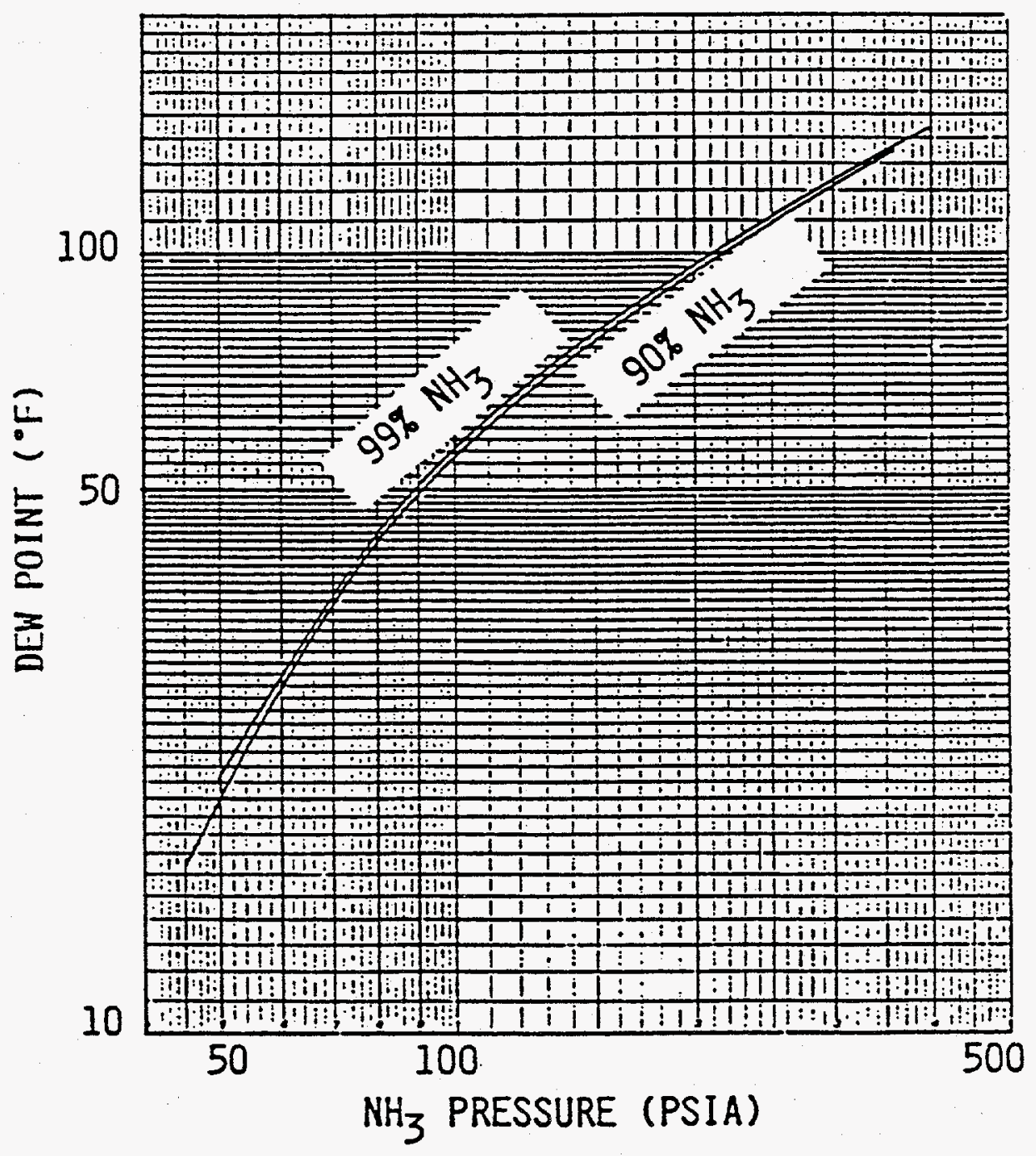

Figure 4.1-3: Relationship of Dew Point to Pressure for High Purity Ammonia Streams 


\subsubsection{Membrane Test Plan}

Based on the above information a test plan was developed for evaluating lab-scale, $\mathrm{NH}_{3}$-selective membranes under simulated process conditions. For these tests, $\mathrm{N}_{2}$ was substituted in the feed gas stream for the small amounts of methane and argon found in the actual process. This considerably reduced the complexity of the permeate gas analysis system.

Laboratory-scale membranes were to be evaluated for $\mathrm{NH}_{3}, \mathrm{~N}_{2}$ and $\mathrm{H}_{2}$ permeability under conditions shown in Table 4.1-2. Successful membrane operation at these conditions represent milestones for the program. Data collected near these conditions can be used in APCIdeveloped computer models to evaluate the feasibility of the processes proposed in Cases A and B. Experiments were to be conducted in the order shown in Table 4.1-2; that is, in order of increasing experimental complexity and severity of operating conditions. In addition, membranes were to be tested at intermediate pressures to verify membrane integrity before "process conditions" were reached. These experiments would typically consist of 3-6 measurements of permselectivity at the same temperature as the milestone test, but would begin at lower total stream pressures. After performance is verified at one set of conditions, the total feed stream pressure would be increased. By repeating this process we would ultimately arrive at the milestone test. Sufficient data was collected at each set of conditions to establish steadystate operation (usually $24-48 \mathrm{hrs}$ ).

\subsection{Membrane Permeation Test System}

Membrane permeation test equipment was upgraded to produce conditions (feed and permeate gas, temperature, etc.) typical of the end-use application for APCI NH3- and $\mathrm{CO}_{2}$-selective Active Transport membranes; namely, $\mathrm{NH}_{3}$ recovery from the synthesis loop of an ammonia synthesis plant and $\mathrm{CO}_{2}$ removal from reformer effluent in methane steam reformers. The test equipment, which is currently configured for $\mathrm{NH}_{3}$ permeation tests, can be used for either application, after minor changes which are discussed below.

\subsubsection{Flow Diagram}

A process flow diagram (PFD) for the permeation system is shown in Figure 4.2-1. The unit consists of a) a feed gas blending section, b) an oven containing the membrane and cell and c) an analytical system. The feed gas stream is generated by sparging a metered flow of a preblended mixture of $\mathrm{N}_{2}$ in $\mathrm{H}_{2}$ from a high pressure "BX" cylinder (CYL-1) through a second cylinder 
(CYL-2) which contains liquid NH3. (This cylinder, CYL-2, is removed from the system for filling with NH3.). An expanded view of the sample cylinder (CYL-2) inlet/outlet connections is shown in Figure 4.2-2. The concentration, or partial pressure, of $\mathrm{NH}_{3}$ in the feed gas is regulated by the temperature of CYL-2 via HTR-1. The ternary blend is then routed through a preheater to the membrane cell which is housed in the oven. The pressure of the feed stream is maintained at a pressure set via BPR-2 and measured by PT-4. The $\mathrm{NH}_{3}$ is water-stripped from the reject stream before it is discharged to the atmosphere. The permeating gases are collected at a pressure set at BPR-3 and measured by PT-5. As the permeant gas bleeds across BPR-3 it is picked up in a metered flow of helium and routed to a gas chromatograph for analysis. The analytical system (gas chromatograph, integrator etc.) is as reported previously11.

The oven was custom built by APCI support services. It is constructed of aluminum with $2^{\text {" of }}$ insulation in the walls. It was specifically designed to minimize temperature gradients within the oven space and to maintain constant temperature at $30-100^{\circ} \mathrm{C}$. For safety, the oven is constantly purged with $\mathrm{N}_{2}$ to prevent the build-up of combustible gases inside the oven in the event that a leak should occur in the test equipment. Additionally, the $\mathrm{N}_{2}$ flow is part of a safety feedback system; if the $\mathrm{N}_{2}$ flow fails or is impeded, the system will automatically revert to shutdown mode. This is just one of the many safety features incorporated into the design to render it safe for unattended operation. The oven, test equipment analytical system, and associated equipment are shown in Figure 4.2-3. For safety reasons the unit is housed inside a "Process Development High Pressure Cell"

\subsubsection{Electrical Diagram}

"Ladder" diagrams detailing electrical connections are shown in Figure 4.2-4. The majority of these components are mounted in a cabinet (Figure 4.2-5) located outside the Process Development Cell. 


\section{MEMBRANE TEST PLAN}

\begin{tabular}{|c|c|c|c|c|c|c|c|}
\hline \multirow{2}{*}{ Feed Stream } & \multirow{2}{*}{ Membrane Temperature } & \multicolumn{4}{|c|}{ Feed Stream Composition } & \multicolumn{2}{|c|}{ Permeate Stream } \\
\hline & & $\mathrm{PNH}_{3}$ & $\mathrm{PN}_{2}$ & $\mathrm{PH}_{2}$ & $\mathrm{P}_{\text {tot }}$ & $\mathrm{P}_{\text {total }}$ & $\mathrm{PNH}_{3}$ \\
\hline 3rd stage reject & $139^{\circ} \mathrm{F}$ & 55 & 666 & 1244 & 1965 & 40 & 39 \\
\hline 3rd stage feed & $139^{\circ} \mathrm{F}$ & 127 & 642 & 1200 & 1970 & 40 & 39 \\
\hline 2nd stage feed & $146^{\circ} \mathrm{F}$ & 239 & 605 & 1131 & 1975 & 100 & 98 \\
\hline 1st stage feed & $150^{\circ} \mathrm{F}$ & 314 & 580 & 1086 & 1980 & 225 & 220 \\
\hline
\end{tabular}

TARGET PERFORMANCE

$$
\begin{gathered}
\text { Po/ } \mathrm{NH}_{3}=40 \\
\alpha\left(\mathrm{NH}_{3} / \mathrm{N}_{2}\right)>1000 \\
\alpha\left(\mathrm{NH}_{3} / \mathrm{H}_{2}\right)>1500
\end{gathered}
$$

Table 4.1-2: Membrane Test Plan and Target Membrane Performance 


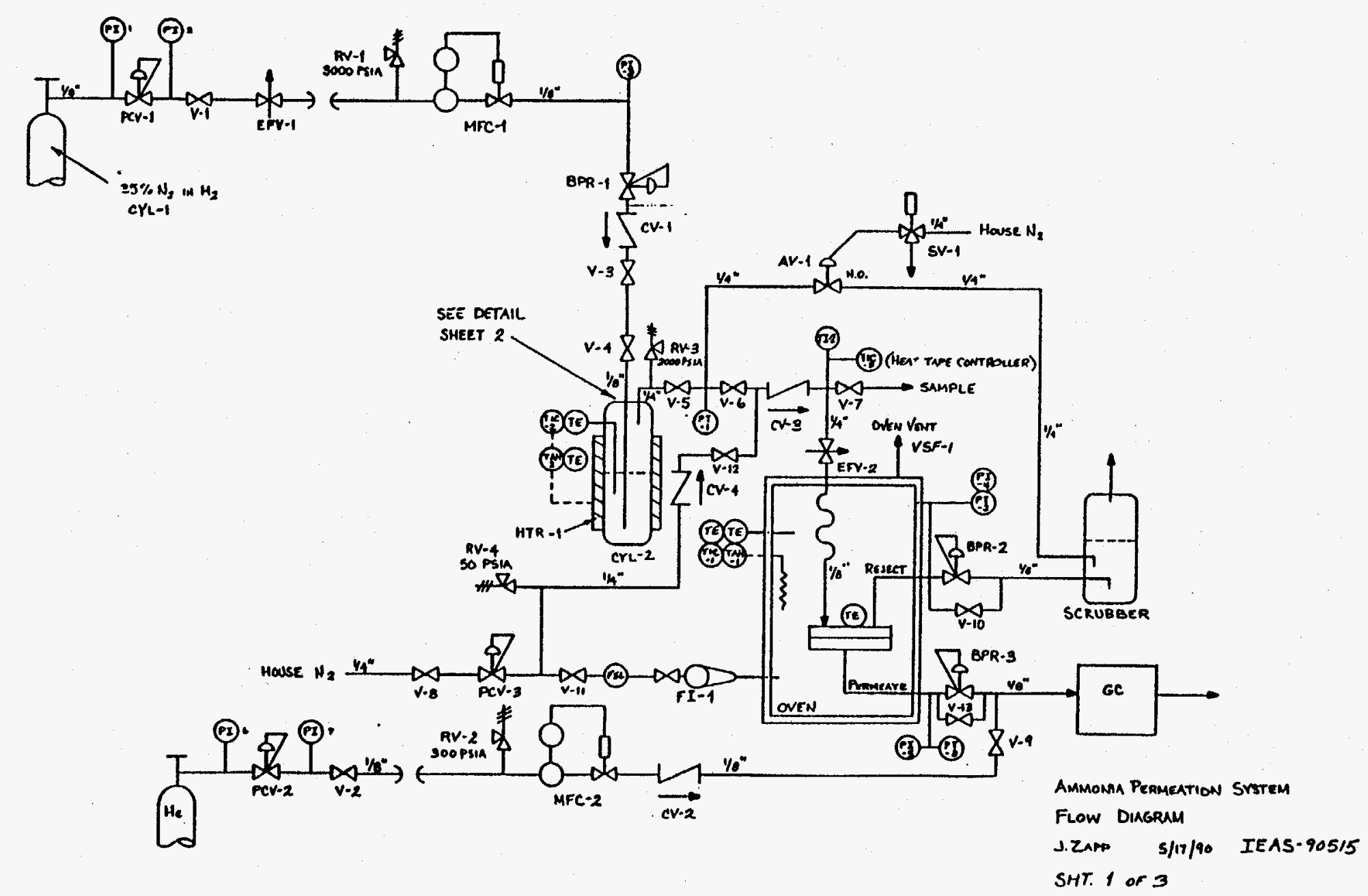

Figure 4.2-1: Process Flow Diagram - High Pressure Membrane Test System 
NOTE: Hent tRnce $1 / 9^{-}$Gas Lane From CMINDER TO OVEN!

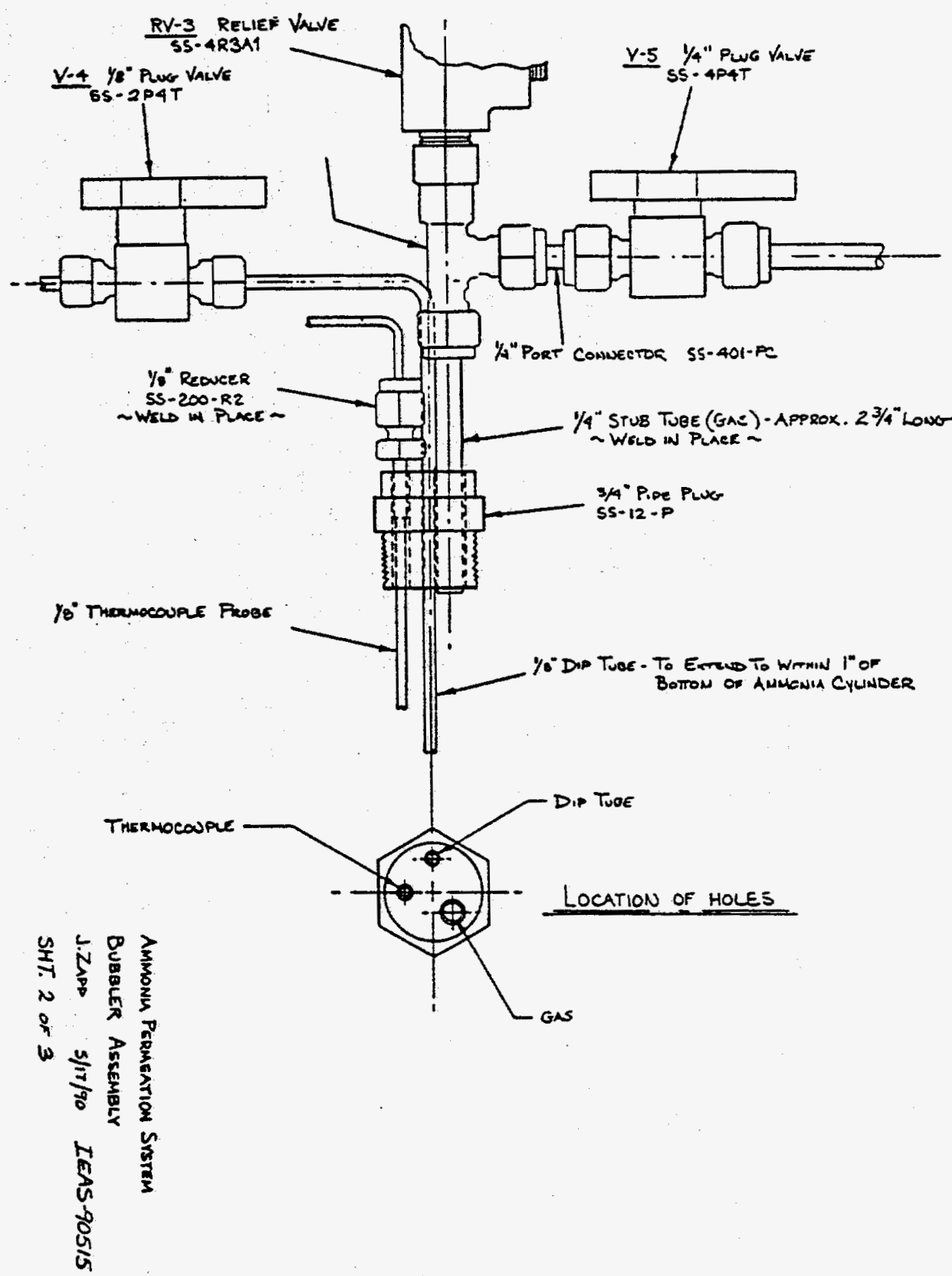

Figure 4.2-2: CYL-2 Connection Assembly -Expanded View 


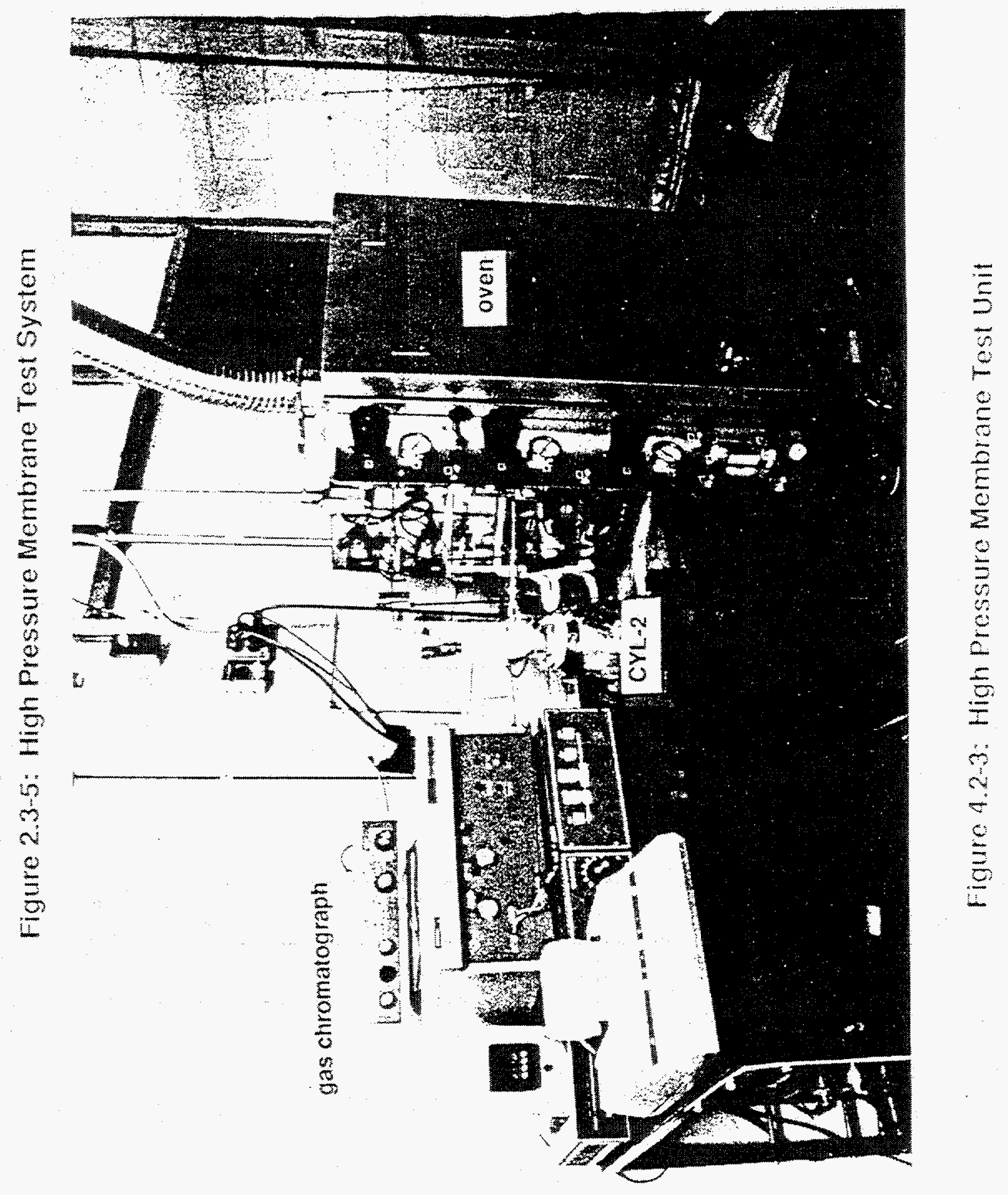




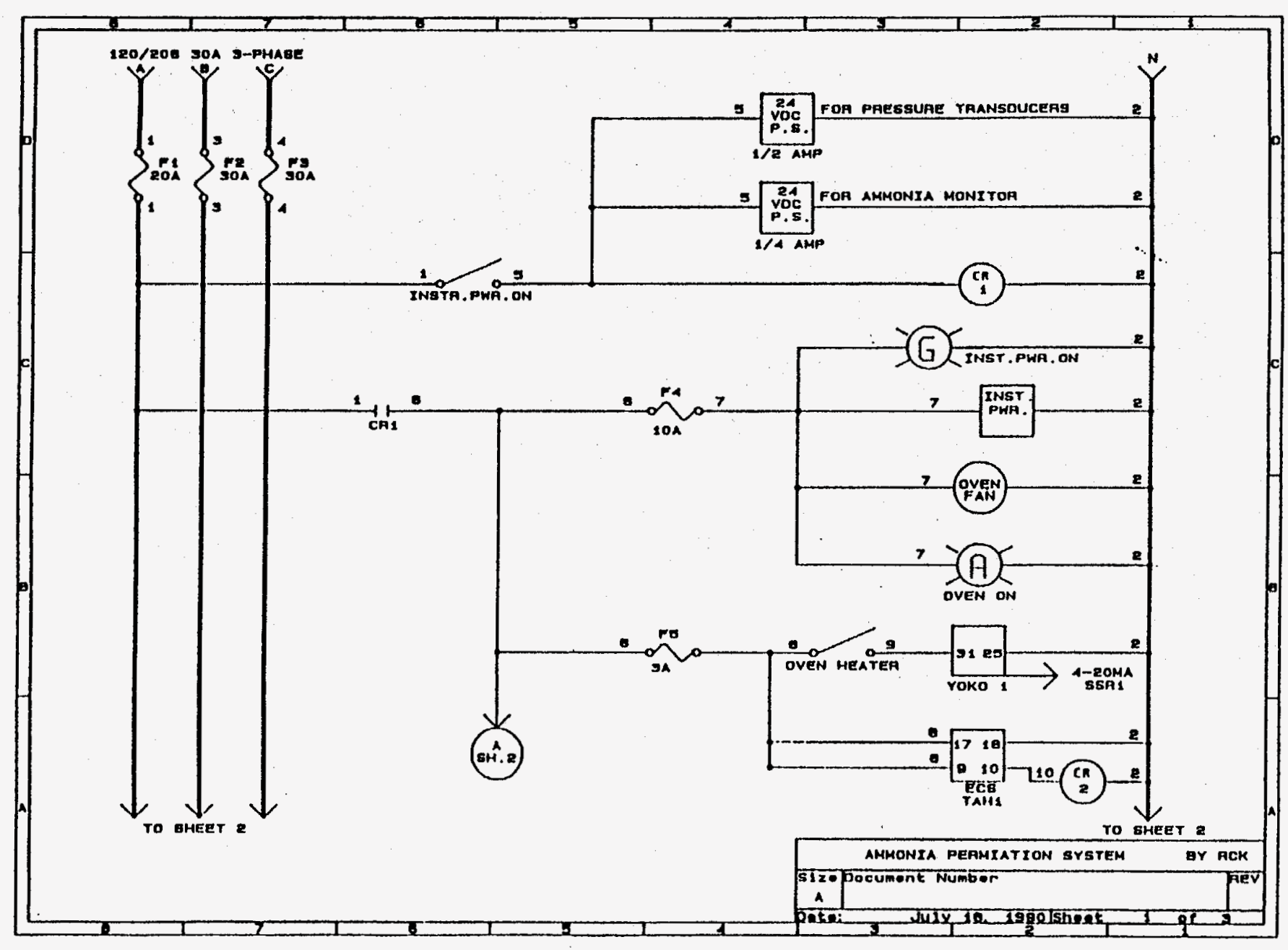

Figure 4.2-4: Electrical Wiring Diagram - High Pressure Membrane Test System 


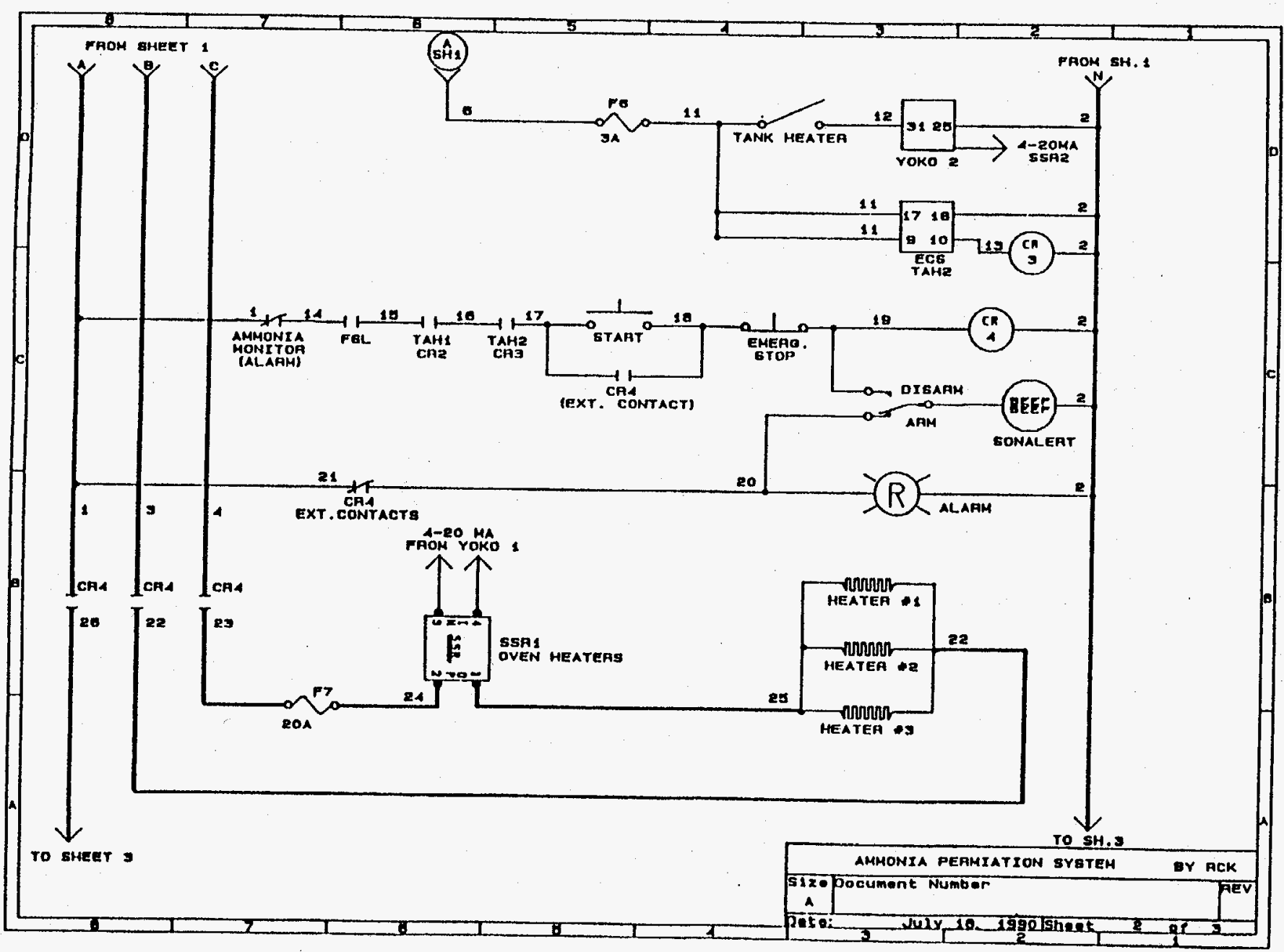

Figure 4.2-4: Electrical Wiring Diagram - High Pressure Membrane Test System (cont) 


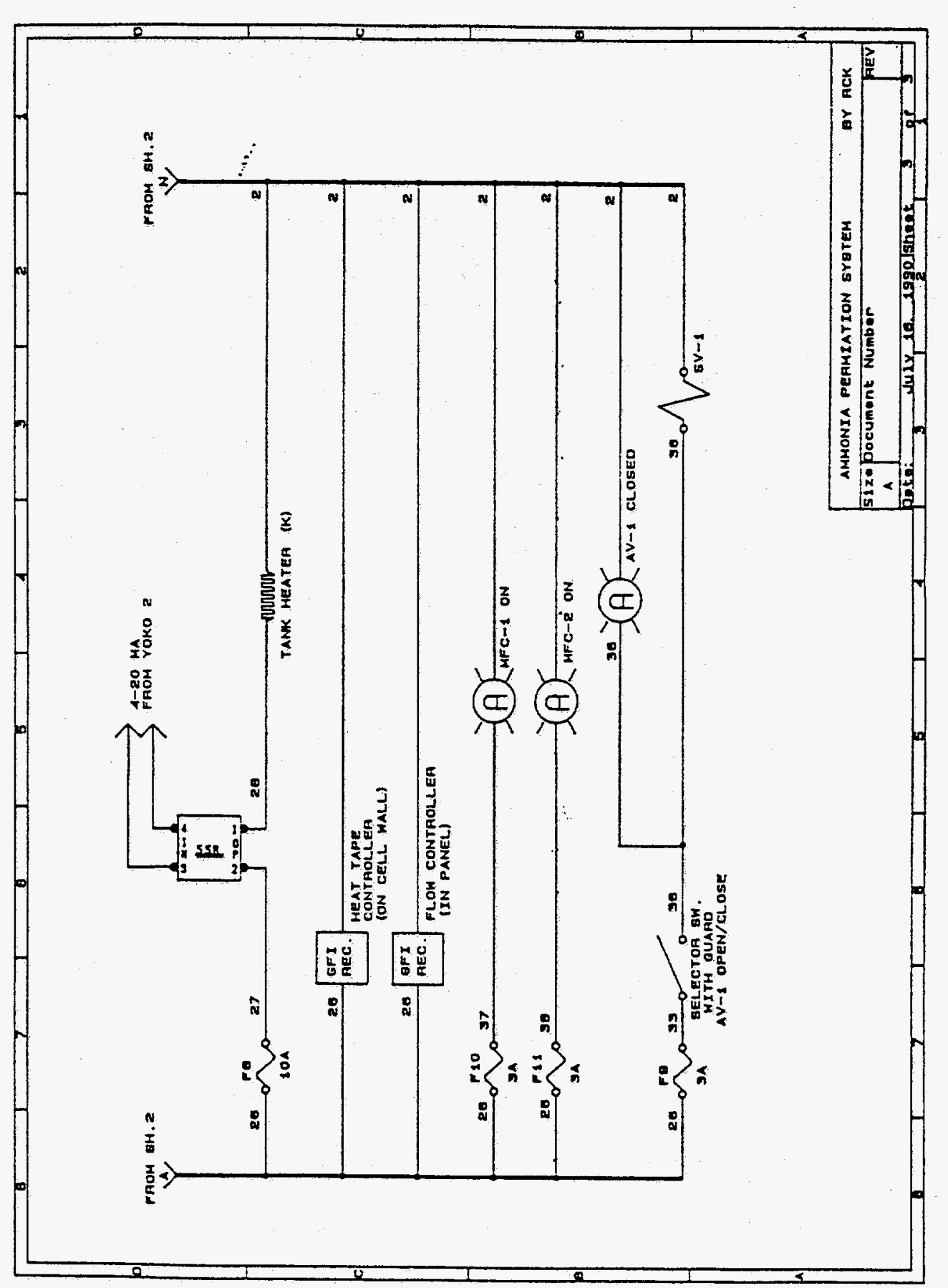

हี 


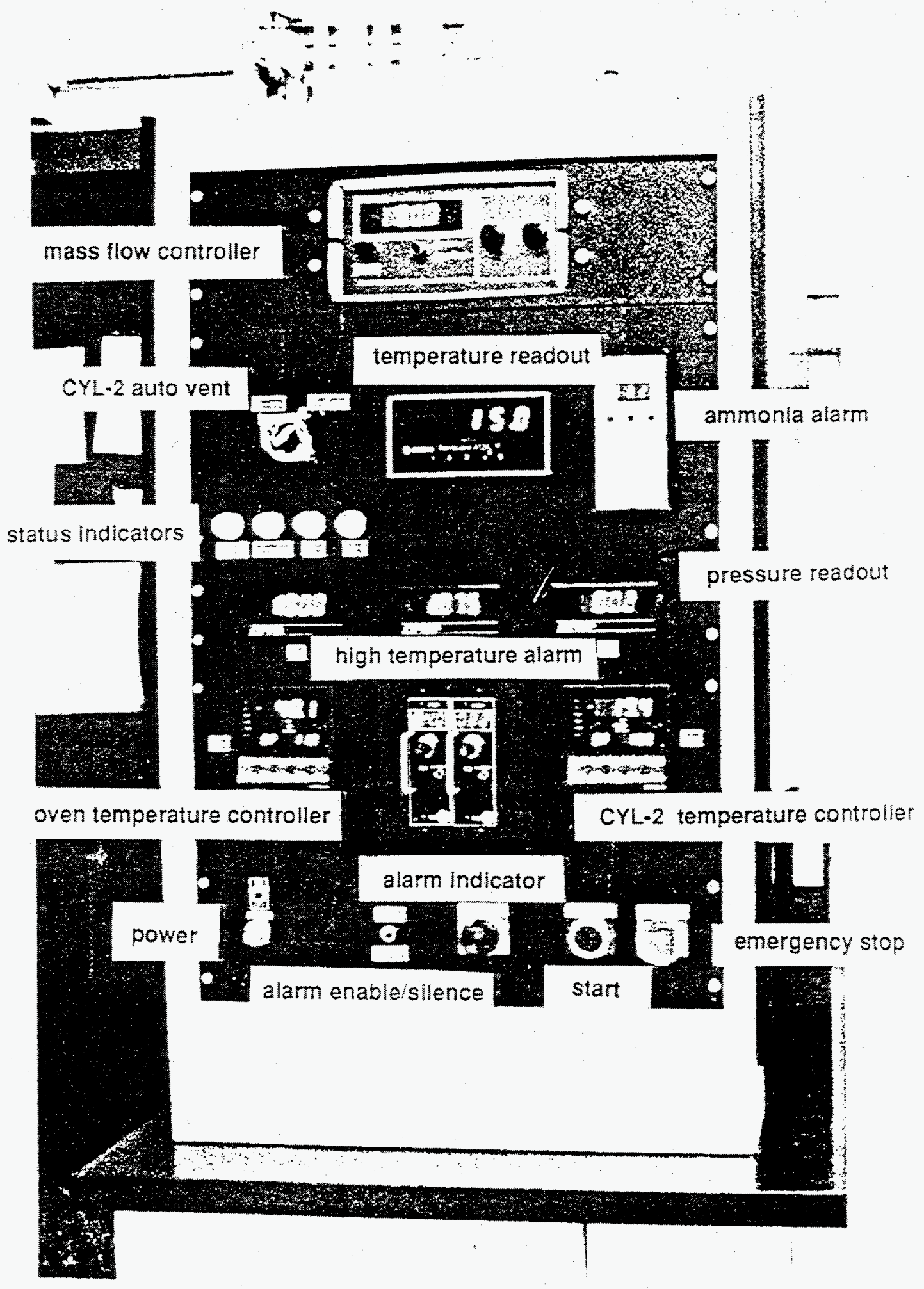

Figure 4.2-5: Control Cabinet - High Pressure Membrane Test Unit 


\subsubsection{Component List}

$\begin{array}{ll}\text { PCV-1 } & \text { 15-2000 psig pressure regulator } \\ \text { PCV-2 } & 0-250 \text { psig pressure regulator } \\ \text { PCV-3 } & 0-50 \text { psig pressure regulator } \\ \text { BPR-1,2 } & \text { 200-2500 psig backpressure regulator } \\ \text { BPR-3 } & 0-250 \text { psig backpressure regulator } \\ \text { MFC-1,2 } & 0-500 \text { sccm high pressure, mass flow controller } \\ \text { AV-1 } & \text { air actuated valve } \\ \text { FI-1 } & \text { tube type flow meter } \\ \text { SV-1 } & \text { solenoid valve } \\ \text { EFV-1 } & \text { excess flow valve 1slm } \\ \text { V1-2 } & \text { shut-off valve } \\ \text { V3-V6 } & \text { plug valve } \\ \text { V7-V10 } & \text { sample valve } \\ \text { V-11,12 } & \text { needle valve } \\ \text { CV-1-CV-4 } & \text { check valve, } 10 \text { psi } \\ \text { RV-1 } & \text { relief valve, 3000 psia } \\ \text { RV-2 } & \text { relief valve, } 300 \text { psia } \\ \text { RV-3 } & \text { relief valve, 2200 psia } \\ \text { RV-4 } & \text { relief valve, } 50 \text { psia } \\ \text { HTR-1 } & \text { Neslab chiller/heater unit } \\ \text { TIC-1,2 } & \text { temperature controller } \\ \text { CYL-2 } & \text { "D" size steel cylinder, modified } \\ \text { TIC-3 } & \text { heat tape controller } \\ \text { PT-3 } & \text { pressure transducer, 1000 psia } \\ \text { PT-1,2 } & \text { pressure transducer, 2000 psia } \\ \text { PI's } & \text { process signal conditioner/power supply } \\ \text { TI-2 } & \text { temperature indicator } \\ \text { TAH1,2 } & \text { high temperature alarm } \\ \text { PI-3,4 } & \text { pressure gauge, } 2000 \text { psia } \\ \text { PI-5 } & \text { pressure gauge, } 300 \text { psia } \\ & \end{array}$

\subsubsection{Conversion to $\mathrm{CO}_{2}$ Applications}

The high pressure test unit can be converted from $\mathrm{NH}_{3}$ to $\mathrm{CO}_{2}$ application testing by performing the following operations:

1) CYL-2 is filled with $\mathrm{H}_{2} \mathrm{O}$ rather than $\mathrm{NH}_{3}$

2) CYL-1 is replaced by a blend of $\mathrm{CH}_{4}$ in $\mathrm{H}_{2}$

3) MFC-1 is recalibrated for the new $\mathrm{CH}_{4} / \mathrm{H}_{2}$ blend

4) $\mathrm{GC}$ columns are replaced with $\mathrm{CO}_{2}$ compatible columns (e.g., Poropak) 


\subsection{Evaluation of NH3-Selective MLC Membranes}

The membranes tested in this part of the program were MLCs of the type PTMSP/PVAmSCN/PTMSP or PTMSP/PVAmSCN/PAN/Hollytex. The latter is typical of a composite which would be used in an actual commercial module. Fabrication of such MLC membranes is detailed in ref. 8 . In the process of evaluating the composite membranes, a number of experimental parameters are set, e.g., feed flow rate, pressures and partial pressures, temperatures etc. In the following sections only those parameters relevant to the discussion at hand are given. Full experimental details and complete results are given in Appendix A.

\subsubsection{Evaluation of NH3-selective MLCs as a Function of Feed Gas Pressure}

These experiments were designed to 1) test the mechanical stability of the membrane as the total transmembrane pressure (the difference in total pressure between the feed and permeate sides of the membrane) was increased to pressures greater than 1000 psia, and 2) track the permselectivity of the membrane under these conditions. To perform these measurements experimentally, the $\mathrm{NH}_{3}$ bubbler temperature was chosen to yield an $\mathrm{NH}_{3}$ partial pressure representative of one of the points in the test matrix. The remainder of the feed gas pressure consisted of gas from the cylinder containing $\mathrm{N}_{2} / \mathrm{H}_{2}$ (CYL-1). For each set of experiments, the $\mathrm{NH}_{3}$ partial pressure in the feed stream was held constant and only the pressure of $\mathrm{N}_{2}$ and $\mathrm{H}_{2}$ was increased. In this way it was possible to test the dimensional stability of the membrane at increasingly harsher conditions. For these tests the membranes were PTMSP/PVAmSCN/PAN/ Hollytex MLCs. Results are summarized in Figure 4.3-1. Details of the experimental parameters and complete results are given in Appendix A. 
Figure 4.3-1

Evaluation of MLC Membrane as a Function of Feed Pressure

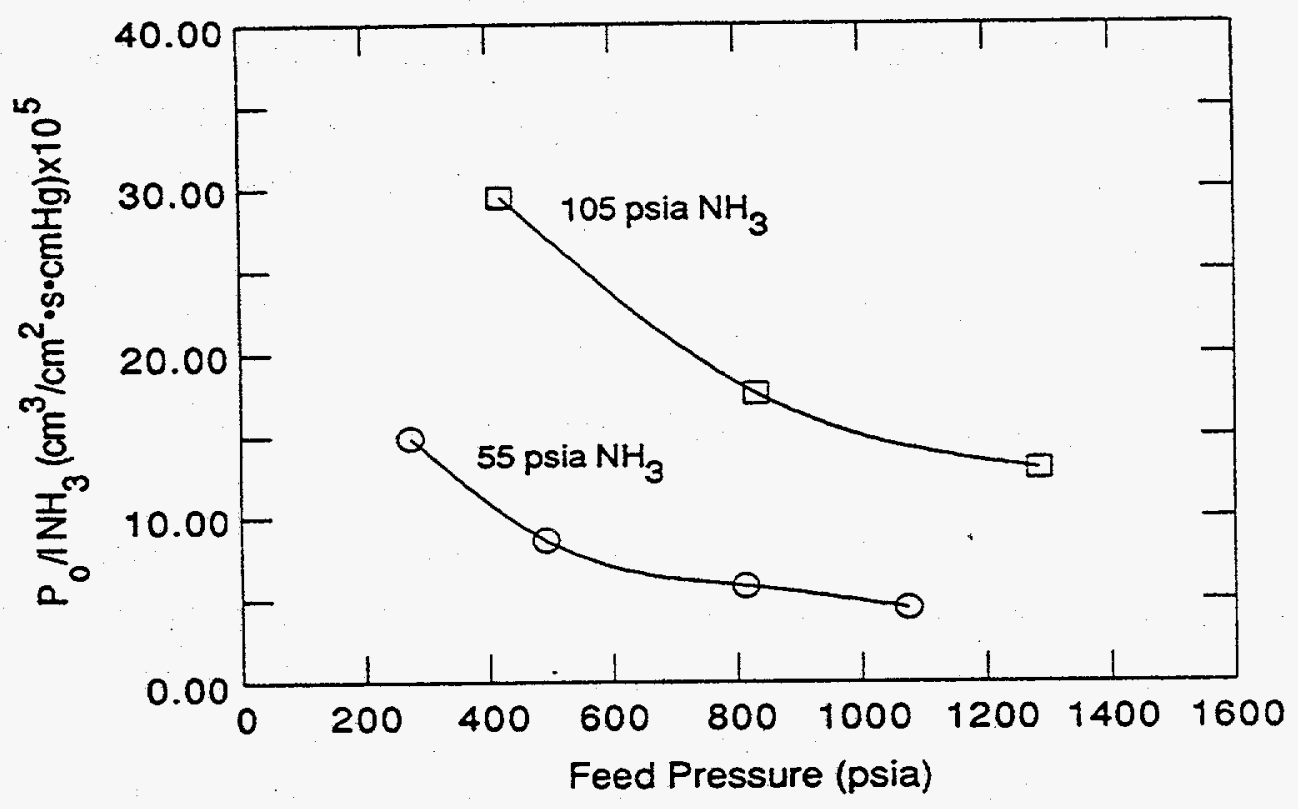

$11497-36,11497-92: T_{\operatorname{mem}}=40^{\circ} \mathrm{C}$

The membrane is able to withstand transmembrane pressure gradients in excess of $1000 \mathrm{psi}$. To our knowledge, this is the first time that a facilitated transport membrane has been operated successfully at these high pressures. To have demonstrated dimensional stability at these pressures represents a milestone in the program. Somewhat surprising is the fact that as the feed pressure is increased, the observed flux of $\mathrm{NH}_{3}$ (Po/1) decreases. This is unexpected since the $\mathrm{NH}_{3}$ partial pressure in the feed and permeate gases, and hence the driving force for $\mathrm{NH}_{3}$ permeation, is constant; one would expect a constant $\mathrm{Po} / \mathrm{NH} 3$ as the system pressure is increased. This is apparently not the case and, if true, has two important implications. First, the obvious feature that the membrane is less productive at high pressures. The $\mathrm{NH}_{3}$ flux at 1200 psia is only $25 \%$ of the flux at 300 psia. Second, since the flux (Po/l) of $\mathrm{N}_{2}$ and $\mathrm{H}_{2}$ is essentially constant for the pressure range studied (Appendix $A$ ), $\alpha\left(\mathrm{NH}_{3} / \mathrm{N}_{2}\right)$ and $\alpha\left(\mathrm{NH}_{3} / \mathrm{H}_{2}\right)$ decrease with increasing total pressure simply as a result of the loss of $\mathrm{NH}_{3}$ flux (Figure 4.3-2). For instance, at 55 psia $\mathrm{NH}_{3}$, and 275 psia total feed pressure $\alpha\left(\mathrm{NH}_{3} / \mathrm{H}_{2}\right)$ is 1400 but at 1075 psia $\alpha\left(\mathrm{NH}_{3} / \mathrm{H}_{2}\right)$ is only 180 . Thus, at the low pressure condition the observed $\mathrm{Po} / \mathrm{NH} 3$ and 
Figure 4.3-2

$\mathrm{NH}_{3} / \mathrm{H}_{2}$ Selectivity of PTMSP/PVAmSCN/PAN/HT MLC Membrane

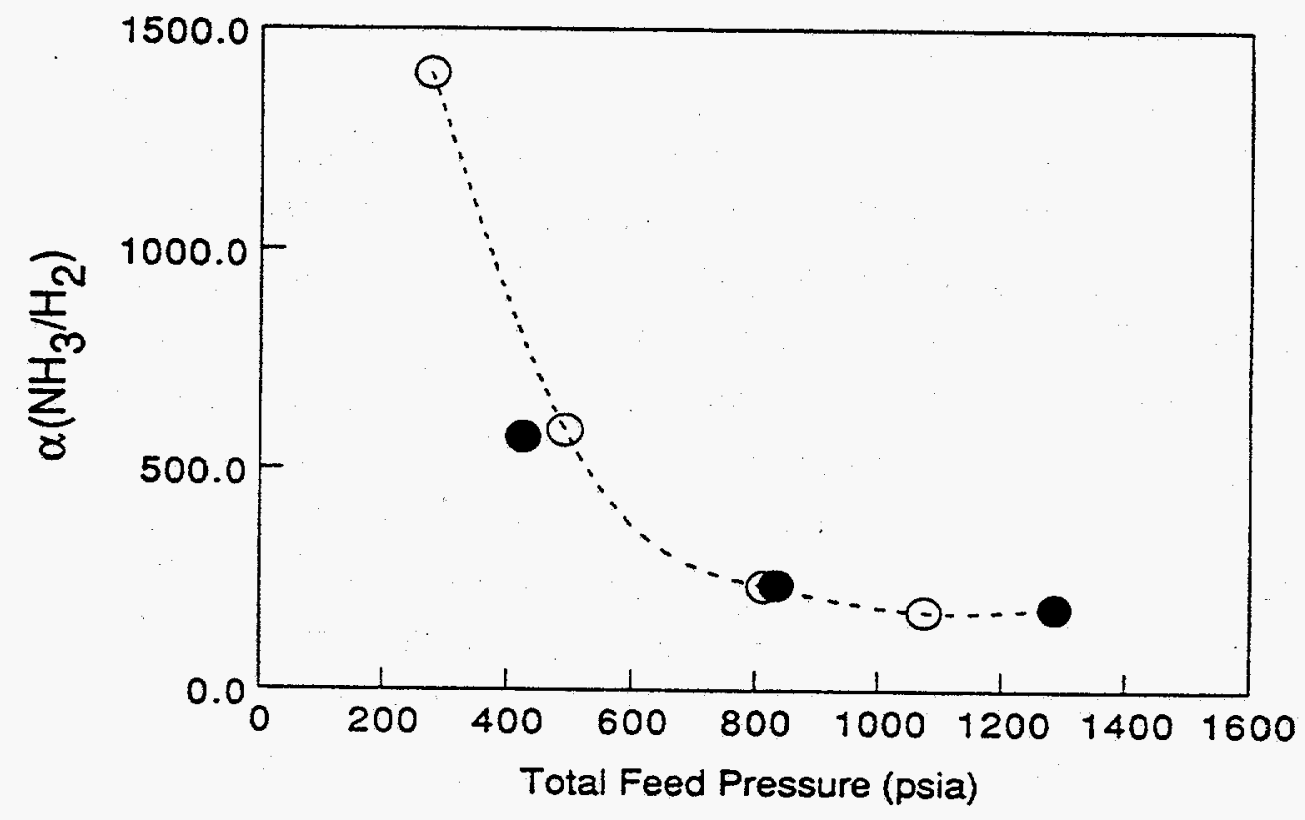

$11497-36,92 ; T_{\text {mem }}=40^{\circ} \mathrm{C}$ 
selectivities are near the target values of 40 and 1500, respectively (see Table 4.1-2) but fall short at pressures under which the membrane would eventually be used in a commercial application. It is therefore important to understand if the observed loss in $\mathrm{NH}_{3}$ flux, and consequently in selectivity, is real or an artifact of the experiment.

\subsubsection{Role of PAN Support Layer}

One possible explanation of the phenomenon centers on physical changes in the MLC brought about by the high pressure test. Specifically, the integrity of the asymmetric microporous support polymer (e.g., the poly(acrylonitrile)) after it is subjected to a large pressure drop. To investigate this possibility, we examined cross-sections of the MLC before and after permeation testing. The photomicrographs, shown in Figure 4.3-3, reveal a significant change in the macroporous region of the PAN layer. The highly oriented macropores have essentially collapsed and now form a tortuous, less porous path. To further investigate the role of the PAN macropore region, we repeated the previous permeation measurements but this time used a membrane which did not contain an asymmetric support layer. If the PAN layer contributes significantly to the flux loss, then we would expect to see significantly less flux loss in the membranes fabricated without this layer. Results are shown in Figure 4.3-4. 

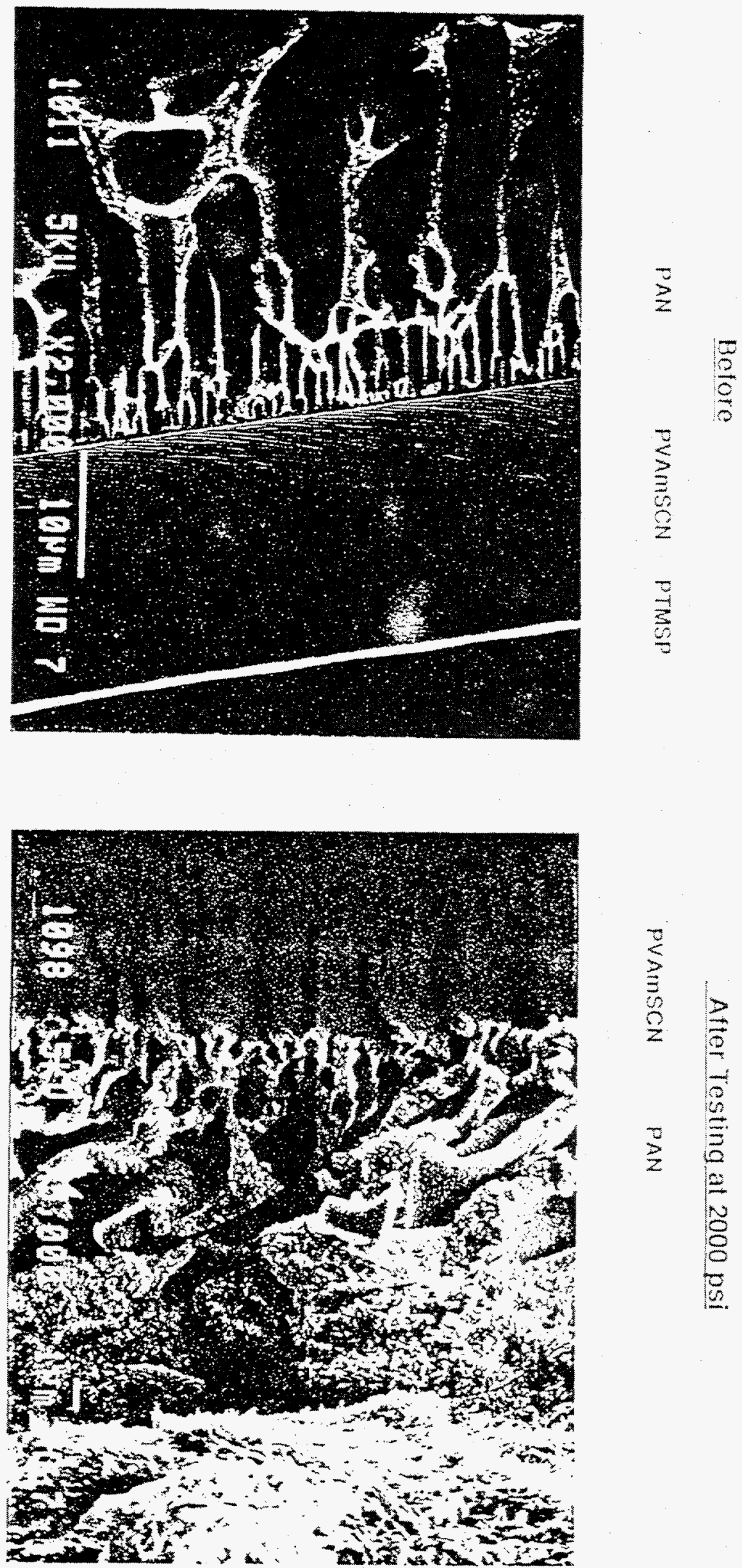
Figure $\quad 4.3-4$

\section{Evaluation of PTMSP/PVAmSCN/PTMSP MLC Membrane}

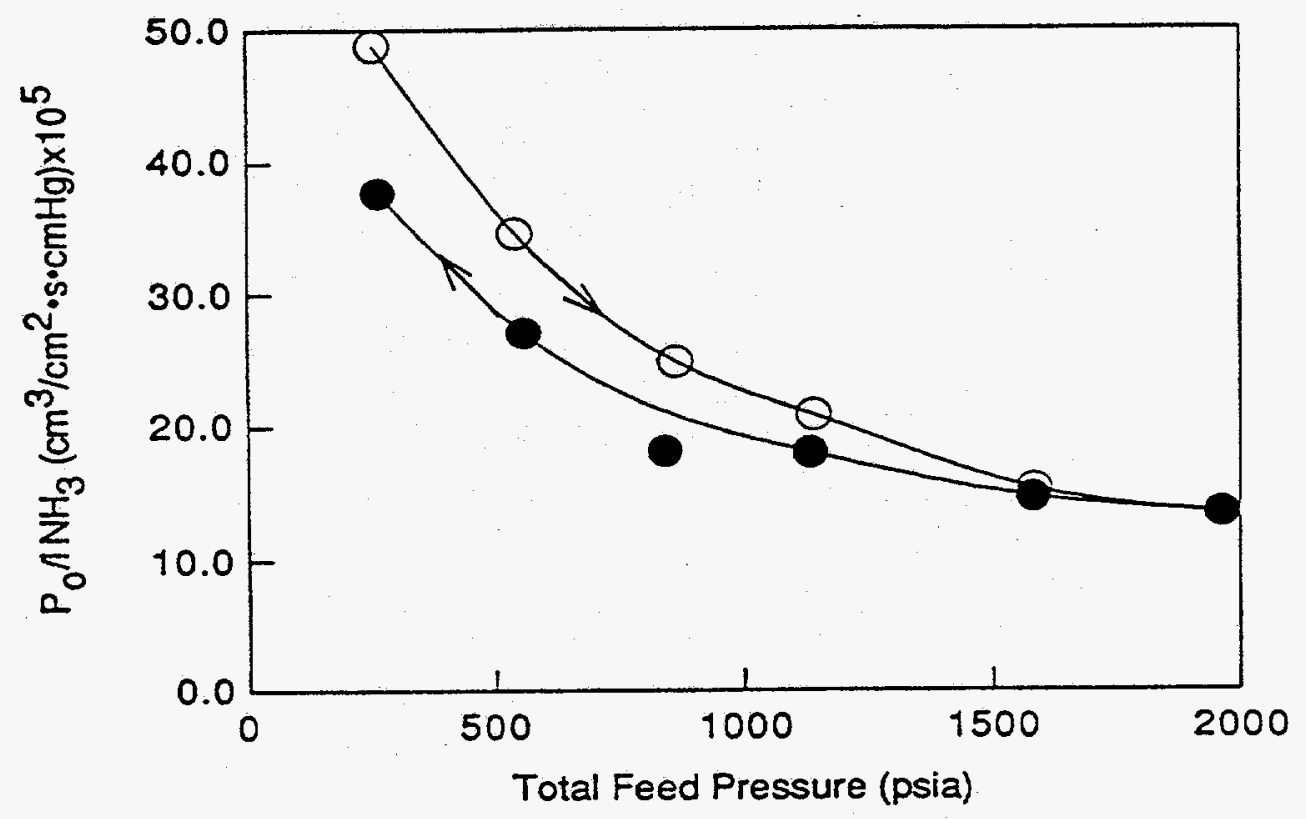

11497-73; $\mathrm{P}_{\mathrm{NH} 3}=55$ psia; $T_{\mathrm{mem}}=40^{\circ} \mathrm{C}$

Although the absolute value of the $\mathrm{NH}_{3}$ flux is higher for this membrane than the previous membranes, the loss in flux is essentially the same. This data indicates that the loss of macroporosity in the PAN layer accompanying high pressure testing is not significantly limiting mass transfer across the membrane. The fact that the membrane without the PAN/Hollytex support possesses higher flux values of all gases simply indicates that the PAN layer imposes some mass transfer resistance to permeation due to its low surface microporosity.

\subsubsection{Concentration Polarization}

Another source of the flux loss revolves around a phenomenon known as "concentration polarization." Concentration polarization is observed most often in membranes which are both highly permeable and highly selective, e.g., RO, UF and pervaporation membranes, but generally not gas separation, since those membranes typically have low selectivity. The phenomenon is associated with the formation of a boundary layer at the feed/membrane interface 
under steady-state conditions (Figure 4.3-5). The boundary layer forms because the region near the membrane surface is depleted of the faster permeating gas (in our case $\mathrm{NH}_{3}$ ). A new gas phase mass transfer barrier is established through which $\mathrm{NH}_{3}$ from the bulk composition must diffuse before reaching the membrane surface. As the pressure is increased, the mass transfer resistance of this boundary layer increases owing to the additional partial pressure of the nonpermeating gases. In short, there is poor mixing in the space directly over the membrane.

As one might expect, the extent of concentration polarization is dependent on the mixing patterns in the test cell/module and consequently the geometry of the test. If the loss in flux arises from poor mixing, then improving the mixing (e.g. by increasing the flow rate of feed gas) would be expected to restore some of the flux loss. Results from such experiments, in which the $\mathrm{NH} 3$ permeance was measured at different pressures as a function of feed gas flow rate, are shown in Figure 4.3-6. As is evident, increasing the feed flow rate has a marked effect on the observed $\mathrm{P}_{\mathrm{O}} / 1 \mathrm{NH} 3$. At low total pressures $(\approx 250 \mathrm{psi}$ ) only a small (but significant) increase in observed $\mathrm{NH}_{3}$ flux is realized. Indeed, at low pressures there is no difference between the flux measured at a feed gas flow rate of $250 \mathrm{sccm}$ and $450 \mathrm{sccm}$. We believe this value represents the membrane-limited $\mathrm{NH}_{3}$ flux. The effect of feed flow rate becomes more pronounced as the total pressure is increased. At high pressure, nearly $75 \%$ of the flux loss has been restored. Other data, given in Appendix A, provide additional support for these conclusions (see e.g., 11478-92). 
F4.3-5

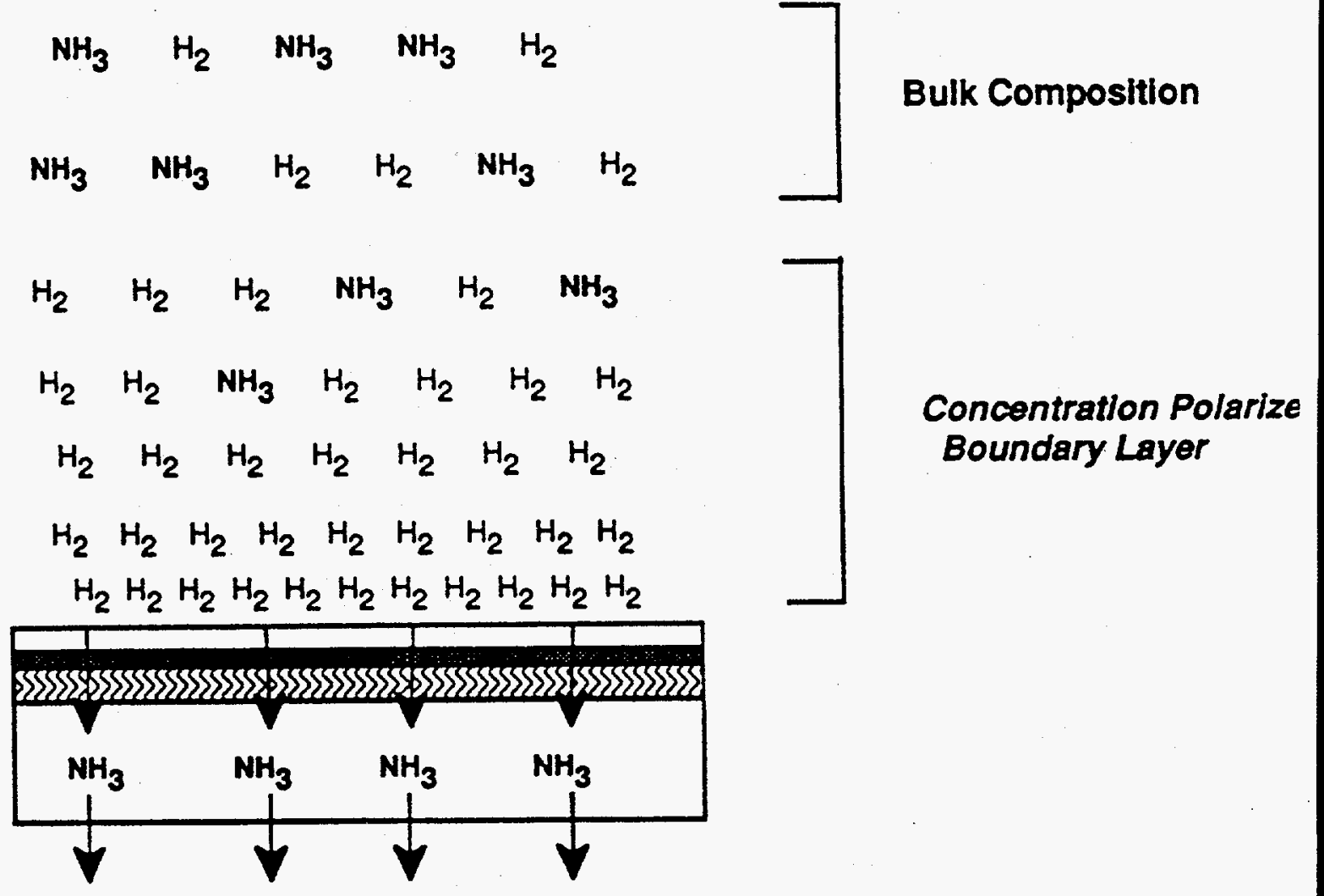

Figure 4.3-5: Concentration Polarization Phenomenon 
Figure 4.3-6

\section{Effect of Feed Flow Rate on Membrane Performance (PTMSP/PVAmSCN/PTMSP)}

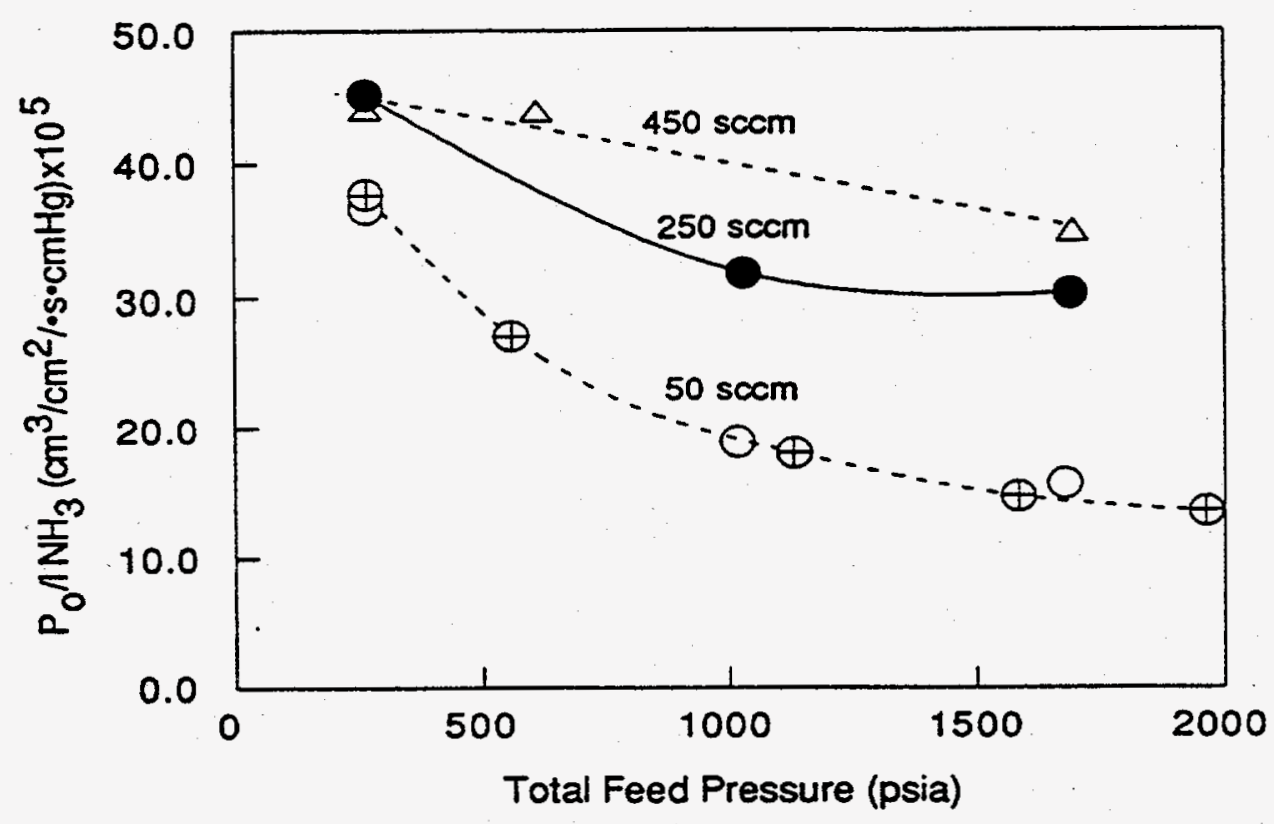

11497-73; $P_{\mathrm{NH} 3}=55$ psia; $T_{\text {mem }}=40^{\circ} \mathrm{C}$

This explanation can be verified by a simple calculation of the mass transfer coefficient of a boundary layer using estimates of the $\mathrm{NH}_{3}$ diffusion coefficient in the $\mathrm{H}_{2} / \mathrm{N}_{2} / \mathrm{NH}_{3}$ mixture. Table 4.3-1 lists the diffusion coefficients for the indicated conditions as calculated by CAPP, an APCI computer-based thermodynamics program. As expected, the diffusivity is almost exactly inversely proportional to pressure. The flux loss displayed in Figure 4.3-4 could be explained if there were a mass transfer resistance proportional to total pressure and having a mass transfer coefficient of about $38 \times 10^{-5} \mathrm{scc} / \mathrm{cm} 2 \cdot \mathrm{s} \cdot \mathrm{cmHg}$ at $1000 \mathrm{psia}$. This resistance is in series with the resistance of the membrane itself. A simple scenario which can lead to such a resistance is that of a stagnant layer above the membrane surface through which the ammonia must diffuse. The resistance of such a layer is given by

$$
\mathrm{I}=\mathrm{D}_{\mathrm{m}} / \mathrm{dRT}
$$


where $D_{m}=$ diffusion coefficient, $\mathrm{cm}^{2} / \mathrm{s}$

$\mathrm{d}=$ thickness of the stagnant layer, $\mathrm{cm}$

$\mathrm{T}=$ temperature, $\mathrm{K}$

$\mathrm{R}=$ gas constant $(0.2784 \mathrm{~cm} 3 \cdot \mathrm{cmHg} / \mathrm{scc} \cdot \mathrm{K})$

Mass transfer is a potential explanation of the results in Figure 4.3-4 if the layer thickness, d, is less than the approximately $1 \mathrm{~cm}$ distance between the membrane surface and the outlet tube.

Inserting the values of $\mathrm{r}=38 \times 10-5 \mathrm{scc} / \mathrm{cm} 2 \cdot \cdot \cdot \mathrm{cmHg}, \mathrm{Dm}=0.0056 \mathrm{~cm} 2 / \mathrm{s}$ and $\mathrm{T}=313 \mathrm{~K}$ gives $\mathrm{d}=0.17 \mathrm{~cm}$. This is small enough to conclude that mass transfer is a potential explanation for the observed results.

Table 4.3-1

Diffusion Coefficients for Ammonia

$\begin{array}{cllll}\begin{array}{c}\text { Pressure, psia } \\ \text { Temperature, C }\end{array} & 250 & 500 & 1000 & 2000 \\ \begin{array}{c}\text { Gas Composition } \\ \mathrm{NH} 3 . \%\end{array} & 22 & 40 & 40 & 40 \\ \mathrm{~N} 2, \% & 46.8 & 11.0 & 5.5 & 2.75 \\ \mathrm{H} 2, \% & 31.2 & 53.4 & 56.7 & 58.35 \\ \mathrm{NH}_{3} \text { Diffusivity: } & & 35.6 & 37.8 & 38.90 \\ \mathrm{ft} 2 / \mathrm{hr} & 0.0832 & 0.0421 & 0.0215 & 0.0112 \\ \mathrm{~cm}^{2} / \mathrm{s} & 0.0215 & 0.0109 & 0.0056 & 0.0028\end{array}$

To further test this theory we examined the effect of reversing the direction of the feed input and feed reject gas flows. This was possible to do because the test cell is highly unsymmetrical as shown below. 


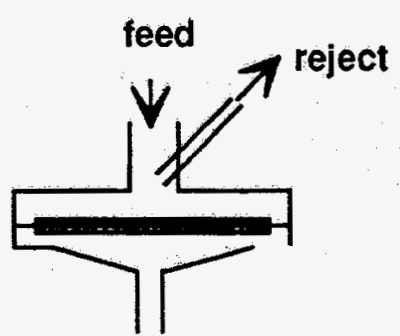

configuration \#1

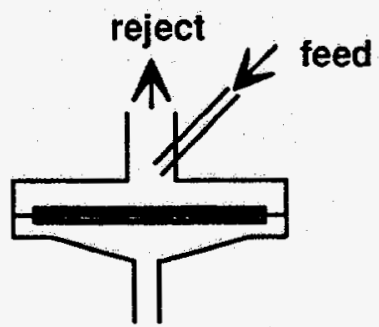

configuration \#2

In configuration \#1, the standard configuration used for all previous tests, the feed gas enters directly above the membrane through a $3 / 8^{\prime \prime}$ diameter orifice and exits at an angle $\left(\sim 45^{\circ}\right)$ to the membrane surface through a $1 / 8^{\prime \prime}$ diameter tube. In configuration $\# 2$ the feed gas enters through the smaller orifice and exits through the larger. If concentration polarization plays a dominant role then one would expect a significant difference in the measured $\mathrm{NH}_{3}$ flux for the two configurations. Results are shown in Figure 4.3-7. In configuration \#1 we observe the typical $\mathrm{NH}_{3}$ flux loss as the total feed gas pressure is increased. In configuration \#2 the decrease in $\mathrm{NH}_{3}$ flux with total feed pressure is not significant, however the $\mathrm{NH}_{3}$ flux for both flow rates is considerably lower than in configuration \#1. This is strong evidence for the concentration polarization effect.

\subsubsection{Evaluation of MLC Membranes at Process Conditions}

This section summarizes results for a variety of membranes which were tested under "process conditions". It was experimentally difficult to obtain precisely those conditions outlined in the test plan, but every attempt was made to set experimental parameters which would be useful in evaluating the utility of these membranes. Results are summarized in Table 4.3-1.

The MLC membranes were able to withstand the high transmembrane pressures for all test conditions. This is especially important for cases in which the $\mathrm{NH}_{3}$ partial pressure in the feed gas in quite high, and consequently, the membrane contains large quantities of sorbed $\mathrm{NH}_{3}$; that is, the "active transport" layer is highly gelled under these conditions. In general, as the driving force (difference in $\mathrm{NH}_{3}$ partial pressure between feed and permeate interfaces) is decreased the $\mathrm{NH}_{3}$ permeance decreases. This is also an indication of polarization induced mass transfer limitations. As expected, permeance is a strong function of temperature due to the equilibrium between gas phase $\mathrm{NH}_{3}$ and $\mathrm{NH}_{3}$ sorbed in the membrane. 
Figure 4.3-7

Effect of Test Cell Geometry on Membrane Performance

(PTMSP/PVAmSCN/PAN/HT)

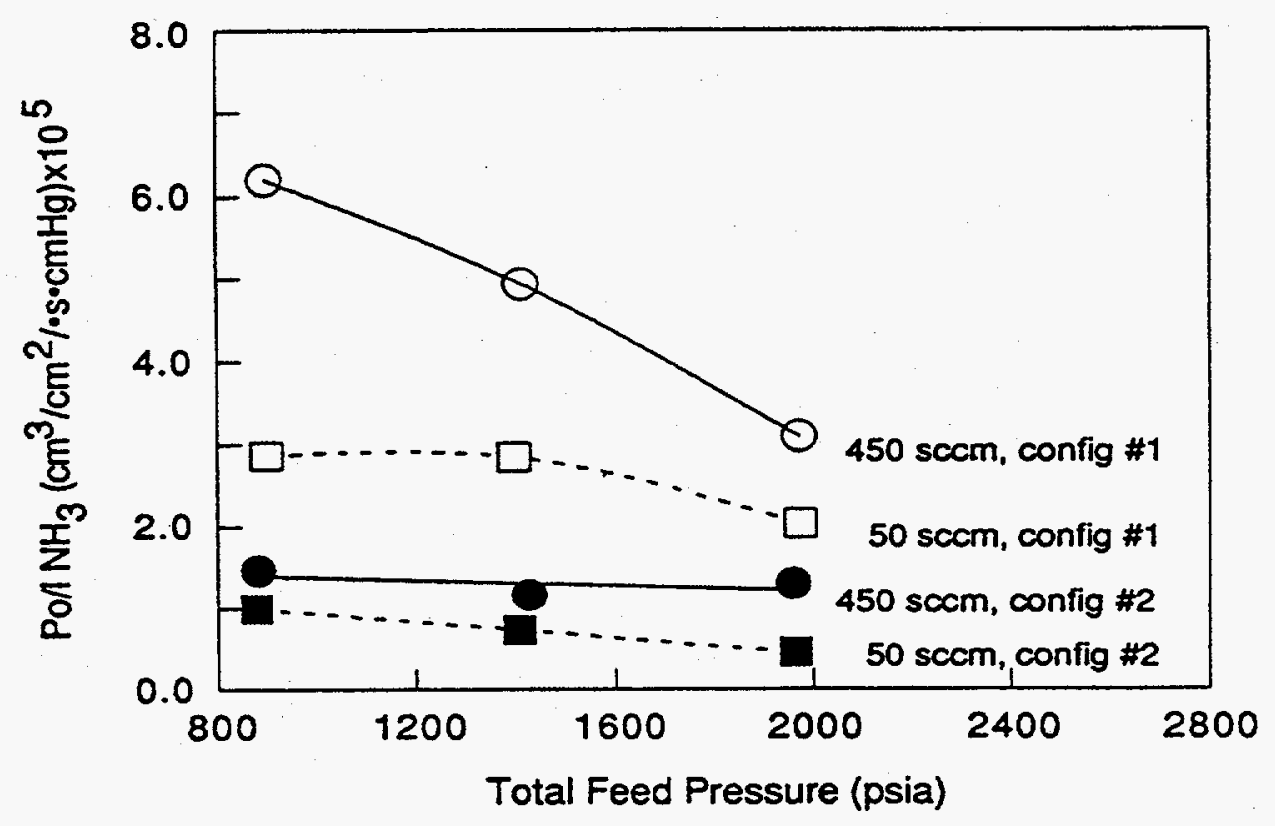

11786-63B, $T_{\text {mem }}=60^{\circ} \mathrm{C}, \mathrm{P}_{\mathrm{NH} 3}=55$ psia

Table 4.3-2

Evaluation of MLC Membranes at Process Conditions

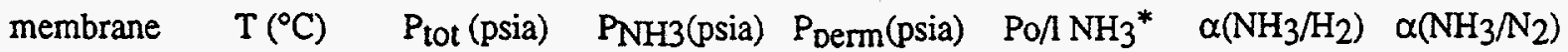

$\begin{array}{lrrrrrrr}11497-44 & 65 & 1928 & 55 & 53 & 6.9 & 449 & 696 \\ 11497-44 & 65 & 1938 & 145 & 55 & 2.9 & 76 & 250 \\ 11786-1 & 40 & 1984 & 105 & 19 & 8.8 & 127 & 379 \\ 11786-15 & 40 & 1973 & 105 & 44 & 10.2 & 251 & 689 \\ 11786-40 & 40 & 1998 & 125 & 42 & 16.1 & 777 & 4984 \\ 11786-40 & 60 & 1967 & 240 & 69 & 16.6 & 238 & 1000 \\ 11786-55 & 60 & 1710 & 125 & 68 & 2.9 & 69 & 346 \\ 11786-59 & 60 & 1695 & 240 & 105 & 0.5 & 14 & 26\end{array}$


In reviewing this data, one should bear in mind that it was collected before the concentration effects were fully appreciated. Therefore, one must be careful not to infer too much about the usefulness of these membranes (from an economic point of view) from this data. The results should be appreciated for what they actually indicate; that is, that the membranes are stable at elevated temperatures and extreme transmembrane pressures and exhibit reasonable permselectivity.

\subsubsection{Lifetime of MLC Membranes}

On-stream data for membranes tested in task 2 is summarized in the table below. Most membranes survived testing intact. In general, testing was terminated for reasons other than membrane failure, e.g., cooling bath failure, scheduled equipment or facilities maintenance. Onstream membrane evaluation represents 20 weeks of task 2 activities.

\begin{tabular}{ccl} 
Membrane Run \# & \multicolumn{1}{c}{ Time on Stream (davs) } & \multicolumn{1}{c}{ Comments } \\
\cline { 2 - 3 } $11497-36$ & 7 & ok \\
$11497-44$ & 19 & $\begin{array}{l}\text { ok but tore upon } \\
\text { depressurization }\end{array}$ \\
& & ok, exp. terminated to refill \\
$11497-73$ & 23 & NH3 supplv \\
& & formed a hole \\
$11497-92$ & 8 & ok \\
$11497-101$ & 9 & ok, some discoloration \\
$11786-1$ & 14 & cooling bath failure \\
$11786-15$ & 9 & ok \\
$11786-40$ & 15 & ok \\
$11786-55$ & 8 & ok \\
$11786-59 \mathrm{~B}$ & 8 & ok \\
$11786-63 \mathrm{~B}$ & 16 & \\
& Total= 136 hrs (19.5 weeks) &
\end{tabular}




\subsection{Summary/Status}

PTMSP/PVAmSCN/PAN/HT Multilayer Composite Membranes have been shown to be stable at the very high transmembrane pressures required by the process applications $(\mathrm{NH} 3$ synthesis plant). Feed gas flow rate and test cell orientation strongly effect the observed $\mathrm{NH}_{3}$ permeance and $\mathrm{NH}_{3} / \mathrm{H}_{2}$ and $\mathrm{NH}_{3} / \mathrm{N}_{2}$ selectivity of these membranes. These results indicate that concentration polarization plays a predominant role in limiting mass transfer of $\mathrm{NH}_{3}$ through these membranes at high feed pressures. This issue will need to be addressed in downstream fabrication of modules.

While membranes have been evaluated per the membrane test plan, some deviations were necessary to investigate the observed loss in $\mathrm{NH}_{3}$ flux (concentration polarization). Thus the last point in the test matrix was not completed. It will not be necessary to complete the test matrix before proceeding to task 3 (see section 5.3, planning). 


\subsection{Conclusions and Recommendations}

\subsection{Microencapsulation}

Air Products' "Active Transport" materials have been microencapsulated within a shell of the gas permeable polymer poly(trimethylsilylpropyne). Gas absorption studies demonstrate that the capsules selectively absorb $\mathrm{NH}_{3}$ and $\mathrm{CO}_{2}$ from gas streams and could, in principle, be used to perform a pressure- or temperature-swing absorption-based separation of these gases from mixtures with e.g., $\mathrm{N}_{2}, \mathrm{H}_{2}$ or $\mathrm{CH}_{4}$. For example, PTMSP-encapsulated $\mathrm{NH}_{4} \mathrm{SCN}$ had an $\mathrm{NH}_{3} / \mathrm{N}_{2}$ selectivity of 185 at $25^{\circ} \mathrm{C}$, and PTMSP-encapsulated TEAA $44 \mathrm{H}_{2} \mathrm{O}$ had a $\mathrm{CO}_{2} / \mathrm{N}_{2}$ selectivity of 43 at $50^{\circ} \mathrm{C}$. The selectivity will increase if higher payloads can be achieved. Most of the capsules fabricated were 100-500 $\mu \mathrm{m}$ in diameter - larger than the target 25-50 $\mu \mathrm{m}$ needed to fabricate practical gas separation membranes. Two runs produced capsules $30-50 \mu \mathrm{m}$ in diameter, however, they could not be harvested before they agglomerated into larger particles.

Recommendation:

No further experimental work is planned under this cooperative agreement. Air Products is actively pursuing patent protection on the fabrication and use of microencapsulated liquid absorbents for gas separation.

\subsection{MLC Membranes}

The multilayer composite (MLC) technique is viable for fabricating membranes which utilize Air Products' proprietary AT CO 2 -selective materials. Carbon dioxide permeance of $0.2 \times 10^{-5}$ $\mathrm{cm} 3 / \mathrm{cm}^{2} \cdot \mathrm{s} \cdot \mathrm{cmHg}$ and $\mathrm{CO}_{2} / \mathrm{H}_{2}$ selectivity of 80 were observed for laboratory flat sheet membranes. A 10 -fold decrease in AT layer thickness is required for these membranes to compete effectively with alternate $\mathrm{CO}_{2}$ removal technologies. The MLC design was proven to be stable for up to 3 weeks of continuous operation.

Recommendation:

Air Products recommends further testing of $\mathrm{CO}_{2}$-selective MLCs under end-use conditions. This work will be done in part under the cooperative agreement and in part under an Air Products'-funded materials development program. Air Products further recommends that fabrication of lab-scale membrane modules proceed on schedule as outlined in section 5.3. 
Ammonia-selective MLC membranes were fabricated and evaluated under end-use conditions. The MLC design is able to withstand the high transmembrane pressure ( 2000 psi) required in Air Products' membrane-based process for recovering $\mathrm{NH}_{3}$ from the ammonia synthesis process. Concentration polarization effects were observed in membranes tested under high pressure. These effects should be considered in future module designs. The MLC membranes were demonstrated to be stable for up to 3 weeks of continuous operation.

Recommendation:

Air Products recommends that fabrication of lab-scale membrane modules proceed on schedule as outlined in section 5.3.

\subsection{Third Year Planning}

Based on promising results from the first and second budget periods we recommend the following action plan for the third budget period of this cooperative agreement.

1) Synthesize sufficient quantities of Air Products AT materials to fabricate lab-scale membrane modules. We estimate approximately $500 \mathrm{~g}$ each of PTMSP, PVAmSCN, PDMS and DADMAF will be needed for work during the third budget year.

2) Modify membrane test equipment to accommodate lab-scale modules (e.g. changeout mass flow controller valves, increase scrubber capacity etc)

3) Identify and contract with a suitable fabrication partner to fabricate lab-scale spiral wound modules.

4) Measure permselectivity and lifetimes of lab-scale membrane modules under process conditions.

Task planning for the third budget period of this program is shown in Figure 5.3-1. 


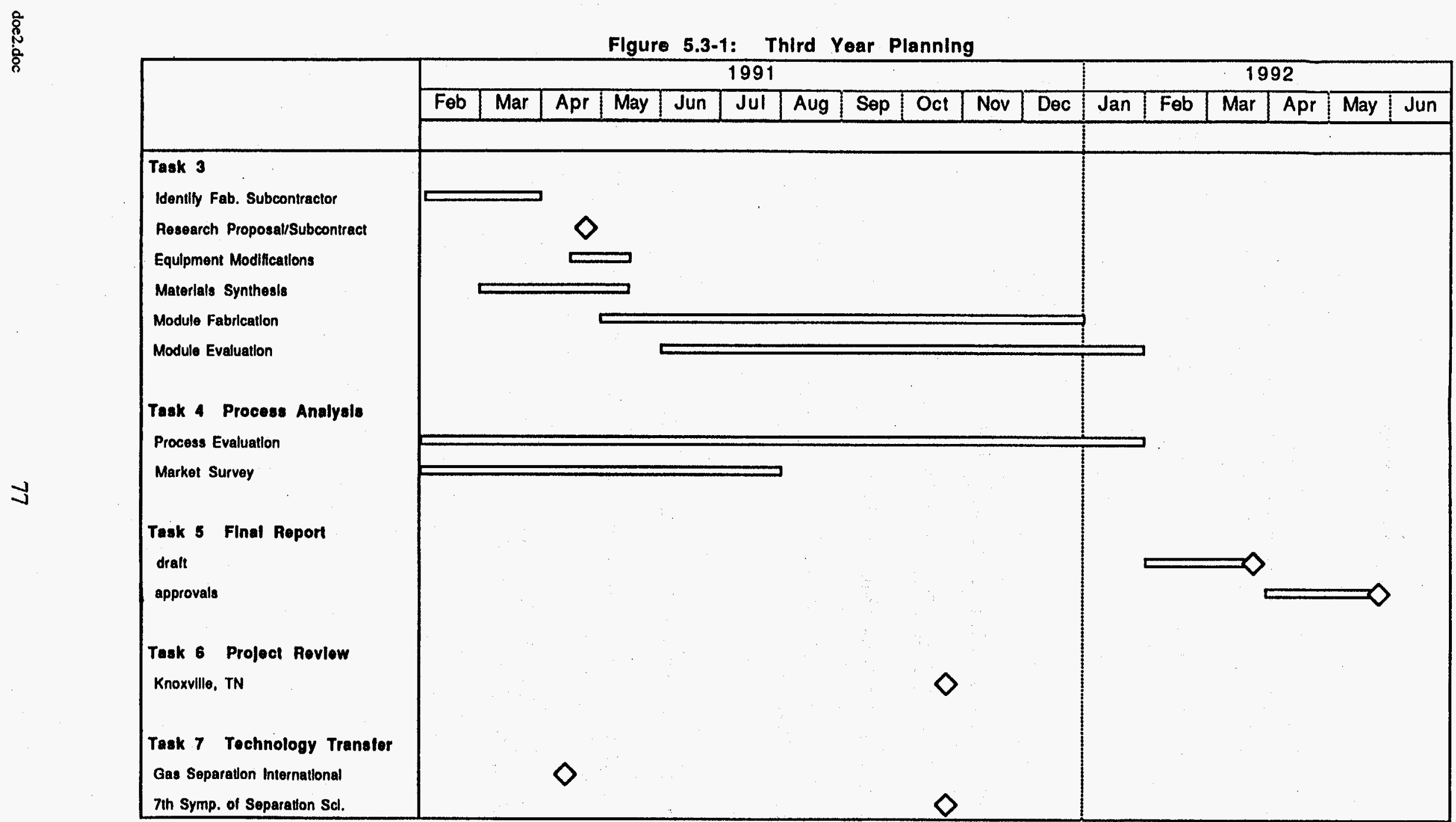




\subsection{References}

1. Air Products and Chemicals, Inc., Technical Proposal to the United States Department of Energy, Office of Industrial Programs for "Development of Novel Active-Transport Membrane Devices," September 1987, p. 42.

2. D. V. Laciak, "Development of Novel Active Transport Membrane Devices," Interim Report, February 1990, p. 117.

3. Ibid., p. 149.

4. Ibid., p.119.

5. M. Langsam et al., Gas Separation and Purification, 2 , (1988), p. 162.

6. S.T. Hwang et al., Sep.Sci. and Tech. 2, (1979), p. 461.

7. Hayaishi et al., U.S. Pat. No. 4384017 (1983).

8. D. V. Laciak, "Development of Novel Active-Transport Membrane Devices," Interim Report, February 1990, p. 61.

9. Ibid., p.135.

10. D. W. Brubaker and K. Kammermeyer, Ind.Ind.Chem., 46, (1954), p. 733.

11. D. V. Laciak, "Development of Novel Active Transport Membrane Devices," Interim Report, February 1990, p. 63.

12. R. Quinn, D. V. Laciak et al, "Polyelectrolyte Membranes for the Separation of Acid Gases," U.S. Pat. No. 5,336,298 (1994) 


\subsection{Appendix}

Summary of NH3-Selective MLC Test Runs

This Appendix contains the experimental parameters used during the evaluation of $\mathrm{NH}_{3}-$ selective MLC membranes. It also contains the detailed results from each test. The material is arranged in spreadsheet form by membrane number. 


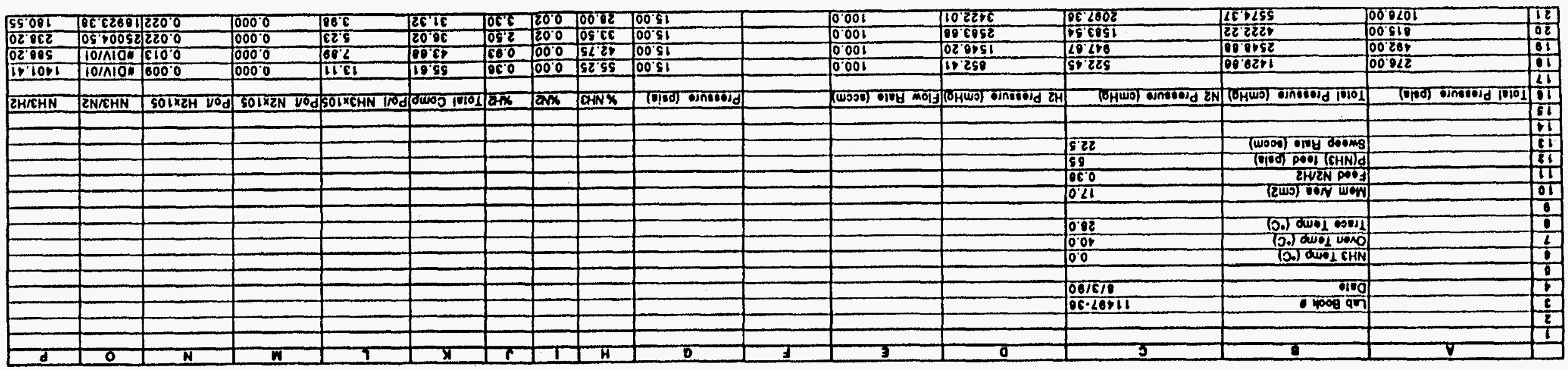

9c-Lor11 


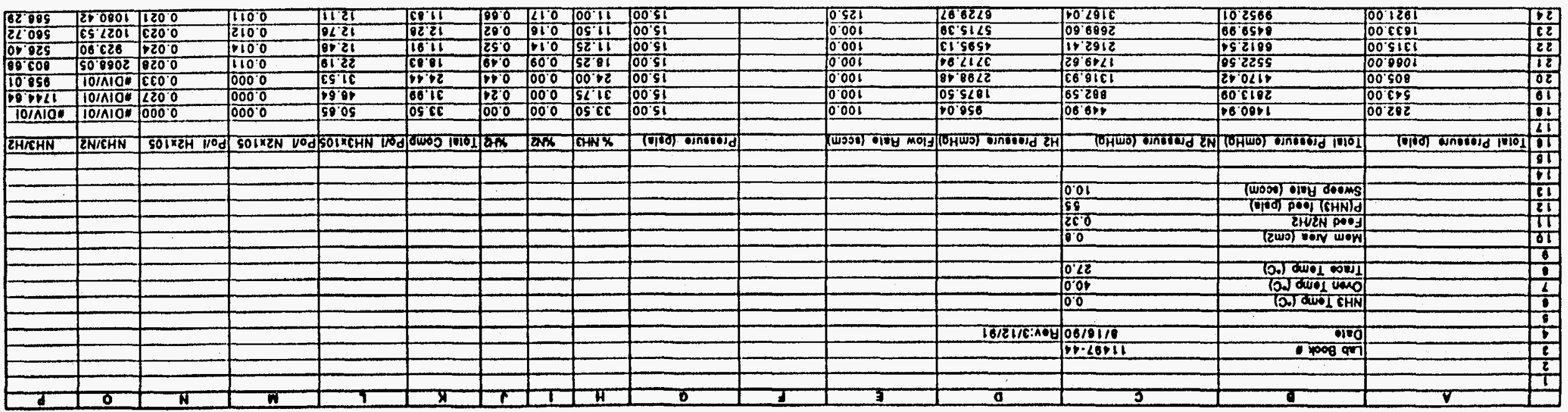

1.pr-20111 


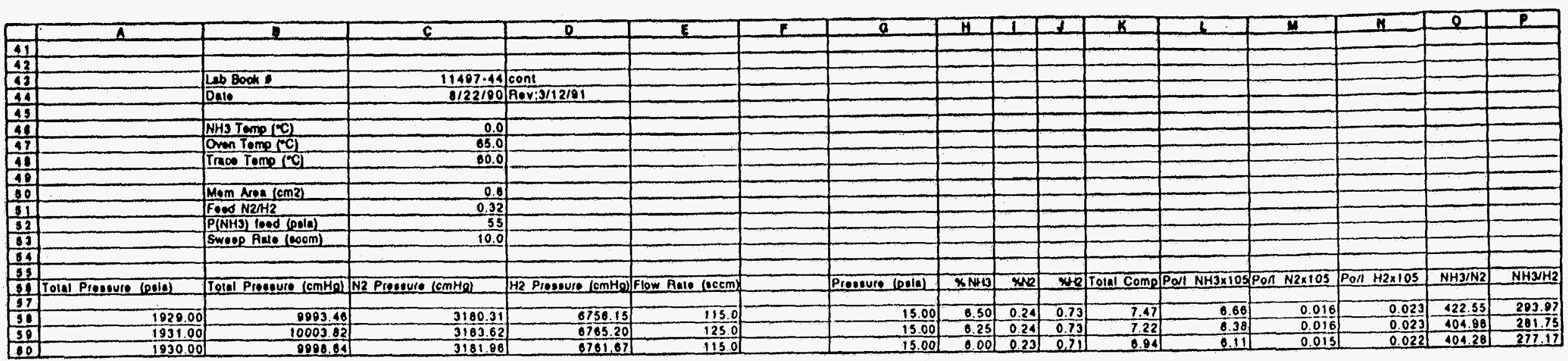




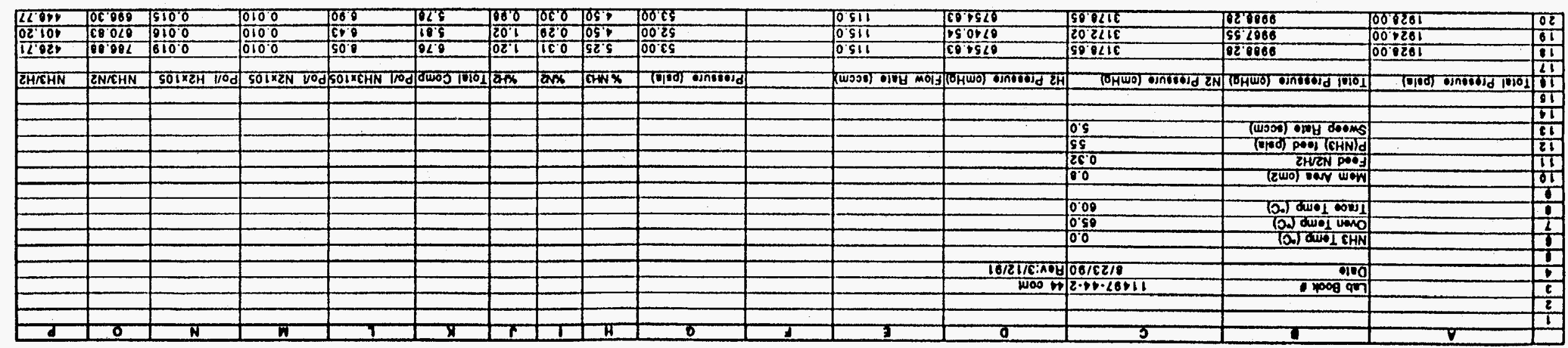




\begin{tabular}{|c|c|c|c|c|c|c|c|c|c|c|c|c|c|c|c|c|}
\hline & 1 & $E$ & c & D & $E$ & $f$ & $a$ & H & 1 & 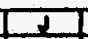 & $\bar{K}$ & L & III & $\bar{N}$ & 0 & P \\
\hline \multicolumn{17}{|c|}{49} \\
\hline \multicolumn{17}{|l|}{41} \\
\hline$\frac{78}{43}$ & & Lat Book & $11407-44.2$ & oont & & & & & & & & & & & & \\
\hline 14 & & Date & 0124100 & A०V:3/12/91 & & & & & & & & & & & & \\
\hline \multicolumn{17}{|c|}{ 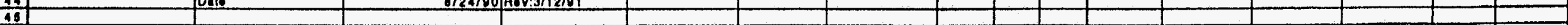 } \\
\hline 41 & & NH3 Temp (C) & 25.0 & & & & & & & & & & & & & \\
\hline 67 & & Oven Tomp (C) & $\frac{-5.0 .0}{05.0}$ & & & & & & & & & & & & & \\
\hline 40 & & Trea Teme (C) & 60.0 & & & & & & & & & & & & & \\
\hline \multicolumn{17}{|c|}{ 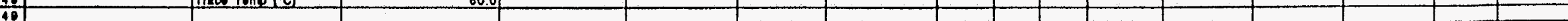 } \\
\hline 60 & & Mem Ave (cm2) & 0.0 & & & & & & & & & & & & & \\
\hline 11 & & FoOd N $2 / 12$ & 0.32 & & & & & & & & & & & & & \\
\hline 63 & & Swoep Ante (coom) & 5.0 & & & & & & & & & & & & & \\
\hline \multirow{2}{*}{\multicolumn{17}{|c|}{94}} \\
\hline II & & & & & & & & & & & & & & & & \\
\hline 81 & 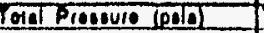 & Tolel propoun Tom Hal & N2 Ploneule $(\mathrm{cmH}$ & F2 Plogeure (om $\mathrm{Ha}$ & Plow Rolo locom & & Proneule (psia) & $8 \mathrm{NH}$ & क्र० & क्ष० & Toill Comp & pol $\mathrm{NH} 3 \times 103$ & Po/1 $\mathrm{N} 2 \times 103$ & Poll $142 \times 105$ & NHJ/N2 & NMT/H2 \\
\hline 37 & & & & & & & & & & & & & & & & \\
\hline 80 & 1003.00 & 0800.12 & 3111.72 & 6012.40 & 225.0 & & 53.00 & 0.00 & 0.11 & 2.80 & $\pi 1.00$ & 1.00 & 0.014 & 0.043 & 120.05 & 30.23 \\
\hline$B 0$ & 1038.00 & 10040.08 & 3108.43 & 8728.06 & 200.0 & & 35.00 & 12.60 & 0.33 & 2.10 & 15.35 & 2.00 & 0.012 & 0.036 & 250.73 & 70.23 \\
\hline 10 & 316.00 & 103700 & 177.47 & 1011.82 & 200.0 & & 19.00 & 46.00 & 15.00 & 3700 & 90.00 & 14.04 & 4.181 & 0.93 & 3.35 & 2.16 \\
\hline
\end{tabular}




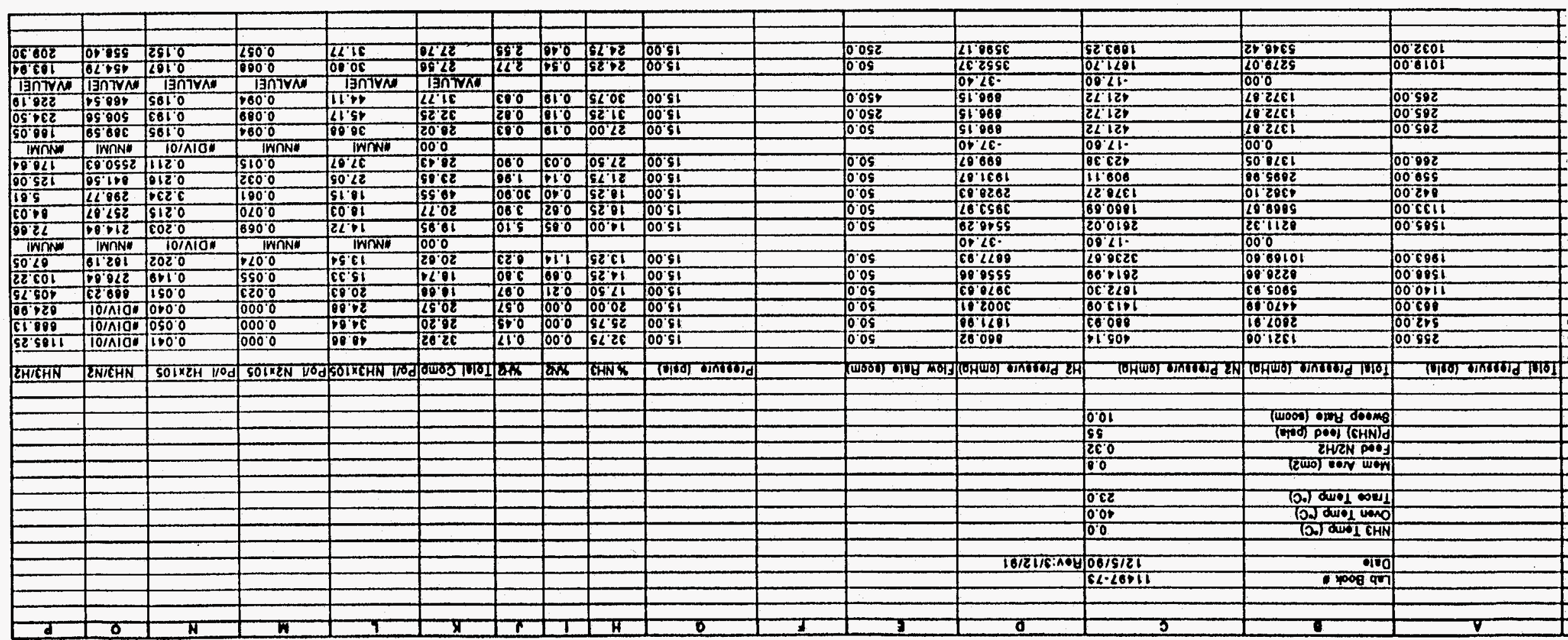




\begin{tabular}{|c|c|c|c|c|c|c|c|c|c|c|c|c|c|c|c|c|}
\hline & a & D & c & D & $E$ & $F$ & $a$ & $\mathrm{H}$ & 1 & L & K & $t$ & III & $\mathbf{H}$ & 9 & $p$ \\
\hline$\frac{91}{12}$ & & & & & & & & & & & & & & & & \\
\hline 43 & & Lot Book & 11407.73 & & & & & & & & & & & & & \\
\hline 44 & & D.10 & $12 / 5100$ & Rov:3/12/01 & & & & & & & & & & & {[} & \\
\hline 49 & & & & & & & & & & & & & & & & \\
\hline 41 & & $\mathrm{NH} 3$ Tomp $(\mathrm{C})$ & 0.0 & & & & & & & & & & & & & \\
\hline 47 & & Oven Tomp $\left({ }^{\circ} \mathrm{C}\right)$ & 40.0 & & & & & & & & & & & & & \\
\hline 41 & & Tleas Tomp ( $\left.{ }^{\circ} \mathrm{C}\right)$ & 23.0 & & & & & & & & & & & & & \\
\hline 40 & & & & & & & & & & & & & & & & \\
\hline ef & & Mom Not $(0 m 2)$ & 0.6 & & & & & & & & & & & & & \\
\hline$\frac{31}{12}$ & & Food N2M2 & 0.32 & & & & & & & & & & & & & \\
\hline$\frac{22}{83}$ & & $P(N H 3)$ loed (eale) & 55 & & & & & & & & & & & & & \\
\hline 33 & & Swoep Aate (coom) & 10.0 & & & & & & & & & & & & & \\
\hline 14 & - & (2) & 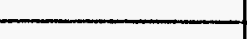 & > & 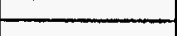 & & & & $-m_{-1}$ & & $+\infty$ & & & & & \\
\hline il & Iolal Pienever feelel & Iolal Praflure lomHol & N2 Pienente lom $\mathrm{Hol}$ & H2 Pleneure (omHo) & Flow fale $(000 \mathrm{~cm})$ & & 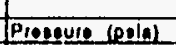 & $\mathrm{XNH3}$ & $x \times 2$ & $x+0$ & Iolal Comp & Poll NH3xios & Pon $2 \times 105$ & Poll H2x105 & NH3IN2 & $\mathrm{NH} / \mathrm{H} 2$ \\
\hline$\frac{37}{38}$ & 107800 & & & & & & & & & & & & & & & \\
\hline$\frac{36}{30}$ & $\frac{1010.00}{180000}$ & $\frac{8693.12}{8755.20}$ & $\frac{2764.20}{27409}$ & $\frac{5873.92}{591810}$ & 50.0 & & $\frac{15.00}{1.00}$ & $\frac{14.73}{2.07}$ & 0.50 & 3.70 & 20.95 & 15.66 & 0.030 & 0.215 & -413.12 & $-72.0 \mathrm{9}$ \\
\hline 60 & 1095.00 & 8901.10 & $\frac{2106.08}{2792.38}$ & $\frac{5910.19}{5833.61}$ & $\frac{250.0}{4500}$ & & $\frac{15.00}{1500}$ & $\frac{24.25}{2700}$ & $\frac{0.45}{0.50}$ & $\frac{4.40}{500}$ & $\frac{29.10}{32.50}$ & $\frac{30.29}{34.97}$ & $\frac{0.034}{0.038}$ & $\frac{0.162}{0.85}$ & $\frac{995.12}{932.32}$ & $\frac{106.79}{10000}$ \\
\hline i1 & & 0.00 & .17 .60 & .37 .40 & & & & & & & $\frac{0.00}{0.0}$ & NUMI & NNUMI & BNUMI & NUMI & NUMI \\
\hline
\end{tabular}




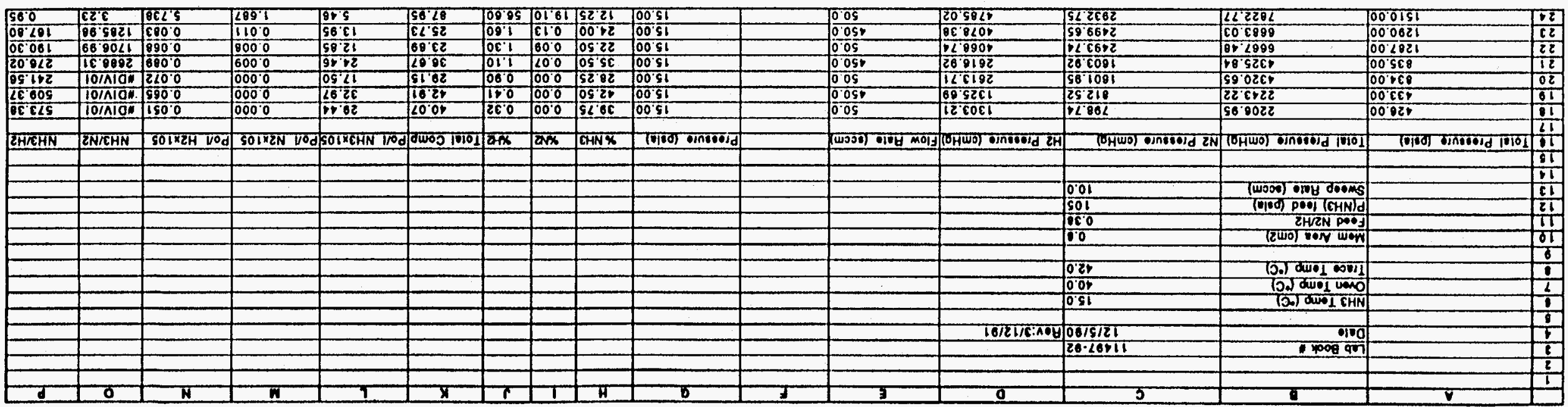




\begin{tabular}{|c|c|c|c|c|c|c|c|c|c|c|c|c|c|c|c|c|}
\hline & 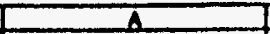 & $\mathbf{n}$ & c & $D$ & $F$ & $\boldsymbol{F}$ & a & $\mathrm{H}$ & 1 & J & $\bar{K}$ & $h$ & $M$ & H & 0 & $\mathbf{P}$ \\
\hline 1 & & & & & & & & & & & & & & & & \\
\hline 2 & & & & & & & & & & & & & & & & \\
\hline 3 & & Lab book & 11497.101 & & & & & & & & & & & & & \\
\hline 3 & & Dalo & $12 / 3100$ & Rer:3/12/O1 & & & & & & & & & & & & \\
\hline 6 & & & & & & & & & & & & & & & & \\
\hline I & & $\mathrm{NH} 3 \mathrm{Tem}(\mathrm{CO})$ & 15.0 & & & & & & & & & & & & & \\
\hline 7 & & Owen Tomp (C) & 40.0 & & & & & & & & & & & & & \\
\hline e & & Ireas Teme $\left({ }^{(0)}\right.$ & 42.0 & & & & & & & & & & & & & \\
\hline 2 & & & & & & & & & & & & & & & & \\
\hline 10 & & Mom Are $(\mathrm{cm} 2)$ & 0.8 & & & & & & & & & & & & & \\
\hline$[1$ & & Foed N2M & 0.38 & & & & & & & & & & & & & \\
\hline 12 & & P(NH3) food (pola) & 105 & & & & & & & & & & & & & \\
\hline 13 & & Swoep Anto (cecm) & 10.0 & & & & & & & & & & & & & \\
\hline 14 & & & & & & & & & & & & & & & & \\
\hline$\frac{16}{18}$ & 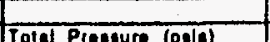 & Trol Pron & & AP. Prochure (om Hol & Flow Aal $(100 \mathrm{~m})$ & & Pienevie (ota) & KNHS & & $x+?$ & & & PON N2x105 & Pof H $2 \times 105$ & NH3/N2 & $\mathrm{NH3/H2}$ \\
\hline$\frac{11}{17}$ & 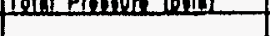 & 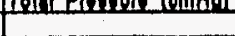 & 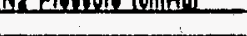 & & & & & & & & & & & & & \\
\hline i1 & 417.00 & 2100.33 & 761.02 & 1274.30 & 50.0 & & 15.00 & 32.75 & 0.00 & 0.07 & 32.02 & 21.75 & 0.000 & 0.011 & Rolviol & 1098.12 \\
\hline 10 & 420.00 & 2206.95 & 700.74 & 1303.21 & 450.0 & & 15.00 & 35.73 & 0.00 & 0.00 & 33.03 & 24.05 & 0.000 & 0.013 & DoIVIoI & 1041.48 \\
\hline 30 & 820.00 & 4270.21 & 1686.20 & 2580.01 & 30.0 & & 15.00 & 10.25 & 0.00 & 0.24 & 18.49 & 0.05 & 0.000 & 0.010 & Holviol & 513.75 \\
\hline 21 & 030.00 & 4200.03 & 1504.07 & 2000.00 & 450.0 & & 15.00 & 10.25 & 0.00 & 0.27 & 10.32 & 10.03 & 0.000 & 0.022 & nolviol & 400.05 \\
\hline 22 & 1241.00 & 6420.18 & 2403.10 & 3920.09 & 50.0 & & 15.00 & 14.00 & 0.00 & 0.31 & 14.31 & 7.25 & 0.000 & 0.017 & Tholvol & 430.47 \\
\hline 23 & 1220.00 & 6320.38 & 2361.05 & 3053.54 & 450.0 & & 15.00 & 15.25 & 0.00 & 0.34 & 15.30 & 6.01 & 0.000 & 0.016 & 1001V/01 & 034.15 \\
\hline
\end{tabular}




\begin{tabular}{|c|c|c|c|c|c|c|c|c|c|c|c|c|c|c|c|c|}
\hline & $\Lambda$ & D & द & D & $E$ & $F$ & $a$ & H & $I$ & 1 & I & $I$ & $\mu$ & N & e & $P$ \\
\hline$\frac{1}{3}$ & & & & & & & & & & & & & & & & \\
\hline 2 & & Lob Book & 11780.1 & & & & & & & & & & & & & \\
\hline 4 & & Dele & 1215100 & Rov:3/12/01 & & & & & & & & & & & & \\
\hline 3 & & & & & & & & & & & & & & & & \\
\hline$\frac{1}{1}$ & & 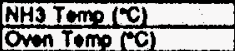 & $\frac{15.0}{100}$ & & & & & & & & & & & & & \\
\hline 0 & & Treos Tome (C) & 42.0 & & & & & & & & & & & & & \\
\hline 9 & & & & & & & & & & & & & & & & \\
\hline 10 & & Mam Aro $(\mathrm{cm} 2)$ & 0.0 & & & & & & & & & & & & & \\
\hline 11 & & Foed N2N12 & 0.30 & & & & & & & & & & & & & \\
\hline 12 & & P(NH3) loed (pole) & 105 & & & & & & & & & & & & & \\
\hline 12 & & Swoop Aete (coom) & 10.0 & & & & & & & & & & & & & \\
\hline 14 & & & & & & & & & & & & & & & & \\
\hline$\frac{10}{10}$ & & & & & & & & & & & & & & & & \\
\hline$\frac{11}{17}$ & Tolal Pieneure belol & Tolel Prenere lom & N2 Propeune (omHol & H2 Prosure compal & Fow Aale $10 \mathrm{ccm}$ & & Prosoune (pela) & S.NH3 & xue & xका & Tplal comp & Pol NH32109 & Pon N2×105 & Pon H2K105 & NH3/N2 & NH3MNR \\
\hline 10 & 1103.00 & 0025.09 & 2210.03 & 3670.45 & 50.0 & & 22.00 & 27.50 & 008 & 1.00 & 28.39 & 18.10 & 0.008 & 0.057 & 2180.00 & 316.90 \\
\hline 10 & 1128.00 & 5813.70 & 2180.73 & 3558.03 & $\frac{50.0}{50.0}$ & & $\frac{22.00}{18.00}$ & $\frac{21.30}{20.25}$ & $\frac{0.08}{0.13}$ & $\frac{1.00}{0.03}$ & $\frac{20.04}{21.31}$ & $\frac{1.90}{11.62}$ & 0.012 & $\frac{0.091}{0.055}$ & $\frac{210.09}{033.95}$ & 211.11 \\
\hline 20 & 1141.00 & 5011.11 & 2206.32 & 3508.70 & 450.0 & & 20.00 & 25.25 & 0.13 & 1.24 & 26.62 & 15.70 & 0.012 & 0.073 & 1284.34 & 217.01 \\
\hline 21 & 1640.00 & 0496.25 & 3108.68 & 5202.50 & 50.0 & & 18.00 & 16.00 & 0.17 & 1.19 & 17.38 & 8.66 & 0.011 & 0.048 & 770.49 & 170.43 \\
\hline 22 & 1045.00 & 8522.15 & 3198.52 & 5218.64 & 450.0 & & 21.00 & 21.25 & 0.10 & 1.58 & 23.02 & 12.67 & 0.012 & 0.004 & 1021.04 & 107.40 \\
\hline 23 & 1060.00 & 10154.08 & 3810.04 & 0230.41 & 50.0 & & 10.00 & 10.75 & 0.44 & 1.73 & 12.02 & 5.28 & 0.024 & 0.050 & 218.94 & 00.30 \\
\hline 24 & 1004.00 & 10270.39 & 3865.69 & 6307.50 & 450.0 & & 18.00 & 16.25 & 0.43 & 2.08 & 10.74 & 0.81 & 0.023 & 0.070 & 378.51 & 126.68 \\
\hline 29 & 1001.00 & 10150.24 & 3820.61 & 6233.63 & 50.0 & & 46.00 & 7.75 & 0.44 & 1.47 & 0.68 & 4.98 & 0.024 & 0.050 & 205.20 & 98.02 \\
\hline 26 & 1985.00 & 10283.57 & 3867.86 & 6310.71 & 450.0 & & 48.00 & 10.50 & 0.48 & 2.07 & 13.05 & 7.11 & 0.026 & 0.070 & 272.94 & 101.22 \\
\hline
\end{tabular}




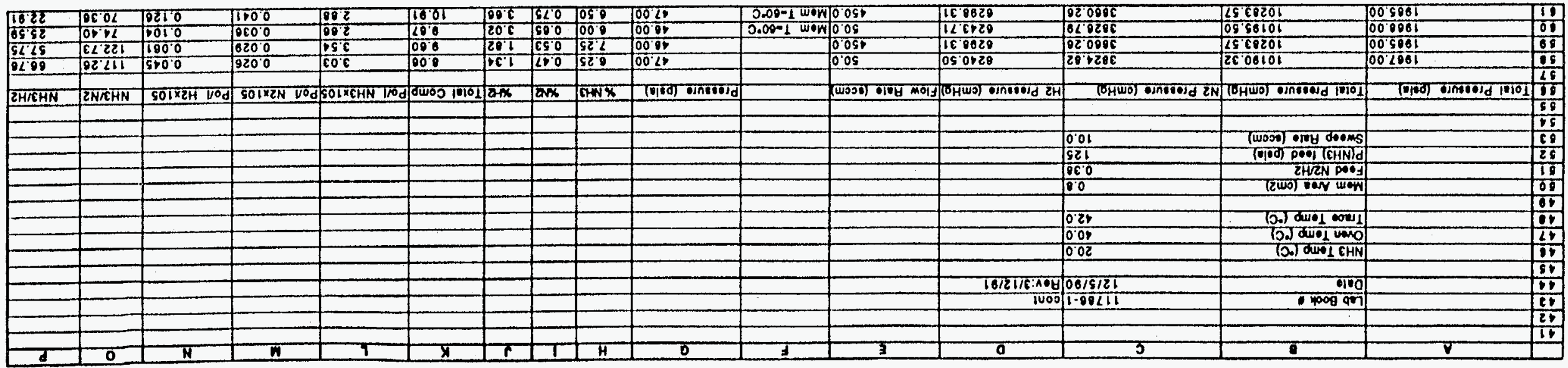




\begin{tabular}{|c|c|c|c|c|c|c|c|c|c|c|c|c|c|c|c|c|}
\hline & $\Lambda$ & & & 0 & & $F$ & 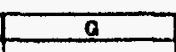 & $\mathrm{H}$ & 1 & a & $\mathrm{k}$ & 1 & II & $\mathrm{N}$ & 0 & $P$ \\
\hline$\frac{1}{2}$ & & & & & & & & & & & & & & & & \\
\hline$\frac{8}{3}$ & & Lob book : & $11786-15$ & & & & & & - & - & & & & & & \\
\hline$\frac{4}{8}$ & & Dane & 12117100 & Aev:3/12/91 & & & & & & & & & & & & \\
\hline$\frac{1}{7}$ & & NHJTeme & 15.0 & & & & & & & & & & & & & \\
\hline$\frac{1}{6}$ & 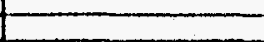 & 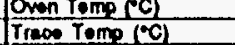 & $\frac{40.0}{42.0}$ & & & & & & & & & & & & & \\
\hline$\frac{8}{10}$ & 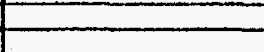 & Mom Aoed (cm²) & r & 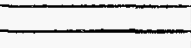 & {[} & & . & & & & & & & & & \\
\hline$\frac{11}{11}$ & & Food N2N2 & $=\frac{0.32}{0.32}$ & $\mathrm{c}_{-1}$ & 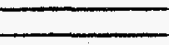 & & & & - & & & & & & & \\
\hline$\frac{12}{13}$ & & 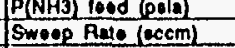 & $\frac{105}{10.0}$ & & & & & & - & 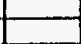 & & & & & & \\
\hline & & & & & & & & & & & & & & & & \\
\hline 11 & 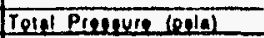 & Iolal Prequere (omHo) & N32 Ponsure lem Hol & 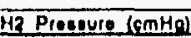 & Flow Aalo $600 \mathrm{~m}$ & & 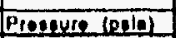 & $x$ xp+10 & $\sqrt{x \times 8}$ & $x+3$ & Ipell cemp & Po/ NH $N \times 10$ & Pon N2n105 & Poll H2*105 & $\mathrm{NH} 3 \mathrm{iN2}$ & $\mathrm{NH} / 3 / \mathrm{Hz}$ \\
\hline 18 & 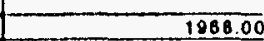 & 10195.50 & 3228.96 & 6861.54 & -50.0 & & 18.00 & 12.50 & 0.17 & 0.03 & 13.50 & 6.37 & 0.011 & 0.02 & 579.59 & 250.40 \\
\hline 20 & $\frac{1808.00}{109000}$ & -8786.37 & $\frac{2778.04}{3109.12}$ & 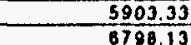 & $\frac{450 .}{500}$ & & 18.00 & $\frac{19.25}{10.50}$ & $\frac{0.10}{0.21}$ & \begin{tabular}{|l}
1.42 \\
0.92 \\
\end{tabular} & & $\frac{10.85}{703}$ & $\frac{0.01}{0.014}$ & $\frac{0.05}{0.02}$ & \begin{tabular}{|l|l|}
759.51 \\
512.58 \\
\end{tabular} & $\frac{213.13}{268.53}$ \\
\hline 21 & 1973.00 & 10221.40 & 3237.25 & 8878.15 & 4500 & & 76.00 & 14.25 & 0.23 & $\frac{.1 .32}{1.32}$ & 15.80 & 10.23 & 0.015 & 0.04 & 686.93 & 251.06 \\
\hline & 1940.00 & 10050.44 & 3182.54 & 6762.80 & 500 & & 1000 & 1125 & 023 & & & 7.50 & & 0.02 & 498.1 & 354.85 \\
\hline
\end{tabular}




\begin{tabular}{|c|c|c|c|c|c|c|c|c|c|c|c|c|c|c|c|c|}
\hline 5,600 & 10/AlOan & 5000 & 0000 & 0.1 & 280 & 260 & & & 0025 & & 0.05 & $20 \cdot 1620$ & & & 100.5886 & $<2$ \\
\hline & $60+16$ & $\frac{9100}{120.0}$ & 2200 & 9021 & 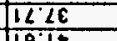 & 980 & & SLSE & $\frac{0.16}{0.06}$ & & 0.058 & 98.868 & $08 \mathrm{CBOE}$ & $\frac{5.501}{2+c 01}$ & 00.2861 & \\
\hline$\frac{10246}{9206}$ & 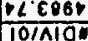 & $\frac{1200}{2000}$ & $\frac{1000}{10000}$ & $\frac{5001}{060}$ & $\frac{18.18}{182}$ & $\frac{121}{110}$ & $\frac{210}{000}$ & $\frac{5201}{052}$ & $\frac{0.26}{00.56}$ & & $\frac{0.05 t}{0.059}$ & 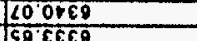 & $\frac{569096}{50.1896}$ & $28.05 \mathrm{~s} 01$ & 00.8686 & \\
\hline$\frac{20}{10 / n 100}$ & $\frac{\mid 0 / 0 / 10 x}{10 / 10 x}$ & $\frac{200 \%}{000 \%}$ & 0000 & 820 & & 000 & $\frac{1000}{1000}$ & & $\begin{array}{ll}0.68 \\
0.68\end{array}$ & & $\frac{0.05 p}{0.05}$ & $\frac{59 \operatorname{cccc} \theta}{00^{2}+120}$ & $\frac{10.189 \varepsilon}{20.608 \varepsilon}$ & 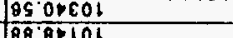 & 100.9686 & 52 \\
\hline 0,215 & 10/410a & 8100 & 0000 & 128 & 50 PE & 501 & 000 & $00 \mathrm{CC}$ & 0001 & & 0.05 & $00^{2}+128$ & $\frac{10008}{200086}$ & $\frac{18.8+101}{89.8+101}$ & 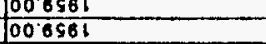 & $\frac{62}{22} \mid$ \\
\hline & & & 5000 & 1000 & 58.1 & 000 & 1010 & & 然 & & 0.09 & 050228 & 20.806 & 2506101 & $100<2881$ & \\
\hline$\frac{0<101}{60}$ & $10 / 104$ & $9 \frac{900}{9100}$ & 0000 & $66 \%$ & $2<9$ & 680 & 1000 & $\frac{s<5 r}{s-5 t}$ & $\frac{0025}{0.13}$ & & 00 os & $59 \mathrm{cEc \theta}$ & 10.1886 & gs:orcol & 00.9661 & 02 \\
\hline 06225 & 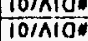 & $\frac{9100}{2100}$ & 0000 & $\frac{108}{80.8}$ & $\frac{120}{10.06}$ & $\frac{960}{10.6}$ & $\frac{100}{000}$ & $\frac{525}{00.26}$ & 00.61 & & $\frac{0.057}{0.05}$ & 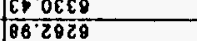 & $\frac{16.686}{0.9685}$ & 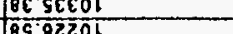 & 然 & 61 \\
\hline & & & & & & & & & & & & & & & & \\
\hline EMACHN & ENAHN & $501 \times 2 \mathrm{H}$ Hod & SOIYEN Vod & 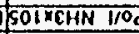 & dwoog 11101 & क्ष & $a \sqrt{x}$ & EN $x$ & (niso) onterole & & 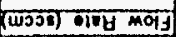 & 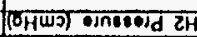 & 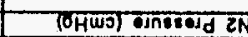 & 60 & 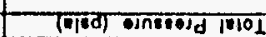 & î \\
\hline & & & & & & & & & & & & & & & & \\
\hline & & & & & & & & & & & & & $\log$ & (w050) & & \\
\hline & & & & & & & & & & & & & sit & Toud poo (chN/) & & $\frac{11}{11}$ \\
\hline & & & & & & & & & & & & & $\frac{100}{860}$ & 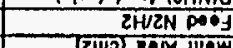 & & III \\
\hline & & & & & & & & & & & & & 00 & $(2 \omega s)$ wor wow & & \\
\hline & & & & & & 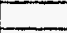 & & & & & & & O. It & & & 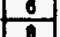 \\
\hline & & & & & & & & & & & & & 000 & 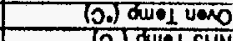 & & \\
\hline & & & & & & & & & & & & & & & & \\
\hline & & & & & & & & & & & & 10/21/K:AOH & $10 / 61 / 1$ & & & $\because$ \\
\hline & & & & & & & & & & & & & $0 r \cdot 00261$ & 100099 & & \\
\hline & & & & & & & & & & & & & & & & \\
\hline d & $\boldsymbol{\gamma}$ & 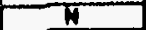 & $\overline{\boldsymbol{T}}$ & 1 & $\bar{X}$ & 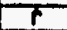 & $T$ & $\mathrm{H}$ & 5 & & & व & & & & \\
\hline
\end{tabular}




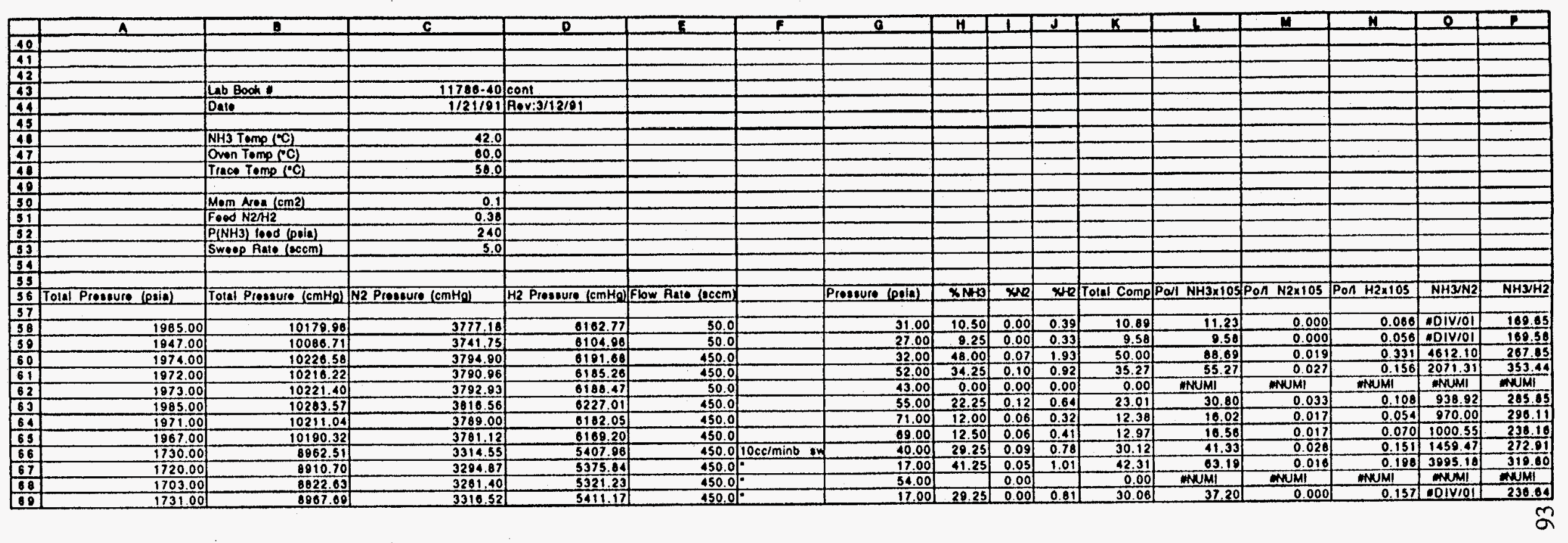




\begin{tabular}{|c|c|c|c|c|c|c|c|c|c|c|c|c|c|c|c|c|}
\hline & $A$ & B & $\mathcal{E}$ & $D$ & $E$ & $F$ & $a$ & $\mathrm{H}$ & 1 & 5 & $\mathbf{K}$ & I & $\bar{M}$ & 도 & 0 & I \\
\hline 1 & & & & & & & & & & & & & & & & \\
\hline$\frac{1}{2}$ & & & & & & & & & & & & & & & & \\
\hline 3 & & Lab book : & $11706-55$ & & & & & & & & & & & & & \\
\hline 4 & & Dalo & $1 / 20101$ & & & & & & & & & & & & & \\
\hline 3 & & & & & & & & & & & & & & & & \\
\hline E & & NH3 Temp $\int^{\circ} \mathrm{Cl}$ & 20.0 & & & & & & & & & & & & & \\
\hline 7 & & Doon Tomp ( 10 C) & 60.0 & & & & & & & & & & & & & \\
\hline 8 & & Trase Tomp $\left({ }^{\circ} \mathrm{C}\right)$ & 84.0 & & & & & & & & & & & & & \\
\hline 2 & & & & & & & & & & & & & & & & \\
\hline 10 & & Mem Aros (cm2) & 0.0 & & & & & & & & & & & & & \\
\hline 11 & & Food N2/H2 & 0.36 & & & & & & & & & & & & & \\
\hline 12 & & $P(N H 3)$ lood (pia) & 125 & & & & & & & & & & & & & \\
\hline 13 & & Swoep Aale $(\mathrm{lecm})$ & 3.0 & & & & & $m$ & $\ldots$ & & & & & & & \\
\hline 14 & & & & & & & & & & & - & & & & & \\
\hline 15 & & & & & & & & & & & & & & To & (19) & (1) \\
\hline 18 & Tolal Proseure (polia) & Tolal Prossure $(\mathrm{cmH}$ ) & N2 Propoure $(\mathrm{cmH}$ - & H2 Prossure $(\mathrm{emHo}$ & Flow Rate $(10 \mathrm{~cm})$ & & Propgure loglal & XN+D & $x \times 2$ & $x+2$ & Tolal comp & Poll NH3 $\times 105$ & Pon N2x10S & Pon H2×105 & NH3/N2 & $\mathrm{NH} 3 / \mathrm{H} 2$ \\
\hline$\frac{17}{18}$ & 172000 & 8910.70 & 3162.05 & 582285 & 4500 & & 10.00 & 28.00 & 0.23 & 3.98 & 32.21 & 7.15 & 0.000 & 0.077 & 041.01 & 02.93 \\
\hline$\frac{18}{19}$ & $\begin{array}{r}171000 \\
\end{array}$ & $\begin{array}{r}0858.90 \\
\end{array}$ & 3144.20 & 5509.09 & 40 & & 60.00 & 9.25 & 0.25 & 2.17 & 11.07 & 2.08 & 0.006 & 0.042 & 346.32 & 60.02 \\
\hline
\end{tabular}




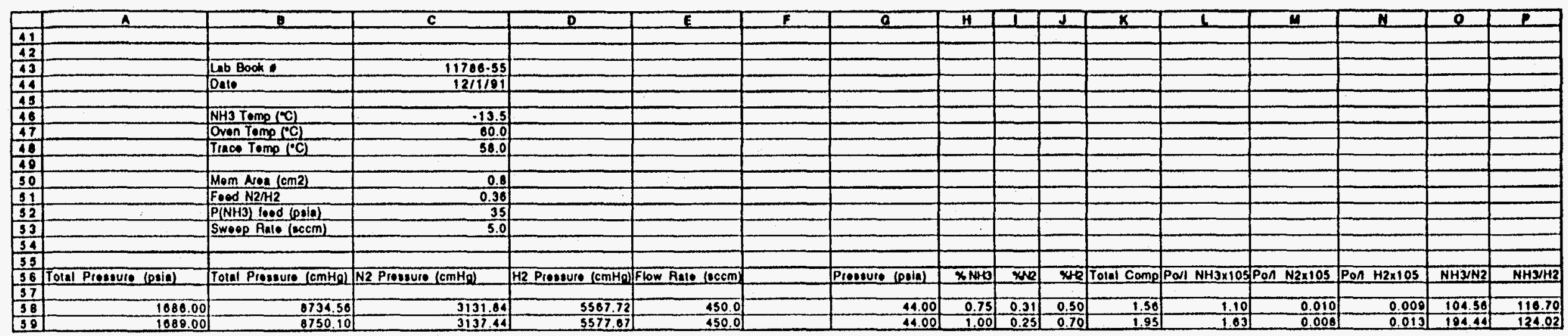




\begin{tabular}{|c|c|c|c|c|c|c|c|c|c|c|c|c|c|c|c|c|}
\hline 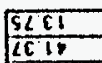 & $\frac{1592}{102.2}$ & $\begin{array}{l}\frac{1600}{6000} \\
6000\end{array}$ & $\frac{10200}{8100}$ & $\frac{150}{6 \varepsilon^{\circ} 0}$ & $\frac{5 L 2}{50^{\circ} \mathrm{C}}$ & 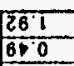 & $\frac{850}{850}$ & $\begin{array}{ll}52 \% \\
00 \% \\
\end{array}$ & $\begin{array}{l}00501 \\
00901 \\
001\end{array}$ & 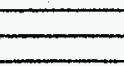 & $\frac{0.05 t}{0.05 t}$ & 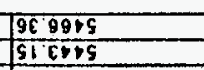 & 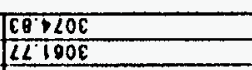 & $\frac{761.1028}{26 \cdot 1+18}$ & $\begin{array}{l}005691 \\
009091 \\
0091\end{array}$ & 85 \\
\hline ZHKHN & ZN/EHM & SOIXZH VOO & SO1K2N VOD & $501 \times E H N$ 10O & fowos & $\overline{2+x}$ & $2 x$ & EHNX & Timol onmosd & & 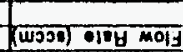 & 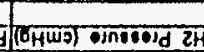 & 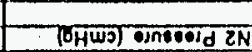 & 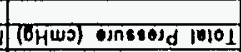 & (nlod onsmod 1001 & 9 \\
\hline & & & & & & & & & & & & & & & & \\
\hline & & & & & & & & & & & & & $\begin{array}{ll}0.5 \\
0.5\end{array}$ & (wכ00) 10y dooms & & EE \\
\hline & & & & & & & & & & & & & $\frac{10+2}{0 \varepsilon^{\prime} 0}$ & 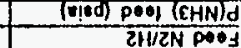 & & $\frac{25}{18}$ \\
\hline & & & & & & & & & & & & & 0 & (2WS & & $\frac{10}{0 \Leftrightarrow}$ \\
\hline & & & & & & & & & & & & & & (10.0001 & & \\
\hline & $=$ & & 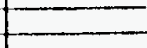 & 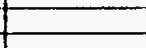 & & 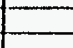 & & & & & & & $\frac{0.09}{0.02}$ & 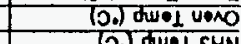 & & 7 \\
\hline & & & & & & & & & & & & & por & A & & $\frac{b i}{5 b}$ \\
\hline & & & & & & & & & & & & & 1801212 & Tro & & $\because$ \\
\hline & & & & & & & & & & & & & $8065.908 \mathrm{Cm}$ & & & \\
\hline & & & & & & & & & & & & & & & & it \\
\hline$d>>$ & 0 & $\mathrm{H}$ & $\pi$ & 9 & $x$ & $r$ & $T$ & $\mathrm{H}$ & 0 & 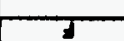 & 3 & a & 3 & & $\boldsymbol{v}$ & \\
\hline
\end{tabular}




\begin{tabular}{|c|c|c|c|c|c|c|c|c|c|c|c|c|c|c|c|c|}
\hline $0+25$ & 20.90 & 5100 & 100 & 200 & 016 & $\$ 90$ & Ero & 1006 & $00 \mathrm{CH}$ & & $0.05 t$ & 90.8055 & $\angle 0$ OrIE & C5:ore8 & 00.8041 & 81 \\
\hline ZHKHN & ENKSHN & SOINZH VOS & SOLKZN VOd & SOIXCHN $100 \mathrm{~d}$ & 70005 10100 & $2 x$ & $2 \sqrt{x}$ & $\operatorname{arn} x$ & Topo ornosolo & & 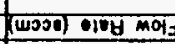 & 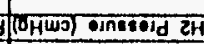 & 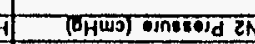 & 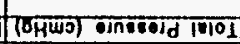 & 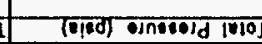 & $1 \frac{10}{8 i}$ \\
\hline & & & & & & $E_{-1}$ & - & & & & & & & & & $\frac{6}{61}$ \\
\hline & & & + & & 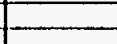 & - & E & 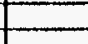 & & & & & $\frac{05}{65}$ & (W029) oly dooms & & Ci \\
\hline & & & & & & 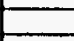 & E & & & & & & $\frac{106}{\sec 0}$ & 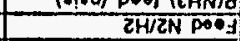 & & $\frac{1}{11}$ \\
\hline & & & & & & & & & & & & & 90 & $(2007$ ) vorv wow & & 01 \\
\hline & & & & & & & & & & & & & 0.12 & 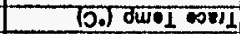 & & 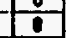 \\
\hline & & & & & & & & & & & & & $\frac{000}{0.02}$ & (10.) $)$ Wण 1 हHN & & $\frac{2}{0}$ \\
\hline & & & & & & 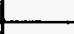 & & & & & & & & & & 5 \\
\hline & & & & & & & & & & & & & $\frac{18756}{965-09211}$ & \% & & $\frac{1}{c}$ \\
\hline & & & & & & & & & & & & & & & & \\
\hline$\pi$ & 0 & $\mathrm{~N}$ & $\pi$ & 9 & $\bar{x}$ & $\frac{1}{4}$ & $T$ & $\mathrm{H}$ & 8 & & & & & & & \\
\hline
\end{tabular}




\begin{tabular}{|c|c|c|c|c|c|c|c|c|c|c|c|c|c|c|c|c|}
\hline & A & $B$ & E & D & $E$ & $\mathbf{F}$ & 0 & $\mathrm{H}$ & $I$ & $J$ & $x$ & 1 & $\boldsymbol{M}$ & $\boldsymbol{N}$ & o & P \\
\hline$\frac{1}{2}$ & & & & & & & & & & & & & & & & \\
\hline$-\frac{2}{3}$ & & Lob Book : & & & & & & & & & & & & & & \\
\hline 1 & & D.10 & $\frac{11700 \cdot 03 \mathrm{~B}}{2120 / 01}$ & $(111470.68-2)$ & & & & & & & & & & & & \\
\hline 3 & & & & & & & & & & & & & & & & \\
\hline$\div$ & & $\mathrm{NH}$ 3 Tomp $\left.1{ }^{\circ} \mathrm{C}\right)$ & 0.0 & & & & & & & & & & & & & \\
\hline 7 & & Open Tomp $(0)$ & 00.0 & & & & & & & & & & & & & \\
\hline$\div$ & & Truos Temp $\left({ }^{\circ} \mathrm{C}\right)$ & 04.0 & & & & & & & & & & & & & \\
\hline 10 & & Mem Aroe $(\mathrm{cm} 2)$ & 0.8 & & - & & 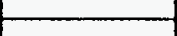 & & & & & & & & & \\
\hline 11 & & FoOd N2N2 & 0.04 & & & & & & & & & & & & & \\
\hline 12 & & P(NHJ) foed leale) & 35 & & & & & & & & & & & & & \\
\hline 13 & & Sweop Aate (eccm) & 5.0 & & & & & & & & & & & & & \\
\hline 14 & & & & & & & & 1 & & & & & & & & \\
\hline 13 & & & & & & & & & & & & & & & & \\
\hline 10 & Tolal Proseune (pald) & Total Prossure $(\mathrm{cmHg})$ & N2 Proseum (omHa) & He Prosure $(\mathrm{cmH}$ O & Flow Anie (10 cm) & & Proseune (poia) & 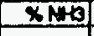 & xna & Wue & Total comp & Pol NH3 $3 \times 105$ & Pon N2x10S & Pof H2x10S & $\mathrm{NH3/N2}$ & $\mathrm{NH} 3 \mathrm{NH2}$ \\
\hline$\frac{17}{18}$ & ofiglnal & 4504.07 & 2000.11 & 1030.75 & & & & & & & & & & & & \\
\hline$\frac{10}{10}$ & 005.00 & $\begin{array}{r}4504.87 \\
7320.25\end{array}$ & $\frac{2800.11}{4640.70}$ & 2030.19 & $\frac{430.0}{4500}$ & & 20.00 & 25.50 & 0.00 & 0.33 & 25.03 & 10.32 & 0.000 & 0.024 & DOIVIOI & $\frac{.24 .08}{714}$ \\
\hline$\frac{10}{20}$ & $\frac{1413.00}{1917.00}$ & $\frac{7320.25}{0031.20}$ & 0320.62 & $\frac{2.019}{3555.18}$ & $\frac{450.0}{450.0}$ & & $\frac{20.00}{1900}$ & $\frac{22.25}{1075}$ & 0.15 & $\frac{0.53}{0.5}$ & $\frac{22.93}{20.60}$ & $\frac{16.17}{13.12}$ & $\frac{0.003}{0.003}$ & $\frac{0.023}{0.023}$ & $\frac{4001.13}{4276}$ & $\frac{714.19}{570.44}$ \\
\hline 21 & ievorne & & & & & & & & & & 0.00 & & & & & \\
\hline 22 & 139900 & 7247.72 & 4003.34 & 2500.30 & 450.0 & & 20.00 & 8.50 & 0.22 & 0.58 & 10.30 & 5.77 & 0.005 & 0.024 & 1155.80 & 237.70 \\
\hline 23 & 070.00 & 1553.70 & 2870.22 & 1019.50 & 450.0 & & 20.00 & 10.25 & 0.22 & 0.37 & 10.04 & 8.30 & 0.000 & 0.025 & 700.71 & 251.51 \\
\hline 24 & & 0.00 & .35 .20 & -10.60 & & & & & & & 0.00 & & & & & \\
\hline 28 & 906.00 & 1083.86 & 2008.74 & 1000.02 & 450.0 & & 20.00 & 11.25 & 0.10 & 0.38 & 11.01 & 7.02 & 0.000 & 0.025 & 1110.31 & 280.05 \\
\hline 20 & orloinal & & & & & & & & & & 0.00 & & & & & \\
\hline 20 & 1111,00 & 7300.80 & 4643.13 & 261176 & 450.0 & & 20.00 & 0.25 & 0.26 & 0.15 & 196 & 4.04 & 0.006 & 0.019 & 844.08 & 205.08 \\
\hline 30 & 1975.00 & 10231.77 & 6513.13 & 3603.04 & 50.0 & & 20.00 & 3.75 & 0.28 & 0.52 & 4.55 & 2.03 & 0.004 & 0.015 & 452.09 & 135.23 \\
\hline 39 & 1073.00 & 10221.40 & 8500.50 & 3659.91 & 450.0 & & 20.00 & 5.50 & 0.30 & 0.58 & 8.38 & 3.10 & 0.005 & 0.010 & 043.38 & 190.55 \\
\hline 32 & everas & & & & & & & & & & 0.00 & & & & & \\
\hline 33 & 1805.00 & 10179.90 & 0470.07 & 3644.20 & 50.0 & & 10.00 & 1.00 & 0.35 & 0.38 & 1.71 & 0.46 & 0.000 & 0.010 & 80.04 & 43.90 \\
\hline 34 & 1000.00 & 10154.00 & 8103.40 & 3035.06 & 450.0 & & 20.00 & 2.50 & 0.33 & 0.46 & 3.20 & 1.30 & 0.005 & 0.013 & 242.20 & 06.94 \\
\hline 38 & 1408.00 & 7294.34 & 4633.18 & 2600.10 & 50.0 & & 10.00 & 1.50 & 0.30 & 0.32 & 2.12 & 0.74 & 0.007 & 0.013 & 100.56 & 56.03 \\
\hline 34 & 1427.00 & 7392.77 & 4890 & 2041 & 450.0 & & 20.00 & 2.25 & 0.30 & 0.34 & 2.09 & 1.17 & 0.007 & 0.014 & 175.41 & 66.30 \\
\hline 37 & 078 & 4546.00 & 2875.91 & 1817.70 & 50.0 & & 18.00 & 2.00 & 0.31 & 0.20 & 2.57 & 1.00 & 0.011 & 0.017 & 00.58 & 58.06 \\
\hline 30 & 002 & 4569.33 & 2000.17 & 1023.10 & 450.0 & & 20.00 & 2.75 & 0.30 & 0.32 & 3.37 & 1.47 & 0.011 & 0.021 & 135.03 & 70.00 \\
\hline 30 & grloinal & & & & 0.0 & & 0.00 & 0.00 & 0.00 & 0.00 & 0.00 & mUMI I & NALUFI & NALUEI & mamil & muMl \\
\hline
\end{tabular}

